Florida International University FIU Digital Commons

FIU Electronic Theses and Dissertations

University Graduate School

$11-23-2004$

\title{
The acculturation of middle income Hispanic households
}

Cecilia Maria Alvarez

Florida International University

DOI: $10.25148 /$ etd.FI14031602

Follow this and additional works at: https://digitalcommons.fiu.edu/etd

Part of the Business Administration, Management, and Operations Commons

\section{Recommended Citation}

Alvarez, Cecilia Maria, "The acculturation of middle income Hispanic households" (2004). FIU Electronic Theses and Dissertations. 1201.

https://digitalcommons.fiu.edu/etd/1201

This work is brought to you for free and open access by the University Graduate School at FIU Digital Commons. It has been accepted for inclusion in FIU Electronic Theses and Dissertations by an authorized administrator of FIU Digital Commons. For more information, please contact dcc@fiu.edu. 
Miami, Florida

THE ACCULTURATION OF MIDDLE INCOME HISPANIC HOUSEHOLDS

A dissertation submitted in partial fulfillment of the

requirements for the degree of

DOCTOR OF PHILOSOPHY

in

BUSINESS ADMINISTRATION

by

Cecilia Maria Alvarez

2004 
To: Dean Joyce Elam

College of Business Administration

This dissertation, written by Cecilia Maria Alvarez, and entitled The Acculturation of Middle Income Hispanic Households, having been approved in respect to style and intellectual content, is referred to you for judgment.

We have read this dissertation and recommend that it be approved.

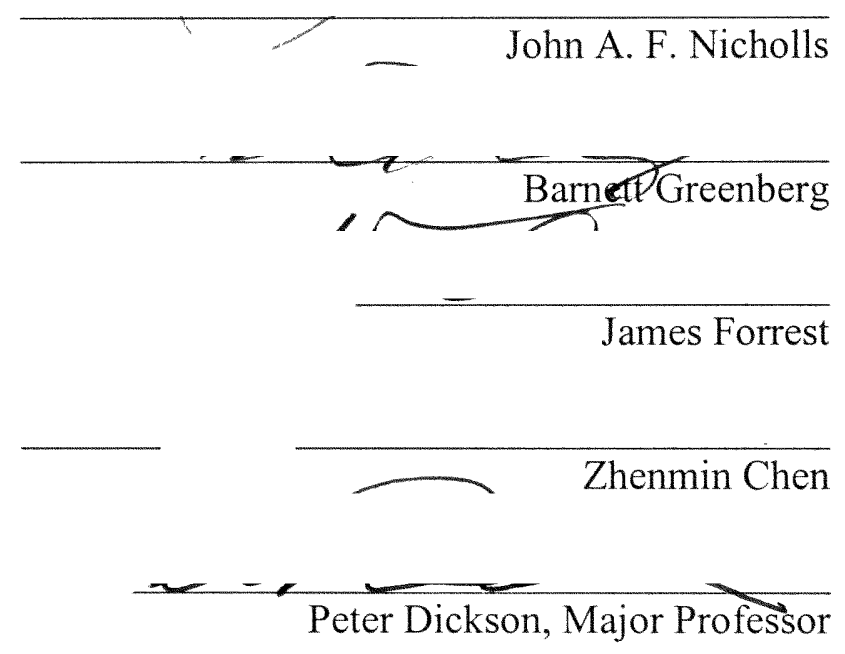

Date of Defense: November 23, 2004

The dissertation of Cecilia Maria Alvarez is approved.

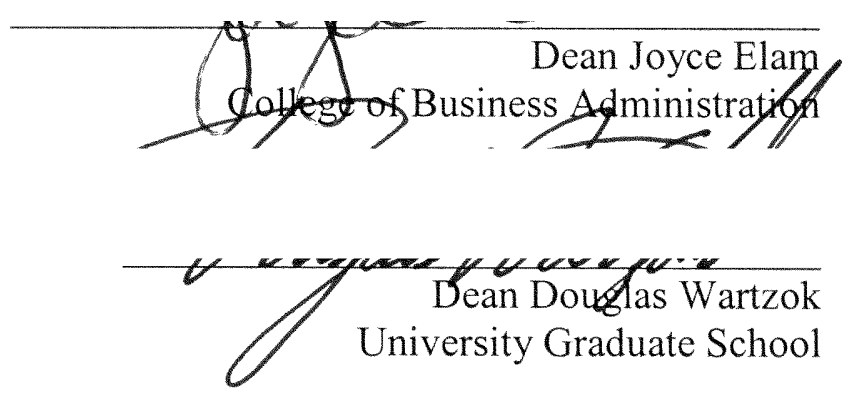

Florida International University, 2004 
(C) Copyright 2004 by Cecilia Maria Alvarez

All rights reserved. 


\section{DEDICATION}

To my father

Dr. Julio Ortiz Marquez 


\section{ACKNOWLEDGMENTS}

I would like to thank my children Gustavo and Ana, and my husband Gustavo Alvarez for all their support, and sacrifices; this dissertation belongs to all of us.

Thanks to the members of my committee, Dr. Forrest, Dr. Greenberg, Dr. Chen, and Dr. Nicholls. The guidance and instruction you have provided has been significant, and is valued as such. In particular, I would like to thank Dr. Nicholls for all the effort, time and dedication, this dissertation has benefited from your experience and knowledge.

Special thanks to my dissertation chair, Peter Dickson, for believing. I am grateful not only for what I have learned from you, but also for your friendship. I consider myself to be a better scholar, and a better person as a result of my association with you.

Last, I would like to thank the College of Business Administration for providing the grant to fund the data collection. 
ABSTRACT OF THE DISSERTATION

THE ACCULTURATION OF MIDDLE INCOME HISPANIC HOUSEHOLDS by

Cecilia Maria Alvarez

Florida International University, 2004

Miami, Florida

Professor Peter Dickson, Major Professor

Research on the consumer behavior of the Hispanic population has recently attracted the attention of marketing practitioners as well as researchers. This study's purpose was to develop a model and scales to examine the acculturation process of Hispanic consumers with income levels of $\$ 35,000$ and above, and its effects on their consumer behavior. The proposed model defined acculturation as a bilinear and multidimensional change process, measuring consumers' selective change process in four dimensions: language preference, Hispanic identification, American identification, and familism. A national sample of 653 consumers was analyzed. The scales developed for testing the model showed good to high internal consistency and adequate concurrent validity. According to the results, consumers' contact with Hispanic and Anglo acculturation agents generates change or reinforces consumers' language preferences. Language preference fully mediates the effects of the agents on consumers' American identification and familism; however, the effects of the acculturation agents on Hispanic identification are only partially mediated by individuals' language preference change. It was proposed that the acculturation process would have an effect on consumers' brand loyalty, attitudes towards high quality and prestigious brands, purchase frequency, and 
savings allocation for their children. Given the lack of significant differences between Hispanic and Anglo consumers and among Hispanic generations, only savings allocation for children's future was studied intensively. According to these results, Hispanic consumers' savings for their children is affected by consumers' language preference through their ethnic identification and familism. No moderating effects were found for consumers' gender, age, and country of origin, suggesting that individual differences do not affect consumers' acculturation process. Additionally, the effects of familism were tested among ethnic groups. The results suggest not only that familism discriminates among Hispanic and Anglo consumers, but also is a significant predictor of consumers' brand loyalty, brand quality attitudes, and savings allocation. Three acculturation segments were obtained through cluster analysis: bicultural, high acculturation, and low acculturation groups, supporting the biculturalism proposition. 


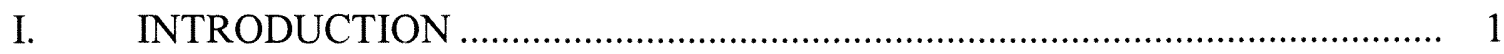

Focus of the study ..........................................................................................

II. ACCULTURATION

Acculturation Scales ................................................................................ 14

III. HISPANIC CONSUMER ACCULTURATION MODEL ............................ 17

Acculturation Agents .................................................................................. 17

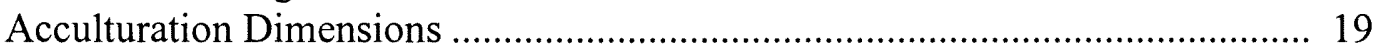

Acculturation and Consumer Behavior......................................................... 28

Acculturation Moderators ........................................................................... 33

Acculturation Outcomes ............................................................................ 36

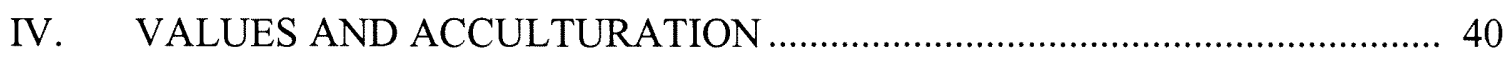

Values and Consumer Behavior..................................................................... 42

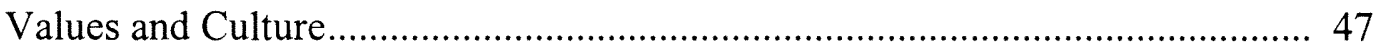

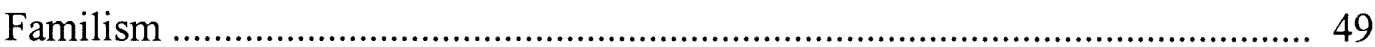

Familism and Acculturation......................................................................... 52

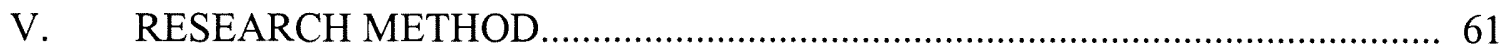

Subjects and Sampling Procedure.................................................................. 61

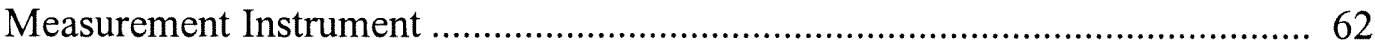

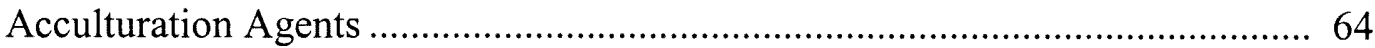

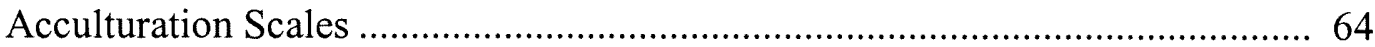

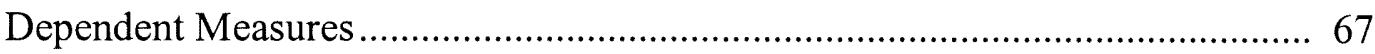

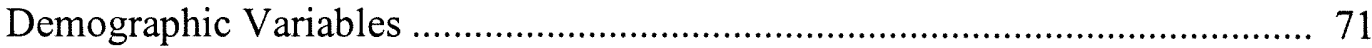

VI. ACCULTURATION SCALES AND DEPENDENT MEASURES

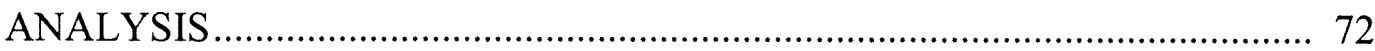

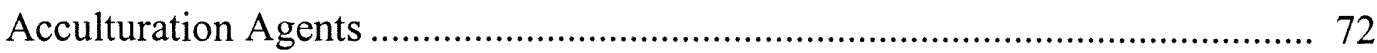

Language Preference Scale ......................................................................... 74

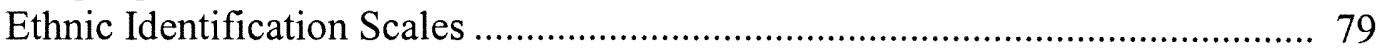

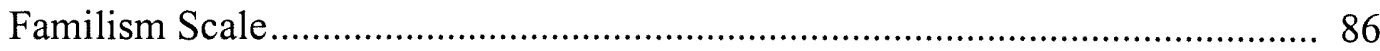

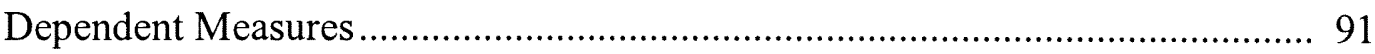

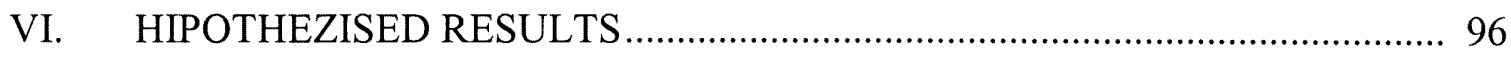

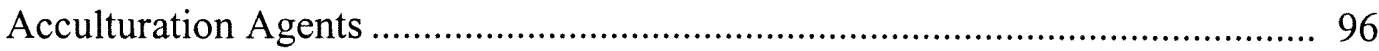

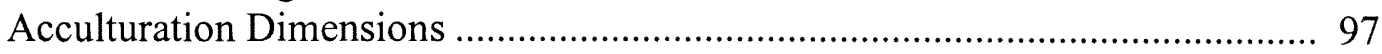

Acculturation and Consumer Behavior.............................................................100

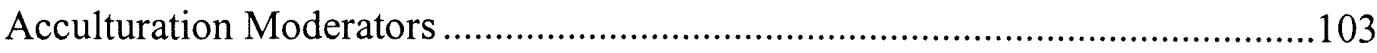

Familism, Acculturation and Consumer Behavior..............................................107 


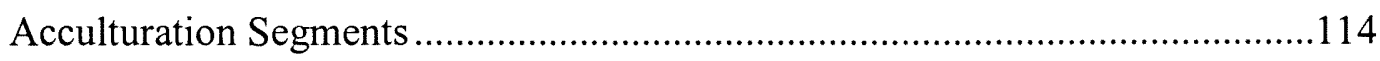

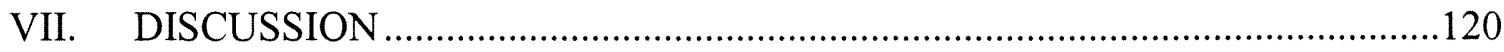

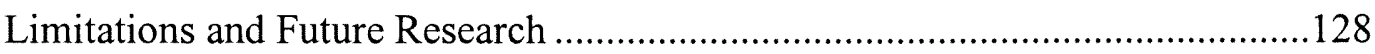

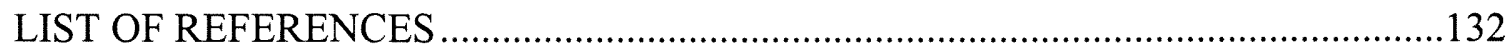

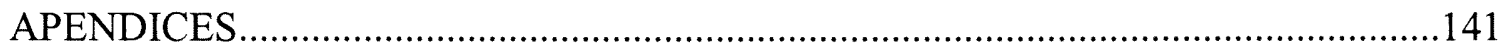

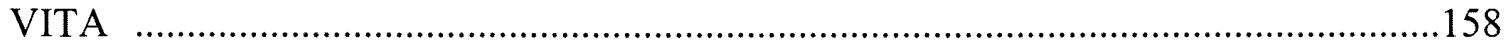




\section{LIST OF TABLES}

TABLE

PAGE

1. Published Bilinear Multidimensional Hispanic Acculturation Scales

2. Post Hoc Multiple Comparisons across Three Generations of Hispanic Adolescents

3. Means, Standard Deviations and F-Ratios for the Acculturation Scales and for Years Living in the U.S. by Psychological Stage

4. Rokeach's Value Survey....

5. Univariate ANOVA Effects, Means and SDs for the Cultural Attitude and Family Measures as a Function of Ethnicity ........................................................ 53

6. Correlations between Familism and Acculturation Dimensions ........................... 55

7. Multiple Regression Analysis on Familism ........................................................ 56

8. Comparisons of Four Cultural Identity Groups on Several Dependent

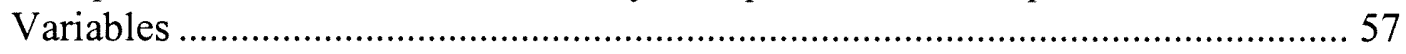

9. Samples' Demographic Variables Means and Size .................................................6 63

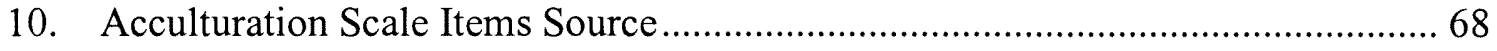

11. Percentage of Not-Applicable and Missing Values of the Agent Acculturation Items..

12. Analysis of Variance of the Acculturation Agent Scale among Test Variables ..... 74

13. Language Preference Scale Descriptive Statistics and Alpha Coefficients ............ 75

14. Analysis of Variance of the Language Preference Scale among Test Variables

15. Pearson Correlations between Language Preference Scale Items and Language Preference Scenarios

16. Principal Component Total Variance Explained of the Ethnic Identification Scale by Sample. 
17. Principal Component Analysis of the Ethnic Identification Scale

18. Rotated Component Matrix of the Ethnic Identification Scale.

19. Ethnic Identification Scales Descriptive Statistic and Alpha Coefficients

20. Partial Correlations between the Ethnic Identification Scales and Indicators of Acculturation

21. Analysis of Variance of the Hispanic and American Ethnic Identification Scales among Test Variables 84

22. Familism Scale Descriptive Statistics and Alpha Coefficients 85

23. Principal Component Total Variance Explained of the Familism Scale by Sample. 86

24. Analysis of Variance of the Familism Scale among Test Variables. 87

25. Principal Component Analysis of the Familism Scale 90

26. Dependent Variables Item Description. 91

27. Alpha Coefficients, Pearson Correlations and Analysis of Variance of the Dependent Measures by Ethnicity 93

28. Analysis of Variance of the Dependent Measures by Generation 95

29. Regression of the Acculturation Agents on Language Preference, Familism American and Hispanic Identification 97

30. Test for the Mediation Effects of Language Preference on Familism, American, and Hispanic Identification

31. Test for the Mediation Effects of Familism, American and Hispanic Identification on Savings for Children's Future

32. Test for the Moderation Effects of Gender, Age and Country of Origin on Language Preference.

33. Analysis of Covariance of Familism by Ethnicity Controlling for Demographic Variables

34. Analysis of Covariance of Familism by Place of Birth Controlling for Demographic Variables 
35. Analysis of Covariance of Familism by Ethnicity and Education Controlling for Income, Age and Number of Children.

36. Regression Models of Brand Loyalty, Brand Quality Attitudes and Savings for Children's Future on Familism and Demographic Variables...........................112

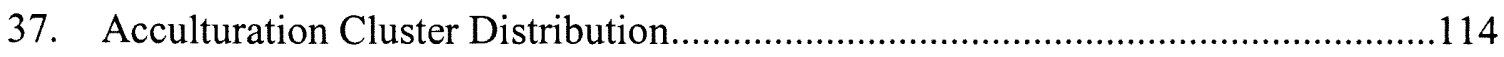

38. Analysis of Variance of Demographic Variables and Acculturation Agents by Clusters 


\section{LIST OF FIGURES}

FIGURE

PAGE

1. Unilinear Acculturation Model ...................................................................... 9

2. Bilinear Acculturation Model ......................................................................... 10

3. An Empirical Model of Consumer Acculturation................................................ 13

4. Hispanic Consumer Acculturation Model ……..................................................... 39

5. Language Preference by Context and Generational Status................................... 76

6. Hispanic Consumer Acculturation Model: Tests Results ......................................107

7. $95 \%$ Confidence Intervals of Language Preference by Cluster .............................117

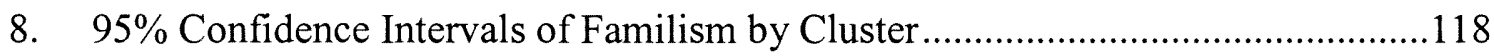

9. $95 \%$ Confidence Intervals of Hispanic Identification by Cluster ..........................118

10. $95 \%$ Confidence Intervals of American Identification by Cluster..........................119 


\section{CHAPTER I}

\section{INTRODUCTION}

In the last decade the importance of reaching the Hispanic market has become increasingly apparent to marketing practitioners (Berman 2003; Strategy Research 2002). Hispanics ${ }^{1}$ have not only increased in numbers to become the largest ethnic minority population in the United States, constituting one of the fastest growing ethnic minority groups (Ramirez and Cruz 2003), but also have reached an estimated purchasing power of $\$ 600$ billion ( $7.4 \%$ of the total U.S. purchasing power), expected to grow at an average annual rate of $9.1 \%$ (Mann 2003).

An examination of the marketing literature reveals a recent increase in attention by consumer researchers towards ethnic markets. However, research on Hispanics is scant and lacks continuity (Parker 1999). For example, in the early ' 80 s, researchers recognized the importance of classifying ethnic consumers by self-identification and the strength of their identification (Hirschman 1981; Deshpande, Hoyer and Donthu 1986). However, subsequent research involving Hispanic-Americans has ignored previous recommendations and classified Hispanics only according to their language preferences and/or language use (e.g., Webster 1991, 1992, 1994 and 1997; Petroshius, Newell, and Ross, 1995; Nicholls and Roslow 1996; Korgaonkar, Karson, and Lund 2000).

\footnotetext{
${ }^{1}$ There are some differences on the connotations given to the terms Hispanics and Latinos. For the Census Bureau, both terms are used indistinctively to designate Hispanic-American individuals, irrespective of their country of origin or race, as long as they identify themselves as Hispanics. This research uses both terms when referring to individuals who identify themselves as Hispanics, live currently in the United States, and speak Spanish.
} 
Other disciplines such as Sociology, Anthropology, and Psychology have long been interested in the phenomena that result when groups of individuals from different cultures come into contact and the subsequent changes generated in both cultures. Initially the interest was focused on the changes of immigrants after their entrance and settlement in the United States (Beiser 2000). More recently, the focus has broadened and much of the work is concerned on how different cultural groups, like Hispanic and nonHispanic individuals, relate to each other and change as a result of their attempt to live together in a culturally plural society (Berry 2003).

Acculturation has been recognized as a core construct in contemporary social and behavioral research with ethnic groups (Chun, Balls Organista, and Marín 2003). Research on Acculturation dates as early as 1936 (Redfield, Linton, and Herskovits 1936), and has evolved significantly over the years. Although there is wide consensus that acculturation is an important variable in cross-cultural and ethnic research (Trimble 2003; Skinner 2002), there is disagreement on how to conceptualize and measure it (Berry 2003). The Acculturation construct has evolved from a linear construct assuming that acculturation is a process of assimilation to the dominant culture, to a bilinear process in which individuals' choice is taken into account and change no longer automatically implies loss of the culture of origin.

Along with the evolution of the acculturation construct several acculturation scales for Hispanics have emerged in the literature, but they have a number of limitations. First, most have been created for specific Hispanic subgroups (e.g., Szapocznik, Scopetta, Kurtines, and Andrade 1978, for Cubans; Cuéllar, Arnold, and Maldonado 1995, for 
Mexican-Americans; Cortés, Rogler, and Malgady 1994, for Puerto Ricans), limiting the generalizability of the instruments. Furthermore, even though acculturation has been considered a multidimensional construct involving individuals' changes in the behavioral, attitudinal and value dimensions, few measures have successfully incorporated all of them (Marín 1992). For example, changes in individuals' values have a limited contribution in current acculturation scales (Félix-Ortiz, Newcomb, and Myers 1994; Cortés et al. 1994). Moreover, none of the acculturation scales have attempted to connect the impact of the individuals' acculturation with consumer behavior.

There is scant research in the marketing literature that addresses acculturation; nonetheless, two acculturation models have been proposed: a consumer acculturation model (Peñaloza 1994) and a marketer acculturation model (Peñaloza and Gilly 1999). Peñaloza's (1994) consumer acculturation model examines Mexican immigrant consumption experiences and changes when confronted with the American consumer environment. The marketer acculturation model (Peñaloza and Gilly 1999) shifts its attention from the consumer and examines the changes that the marketer (dominant culture) goes through in order to accommodate its consumers. However, some limitations must be mentioned. Peñaloza's (1994) acculturation model was built for first generation Mexican immigrants. Acculturation is a complex process of gradual changes; it starts with firsthand contact between both cultures, but continues through generations. Most models assume there is a positive linear relationship between acculturation and generational status (e.g., Szapocznik et al. 1978; Cuéllar, Arnold, and Maldonado 1995; Norris, Ford, and Bova 1996). As Peñaloza states, "It is likely that immigrants' 
consumption patterns change over time and with passing generations" (1994, p. 52). Second, consumers' values have not been taken into consideration, as with the acculturation models proposed by related disciplines. Finally, even though Peñaloza's (1994) acculturation model provides an enriching understanding of the acculturation phenomenon within a market perspective, it lacks instrumental use. Although acculturation has been recognized as a key segmentation construct to be considered in research on ethnic groups, there is no measurement instrument in the marketing literature that can account for consumer acculturation.

\section{Focus of the study}

This research will build upon Peñaloza's (1994) consumer acculturation model. The contributions are twofold, theoretical and practical. Acculturation has been recognized as a complex change process that takes place in several dimensions. Yet, there have been limited attempts to understand how changes at a behavioral (language), affective (ethnic identification), and value levels are related to each other (Jun, Ball, and Gentry 1993). Most models consider these dimensions to be independent and simultaneous. The current investigation aims at understanding how changes at behavioral, attitudinal, and value levels occur. Furthermore, although consumer behavior research has successfully associated ethnic identification and language preferences to certain consumer behaviors such as brand loyalty, coupon use, advertising, and information search behavior (e.g., Deshpande et al.1986; Nicholls and Roslow 1996; Petroshius, Newell, and Ross 1995; Webster 1992), no attempt has been made in the literature to comprehend and measure the impact of the value acculturation dimension on consumer 
behavior. This investigation's effort is to include familism as a core Hispanic value and determine what, if any, is the impact on Hispanics' consumer behavior. Additionally, this research will examine the moderating effects of several individual differences.

As important as the theoretical contributions of this research are the practical implications. The proposed research will also develop and validate an acculturation scale. This scale will be formed of three main components: language preference, ethnic identification, and familism subscales that would determine the level of consumer acculturation of Hispanics (Mexican, Cuban, Puerto Rican, etc.) living in the United States. Future academic research and marketing practitioners would benefit from employing a standard acculturation measure from which consumer knowledge can be built.

This study seeks to understand the behavior of middle income Hispanic consumers and compare it to middle income white non-Hispanics. The purpose of concentrating the research on this market segment is to eliminate the effects that are granted by the existing income and demographic differences between both groups (Therrien and Ramirez 2000).

In Chapter II the conceptualization of acculturation is addressed. This chapter provides a deep comprehensive literature review of the existing acculturation models and scales of the Sociology, Anthropology, and Psychology literatures. Chapter III develops the consumer acculturation model, and hypothesis regarding the constructs of the model are offered. Given the importance that this investigation gives to consumer values, 
Chapter IV provides an extensive literature review on values and suggests the corresponding effects of Familism on consumer behavior. The subsequent chapters describe the design and the execution of the study conducted to test the model. 


\section{CHAPTER II}

\section{ACCULTURATION}

Acculturation has been defined in many ways, but it can be primary understood as the phenomenon of culture change that occurs as a result of continuous contact between cultural groups. As a construct, acculturation refers to changes not only at socio cultural levels, but also at the individual level. Hence, acculturation also refers to the effects that social and environmental changes have on individuals' values, beliefs, attitudes, and behaviors. This research focuses on individual acculturation also known as psychological acculturation (Berry 1980).

Acculturation theories can be found as early as 1936. Redfield, Linton, and Herskovits' work in acculturation introduced and defined acculturation as:

"phenomena which results when groups of individuals having different cultures come into continuous first-hand contact with subsequent changes in the original culture patterns of either or both groups" (1936, p. 149).

According to this definition contact between individuals from different cultures becomes the essential element of acculturation. Additionally this definition points out that change as a result of the contact is necessary on at least one of the two groups.

Twenty years later the Social Science Research Council (1954) redefined acculturation as: 
"Culture change that is initiated by the conjunction of two or more autonomous cultural systems. Acculturative change may be the consequence of direct cultural transmission; it maybe derived from non cultural causes, such as ecological or demographic modification introduced by an imprinting culture; it may be delayed as with internal adjustments following upon acceptance of alien traits or patterns; or it may be a reactive adaptation of traditional modes of life. Its dynamics can be seen as the selective adaptation of value systems, the process of integration and differentiation, the generation of developmental sequences, and the operation of role determinants and personality factors" (p. 974).

This definition includes new important elements. According to Padilla and Perez (2003), the main contribution of this definition is the introduction of the individuals' choice as part of the acculturation process. The change from one cultural orientation to another can be selective and individuals can decide which elements of their culture they wish to change or not. Additionally, this definition describes acculturation as a dynamic process that develops sequentially through role determinants.

In the process of understanding acculturation, several definitions and measurement instruments have been developed since. Early acculturation models conceptualized acculturation, as assimilation to the host culture. Acculturation has been considered as "directional, unilinear, nonreversible and continuous" (Suarez-Orozco 2001, p. 8; Szapocznik, Scopetta, Kurtines, and Andrade 1978). Under this conceptualization, individuals move from one side of a continuum, reflecting involvement in the culture of origin, to the opposite side, reflecting involvement in the dominant culture (Figure 1).

However, other conceptualizations of acculturation stress that change should not be confused by loss; in other words, acculturation should not be confused with 
assimilation to a dominant culture (Berry 1980; Mendoza 1989; Padilla 1994). According to Berry (1980), acculturation is a change in either or both cultures, including the possibility of conflict or resistance, emerged when individuals sought to retain features of their respective culture. Instead of assuming that individuals approach full assimilation, the possibility that individuals acquire features of the host culture while maintaining aspects of their native culture is suggested.

Figure 1

UNILINEAR ACCULTURATION MODEL

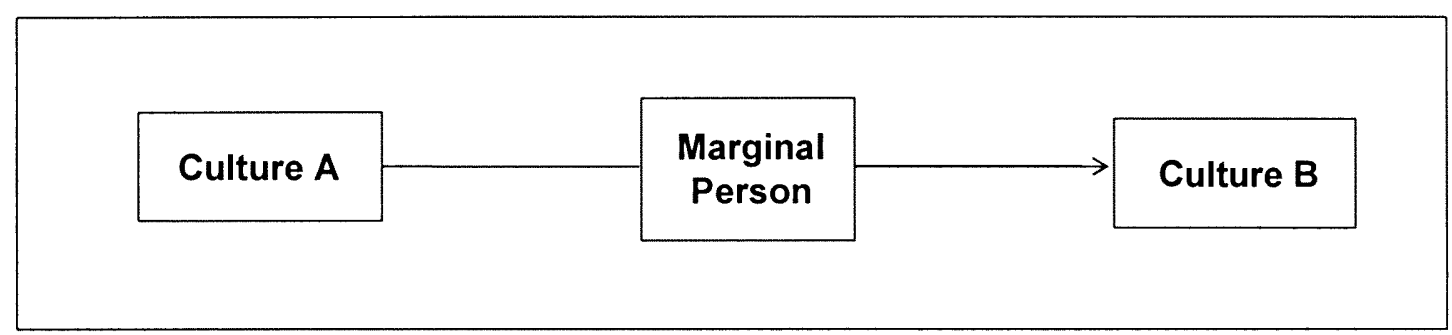

*Figure adapted from Padilla (1994)

In this conceptualization, acculturation is considered bilinear. One dimension represents the individuals' desire to maintain their own heritage culture and identity, and the other dimension represents the individuals' preference or choice for having contact with a larger society. Under Padilla's (1994) conceptualization, individuals who had extensive socialization and participate considerably in both cultures are described as bicultural and individuals who find themselves at the margin of both cultures, but feel as member of neither, are described as marginal (Figure 2).

Berry's (1980) acculturation model recognizes the individual's choice in the acculturation process; by including choice, he introduced four varieties of acculturation: assimilation, integration, separation, and marginalization. Assimilation occurs when an 
individual absorbs the culture of the dominant group and has no interest in maintaining the native culture. Integration occurs when the individual seeks to socialize and adapt to the dominant culture while maintaining its indigenous cultural roots, a bicultural position. Separation occurs when an individual avoids contact with the dominant culture while placing much value in the culture of origin. Finally, marginalization occurs when an individual has no interest in maintaining or acquiring any cultural orientation.

Figure 2

BILINEAR ACCULTURATION MODEL

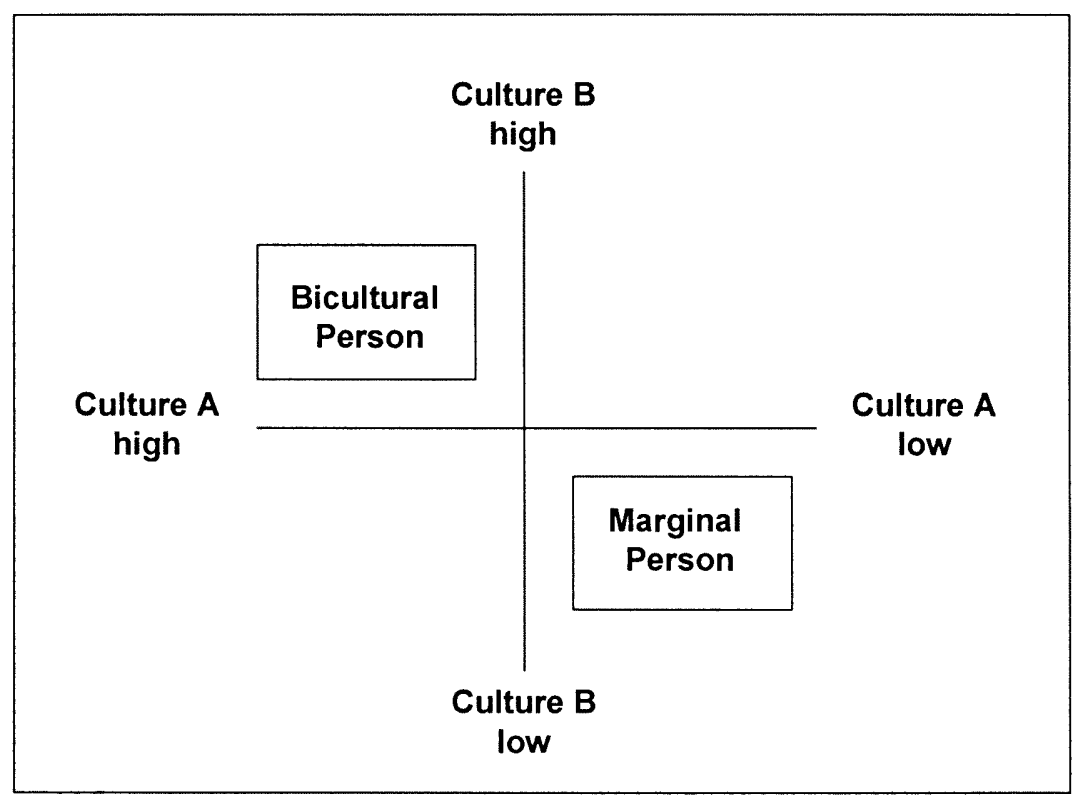

*Figure adapted from Padilla (1994)

In summary, current conceptualizations and operationalizations agree that acculturation is a bilinear process in which the change occurs at two levels, within the culture of origin and the host culture (Cortés, Rogler, and Malgady 1994; Cuéllar, Arnold, and Maldonado 1995; Marín and Gamba 1996; Mendoza 1989; Szapocznik, Kurtines, and Fernandez 1980; Berry 1980). 
Acculturation has also been described as a multidimensional process; implying individuals change along various dimensions of social functioning (Skinner 2002). But, what are these multifaceted alternatives? Berry (1980) identified six dimensions of psychological functioning that can be affected by acculturation: language, cognitive styles, personality, identity, attitudes, and acculturative stress. According to Berry (1980), as the individual moves in the acculturation process, changes occur in each of these areas. In a different conceptualization, Marín (1992) proposed that acculturation generated changes in three levels of functioning: behavioral, affective, and cognitive. The behavioral level includes behaviors such as language use, customs, food consumption, etc. The affective level included emotions that have cultural connections, for example, individuals' feelings towards their country of origin or towards America, individuals' feelings of pride about being identified as Hispanic or American, etc. Finally, the cognitive level includes the individual belief systems and fundamental values.

In a content analysis of the major acculturation measurements, Zane and Mak (2003) suggest that there is a lack of consensus about which dimensions ${ }^{2}$ are directly associated to acculturation. The most frequently assessed dimension is language (e.g., Cuéllar et al. 1997; Ramirez, Cousins, Santos, and Supik 1986; Marín and Gamba 1996). Other dimensions involve people with whom an individual chooses to socialize and affiliate, daily living habits, or behaviors such as music listened to, type of preferred foods, ethnic identification with a particular culture, cultural knowledge and values.

\footnotetext{
${ }^{2}$ Most of the acculturation literature considers the terms dimension and domain synonymous.
} 
As pointed out before, there is scant research in the marketing literature that addresses acculturation. Nonetheless, two acculturation models have been proposed, and ethnic identification has been considered an important moderating variable in the consumer behavior literature (Hirschman 1981; Deshpande, Hoyer, and Donthu 1986; Stayman and Deshpande 1989; Peñaloza 1994; Webster 1994; Petroshius, Newell, and Ross 1995).

Peñaloza (1994) proposed a model of consumer acculturation; she defined consumer acculturation as "the general process of movement and adaptation to the consumer cultural environment in one country by persons of another country"(p. 33). In her definition, Peñaloza establishes the need of contact between individuals from both cultural orientations. It also recognized the concept of movement and adaptation of the consumers from one cultural environment to another. Peñaloza's model (Figure 3) brings in some important contributions. First, in Peñaloza's (1994) definition, the consumer cultural environment is introduced; focusing on a dimension that had not been studied before. Second, the model introduces the effects of the acculturation agents such as their family, friends, media, and institutions that correspond to both cultures. In the model, these agents create a competing "dual pull” (p. 35), from both cultures mediating the acculturation process. According to our previous discussion, Peñaloza's (1994) model can be described as a bilinear model, given the dual pull created by both sets of cultural agents. In this model the adaptation processes that consumers undergo lead to four possible acculturation outcomes: assimilation, maintenance, resistance, and segregation. These outcomes are also a reflection of the bilinear characteristic of the model. 
Figure 3

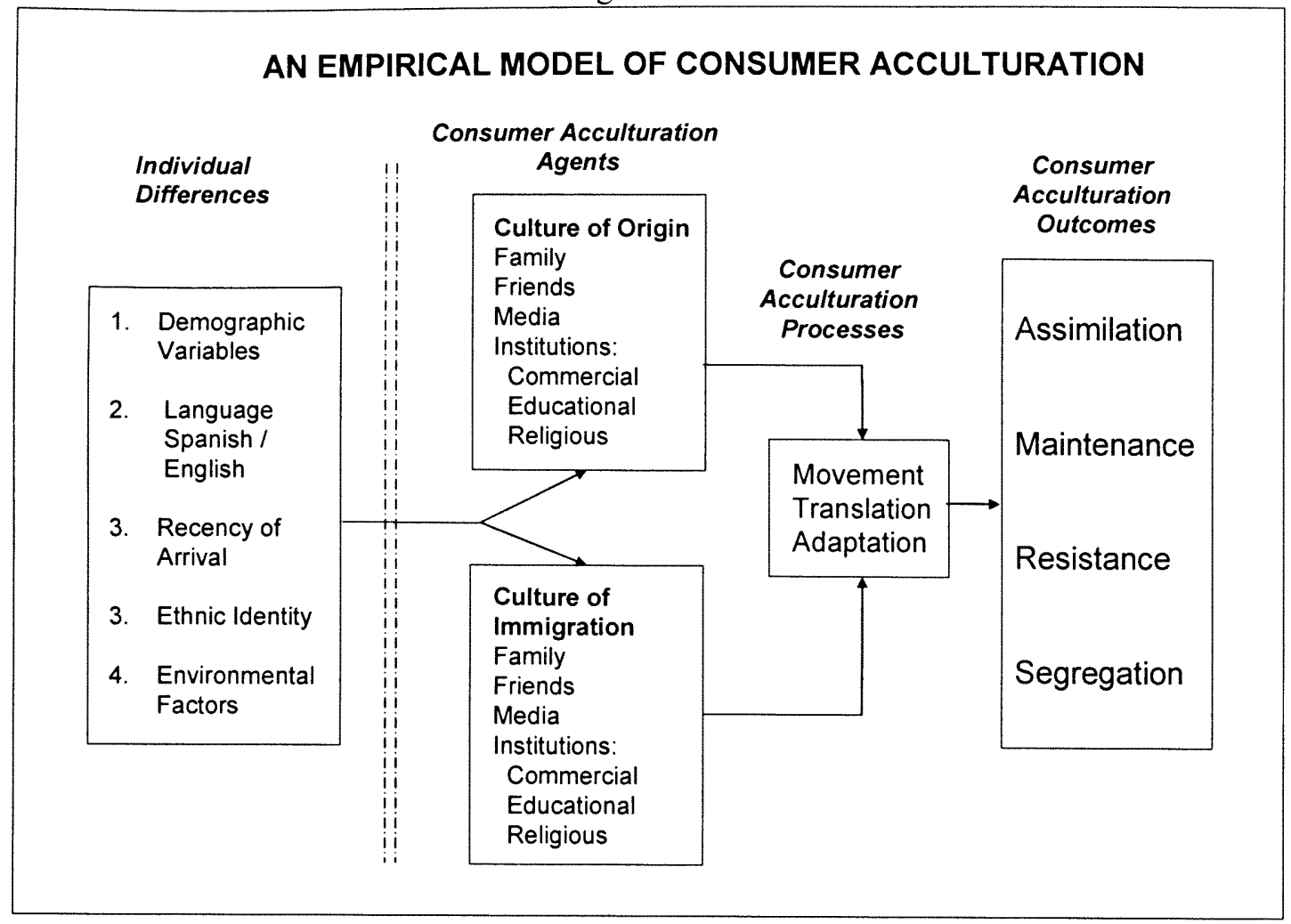

*Figure adapted from Peñaloza (1994)

After reviewing the past and current acculturation models, it can be concluded that acculturation is a complex bilinear and multidimensional construct that studied at an individual level has a potential impact on consumer behavior. However, there are still some questions that remain unanswered. How do the acculturation agents operate? Is consumer behavior affected mainly by behavioral acculturation (language change) or are there other acculturation dimensions, like ethnic identification, that are better predictors of consumer behavior? Before addressing these questions the following section will provide a review of the most relevant acculturation scales available in the literature. 


\section{$\underline{\text { Acculturation Scales }}$}

Along with the different conceptualizations of acculturation, several operationalizations have been developed. Because in recent research acculturation has been characterized as a bilinear, multidimensional process, and this research's primary objective involves only Hispanic ethnic groups, the following review will cover only those measures that meet these criteria. For a complete review of most published acculturation measures the reader can refer to Kim and Abreu (2001) or Zane and Mak (2003).

There are five acculturation scales in the literature that meet the criteria mentioned above (Table 1). These measures vary in the dimensions or factors they include as fields of acculturation, the nature of their samples, and the length of the scale. All five scales include language competence, using and/or preference in different social and communication contexts as the main component of the scale. In most cases language accounts for the highest percentage of variability explained by the corresponding acculturation measures (Cuéllar, Arnold, and Maldonado 1995; Zea Asner-Self, Birman, and Buki 2003). Four of the five scales include cultural/ethnic identification. Cuéllar, Nyberg, Maldonado, and Roberts (1997) found evidence suggesting that ethnic identity with the culture of origin does not necessarily diminish with greater orientation towards the host culture; these results support the conceptualization of acculturation as a bilinear process. Cultural knowledge, competence, or familiarity represents another recurrent dimension in the acculturation measures. Zea et al. (2003) proposed that cultural knowledge affects the individual ability to function effectively in a given culture, 
determining the individuals' acculturation status. A last recurrent dimension should be

mentioned; individuals' behavior has been included in the acculturation measured

through daily living habits or celebrations practices (Cuéllar, Arnold, and Maldonado

1995; Cortés et al. 1994).

Table 1

PUBLISHED BILINEAR, MULTIDIMENSIONAL HISPANIC ACCULTURATION SCALES

\begin{tabular}{|l|l|c|c|l|}
\hline \multicolumn{1}{|c|}{ Measure } & \multicolumn{1}{|c|}{ Dimensions /Factors } & $\begin{array}{c}\text { Number } \\
\text { of Items }\end{array}$ & $\begin{array}{c}\text { Sample } \\
\text { Size }\end{array}$ & \multicolumn{1}{c|}{$\begin{array}{c}\text { Sample } \\
\text { Composition }\end{array}$} \\
\hline $\begin{array}{l}\text { Cultural Life Style } \\
\text { Inventory } \\
\text { (Mendoza 1989) }\end{array}$ & $\begin{array}{l}\text { Intra-family Language Use } \\
\text { Extra-family Language Use } \\
\text { Social Affiliation } \\
\text { Cultural Familiarity } \\
\text { Cultural Identification }\end{array}$ & 29 & 179 & $\begin{array}{l}\text { First generation } \\
\text { Mexican-American } \\
\text { (54\%) and Anglo- } \\
\text { Americans }\end{array}$ \\
\hline $\begin{array}{l}\text { Bicultural Scale for } \\
\text { Puerto Ricans } \\
\text { (Cortés et al. 1994) }\end{array}$ & $\begin{array}{l}\text { Behavioral } \\
\text { Cultural identification } \\
\text { Language } \\
\text { Values }\end{array}$ & 18 & 403 & $\begin{array}{l}\text { Puerto Ricans } \\
(100 \%)\end{array}$ \\
\hline $\begin{array}{l}\text { Multidimensional } \\
\text { Measure of Cultural } \\
\text { Identity } \\
\text { (Félix-Ortiz et al. 1994) }\end{array}$ & $\begin{array}{l}\text { Behavioral } \\
\text { Knowledge } \\
\text { Language } \\
\text { Values }\end{array}$ & 35 & 130 & $\begin{array}{l}\text { Mexican-American } \\
(73 \%) \text { and } \\
\text { Salvadoran (9\%) }\end{array}$ \\
\hline $\begin{array}{l}\text { Acculturation Rating } \\
\text { Scale for Mexican } \\
\text { Americans-II } \\
\text { (Cuéllar, Arnold and } \\
\text { Maldonado 1995) }\end{array}$ & $\begin{array}{l}\text { Language } \\
\text { Cultural Identification } \\
\text { Behavioral }\end{array}$ & 30 & 379 & Mexican-American \\
\hline $\begin{array}{c}\text { AMAS-ZABB } \\
\text { Abbreviated } \\
\text { Multidimensional } \\
\text { Acculturation Scale } \\
\text { (Zea et al. 2003) }\end{array}$ & $\begin{array}{l}\text { Language } \\
\text { Cultural Identity } \\
\text { Cultural Competence }\end{array}$ & 42 & 156 & $\begin{array}{l}\text { South Americans } \\
\text { (28\%), Central } \\
\text { Americans (13.5\%), } \\
\text { Caribbean (6.5\%), } \\
\text { Mexicans (4.5\%), } \\
\text { and 44\% in the born } \\
\text { in the U.S. }\end{array}$ \\
\hline
\end{tabular}

Note: The table is an adaptation from Zea Asner-Self, Birman and Buki (2003).

The five measures included in this review have some limitations. Most have been developed and validated with small convenient-samples (e.g., Cuéllar, Arnold, and Maldonado 1995; Mendoza 1989; Félix-Ortiz et al. 1994), and most of the measures are limited to a single country of origin (e.g., Cuéllar, Arnold, and Maldonado 1995; 
Mendoza 1989; Cortés et al. 1994). The above limitations prevent the generalizability of the scales to broader community samples.

Two measures have incorporated the value dimension (e.g., Félix-Ortiz, Newcomb, and Myers 1994; Cortés, Rogler, and. Malgady 1994). The scale proposed by Cortés et al. (1994) includes values in a generic way; individuals are asked to determine how important American/Puerto Rican values are in their lives. Even though the individuals' values are included in the scale, the only aspect measured is the individuals' preference for cultural values in general; no values are specified. Félix-Ortiz et al. (1994) took a different approach; they included two cultural distinctive values: "respeto" (respect) which captures children's obligation to obey and conform to their parents, and "marianismo" a value that reflects women's submission to their husbands. However, Félix-Ortiz et al.'s (1994) value scale did not correlate significantly with the criterion variables measured (place of birth, number of years in school, and generation) nor differed significantly between acculturation groups (highly bicultural, Latino/a, American, low-level bicultural). Even if the scale validity was not an issue, the development of the scale was restricted to a single Hispanic sub-culture, Puerto Ricans.

Additionally, none of the measures considers the individuals as consumers, whose consumption patterns bring them in contact to the host culture and express their ultimate choice to retain their own cultural orientation or integrate to the dominant culture. This research's purpose is to develop a consumer acculturation model and with it a consumer acculturation scale that overcomes the already mentioned limitations of the previous acculturation conceptualizations. 
CHAPTER III

\section{HISPANIC CONSUMER ACCULTURATION MODEL}

What is consumer acculturation? According to the previous literature review, the first answer to the question would be a change process. Following the Social Science Research Council (1954) definition this change is generated by direct cultural transmission. Several questions could be raised; what changes? What is the outcome of the change? How is the change produced? Taking in consideration all the elements previously discussed in Chapter II, the present research defines consumer acculturation as:

"A dynamic selective change process generated by the contact of a consumer with a different consumer cultural orientation via the acculturation agents or facilitators, through which the consumer adapts to the new culture. This adaptation is expected to be reflected in the consumers' behavior, affect, and values."

Based on the above definition consumer acculturation is considered a bilinear, multidimensional process in which adaptation is selective and dynamic. In the following pages an acculturation model will be offered and each element of the definition will be further developed.

\section{Acculturation Agents}

Cultural transmission takes place through certain behavioral processes such as modeling, role playing, reinforcement and social interaction (Peñaloza 1994). Through these processes consumers learn and create skills to adapt or assimilate to the new culture. These processes are generated by an individual's exposure to two (or more) 
cultural orientations through social agents or facilitators. Padilla (1994) classified these agents in: primary (parents and family members) and secondary (friends, school, and other institutions). Peñaloza's (1994) model also included "acculturation agents" (p. 35). In her model the dual sets of acculturation agents (one per each cultural orientation) mediate or facilitate the acculturation process. These agents reflect both cultures promoting consumers' retention of their culture of origin and/or assimilation to the dominant culture.

If a broader consumer environment is taken into consideration, the institutions surrounding the consumer take on importance as acculturation agents along with family, friends and school. Religious organizations along with the workplace are institutions through which individuals are under continuous exposure to the new cultural orientation or reinforce their culture of origin. Mass media communications and shopping institutions like retail businesses, and direct marketing generate cultural transmission as well. According to McCracken (1986), cultural meaning moves from the cultural constituted world to consumer goods and then from these goods to the individual consumer. McCracken's model proposes that advertising, the fashion system and consumption rituals such as possession and grooming are the instruments by which meaning is drawn out of the goods and transferred. In Peñaloza's (1994; Peñaloza and Gilly 1999) models, marketers are considered mediators between the consumers' ethnic heritage and the larger culture market customs. Marketers generate this mediation by assisting their consumers' needs and by working to alter consumers' consumption patterns. Hence, it is proposed that the acculturation factors that generate the acculturation process should 
include: family, friends, work, media, education, retail institutions, and religious organizations, either Hispanic or Anglo.

\section{Acculturation Dimensions}

Acculturation has been described as a multifaceted process. According to Zane and Mak (2003) the acculturation measures have predominantly assessed the behavioral, attitudinal and cognitive dimensions. Cultural changes can be so complex and diverse that individuals may retain various elements of their culture of origin while simultaneously learn and assimilate to another culture in other dimension. For example, a fifteen year old adolescent who immigrated as a child might prefer to use English to communicate with his friends, speak English at school, read in English, and listen to mainstream music in English; yet, express indifference when asked how he felt about being American. If a language-based acculturation scale assessed this young adolescent acculturation level, he would be considered acculturated; however, if an acculturation scale reflecting strength of ethnicity was employed to measure his level of acculturation, he might not be considered acculturated. Hence, it is not sufficient to determine acculturation with a single dimension, such as language; instead it is necessary to include multiple items that tap into different dimensions of acculturation. The assessment of several acculturation dimensions provides not only a stronger acculturation measure but also a stronger explanatory model.

The question that follows is what dimensions of acculturation should be included? According to Zane and Mak (2003) future acculturation measures should capture specific elements from a psychological domain and measure the extent to which individuals have 
or have not become acculturated on that domain. Since this research is concerned with the effects of acculturation on consumers' behavior, only consumer/market-relevant dimensions will be included in the model and acculturation scale. But, what dimensions can be considered consumer/market relevant?

As mentioned before, language has been one of the most frequently examined behavioral variables. Language has not only shown to have a strong positive relationship with other demographic variables that reflect acculturation, but also is the dimension that explains the largest proportion of acculturation variance in most studies (Mendoza 1989; Cortés et al. 1994; Felix-Ortiz et al. 1994; Cuéllar, Arnold, and Maldonado 1995; Zea et al. 2003). Language is an important consumer/market dimension since it is a fundamental part of the communication process between marketers and their consumers. Language has been considered important in determining media use/preference (Ramirez, Cousins, Santos, and Supik 1986), and main message retention (Nicholls and Roslow 1996).

Several aspects of language have been measured such as language use, language proficiency and language preference in different contexts, mainly at home, work, with family members, and in media. Language use and proficiency reflect consumers' bilingual abilities. However, bilingual individuals are not necessarily bicultural (Padilla 1980), some individuals might be forced to use a specific language at work or school but prefer to communicate with friends and family members with their mother tongue. Of the scales previously developed (Table 1) only the Multidimensional Measure of Cultural Identity included language preference as a dimension in addition to English and Spanish language use. The Hispanic consumer acculturation model seeks to emphasize 
consumers' choice in their language use in different contexts, including shopping situations. Hence, this model will study language preference rather than language proficiency or language use as an acculturation dimension.

The next acculturation dimension considered as consumer/market relevant is consumers' emotions towards the cultures involved that are reflected in their ethnic identity. As Padilla (1980; Padilla and Perez 2003) states, ethnic identity is an essential part of acculturation. According to the social identity theory, people think, feel, and behave as members of collective groups, institutions, and cultures (Markus and Kitayama 1991). Hence, it is likely that the social groups that consumers identify will influence their beliefs that in turn guide their behavior such as fashion they wear, restaurants they choose or the brands they buy. The effects of the strength of identification have been explored in consumer behavior studies involving shopping behavior, coupon use, and loyalty (Deshpande and Hoyer 1986; Donthu and Cherian 1992 and 1994; Webster 1997).

The reader should not confuse consumer's ethnicity with consumer's ethnic identity; although both are involved with the consumer acculturation process, they represent different constructs. According to Gordon (1964) an ethnic group is “... any group which is defined by race, religion, or national origin, or some combination of these categories" (p. 27). Therefore, this research considers consumer's ethnicity as the consumer's ethnic group of origin. This construct has been considered an acculturation antecedent in Peñaloza's (1994) consumer acculturation model, suggesting that the acculturation process is determined by consumer ethnicity. The above takes on even more 
relevance if the reader considers that acculturation is a change process in one or both cultures in contact. There is evidence in the marketing literature that a consumer's ethnicity influences consumption patterns. For example, Hirschman (1981) identified relationships between Jewish ethnicity and levels of consumer innovativeness.

On the other hand, ethnic identity refers to the consumer's subjective feelings about his/her identity or sense of self as a member of an ethnic group. According to Phinney (2003), ethnic identity is not a fixed categorization but a dynamic understanding of the self. Hence, ethnic identity or the consumers' feelings about their ethnicity are likely to change as consumers engage in an acculturation process. Ethnic identity is assumed to include the strength of one's sense of belonging to an ethnic group and valence or the degree to which the attitudes towards one's group membership are positive (Phinney 2003).

On arrival, immigrants are identified with their country of origin, they are not likely to change their identification during their life time; however, they might in time identify themselves as American as well. In contrast, second, and third generations, in addition to identifying themselves as American, might maintain their identification with their country of origin (e.g., Mexican); or feel they belong to a subculture within America (e.g., Hispanic); or identify themselves simply as American (Phinney 2003). Therefore, in accordance with previous acculturation models, this study proposes that individuals' ethnic identification is a bilinear process (Cortés, Rogler, and Malgady 1994; Cuéllar, Arnold, and Maldonado 1995; Marín and Gamba 1996; Mendoza 1989; Szapocznik, Kurtines, and Fernandez 1980; Zea et al. 2003); one dimension establishes the 
individuals' feelings towards their culture of origin and the other one determines the individuals' feelings towards American culture.

The last acculturation dimension to be considered ${ }^{3}$ as consumer/market relevant is the consumer's value system. According to Vinson, Scott, and Lamont (1977), individuals' values represent a criterion that they use in the formulation of attitudes, motives and guidance of behavior. Valencia (1989) reported that different Hispanic groups have similar value systems and they differ in certain aspects from the nonHispanic group. In particular, this research considers familism as a core Hispanic value, and, as such, it is the only value included in this research. The relationship between cultural values, familism, acculturation, and consumer behavior is further discussed in Chapter IV.

According to the definition of consumer acculturation, the acculturation process is initiated by individuals' contact with acculturation agents. These agents either increase exposure to the host culture and/or promote culture retention depending on their nature (Hispanic or non-Hispanic). For example, when thinking about language preference, individuals with family and friends predominately Hispanic initially will exhibit preferences for speaking Spanish and for Spanish-based media; they might be required to learn and communicate in English at their workplace and/or at retail stores. In time, individuals might share friends that speak English and Spanish, pushing them to "culture swap" (Oswald 1999) or shift between roles with friends and family, work and church.

\footnotetext{
${ }^{3}$ This research does not intend to be exhaustive; there might be other acculturation dimensions, like culture competence (cultural knowledge). However, it is believed that these three are the most relevant for measuring consumer acculturation.
} 
The more individuals interact with the host culture through the agents, the faster the language preference is likely to change; in other words, the more the individuals speak English at work and with friends the more they will think and speak English in other contexts, changing their preferences and increasing their overall change. Conversely, individuals living in a city with a high density of Hispanic-Americans might be more exposed to their native language at work, church and shopping compared to English, promoting individuals' retention of their maternal tongue.

The same could be hypothesized for the individuals' feelings towards American culture. Consumers' contact with non-Hispanic institutions such as school, church, or work is likely to increase individuals' feelings of membership and belonging to America. Previous research suggests that as individuals increase their contact with American culture (number of years living in the U.S.), their American identification increases as well (Zea et al. 2003; Cuéllar, Arnold, and Maldonado 1995; Perez and Padilla 2000; Laroche, Kim, Hui, and Joy 1996). Conversely, evidence in the literature supports the proposition that as individuals' feelings towards American culture increase, their feelings towards their culture of origin decrease (Zea et al. 2003; Perez and Padilla 2000). For example, Perez and Padilla's (2000) results, reported in Table 2, show the differences of Hispanic cultural orientation, and American cultural orientation among generations. The evidence suggests that Hispanic cultural orientation and American cultural orientation have a negative relationship and both constructs significantly change across generations. Under this proposition both constructs not only are correlated between each other, but 
also decrease and increase, respectively, as the number of years living in the U.S. increases.

Table 2

POST HOC MULTIPLE COMPARISONS ACROSS THREE GENERATIONS OF HISPANIC ADOLESCENTS

\begin{tabular}{lccccc}
\hline & \multicolumn{5}{c}{ Cultural Identity Group } \\
\hline $\begin{array}{l}\text { Dependent } \\
\text { Variables }\end{array}$ & $\begin{array}{c}\text { Highly } \\
\text { Bicultural }\end{array}$ & Latino/a & American & $\begin{array}{c}\text { Low - Level } \\
\text { Bicultural }\end{array}$ & F value \\
\hline \hline Spanish Language & 13.3 & 14.8 & 11.3 & 12.3 & $7.7^{\star \star \star}$ \\
Proficiency & $(3.5)$ & $(2.1)$ & $(3.2)$ & $(2.4)$ & \\
& & & & & \\
Spanish Language & 8.7 & 10.5 & 5.8 & 7.7 & $16.1^{\star \star \star \star}$ \\
Preference & $(3.0)$ & $(2.5)$ & $(2.1)$ & $(2.7)$ & \\
Respect for Elders & 13.1 & 13.1 & 14 & 13.9 & 1.52 \\
& $(2.6)$ & $(2.4)$ & $(1.7)$ & $(1.7)$ & \\
Feminism & & & & & \\
& 6.0 & 6.9 & 6.2 & 6.0 & .93 \\
& $(2.3)$ & $(2.3)$ & $(2.7)$ & $(2.3)$ & \\
\hline
\end{tabular}

${ }^{*} \mathrm{p}<.05 ;{ }^{* *} \mathrm{p}<.01$

Adapted from the original Perez and Padilla (2000, p. 395)

This model proposes that contact with non-Hispanic agents generates individuals' feelings of belonging to schools, work, church, and commercial institutions, creating feelings towards the dominant culture. At the same time, Hispanics' tendency to live close to one another, and to form strong communities (Keefe 1980), is likely to promote their contact with Hispanic agents reinforcing their Hispanic identification. Both identifications are likely to depend on individuals' exposure to Hispanic and nonHispanic agents.

Previous research on familism and acculturation suggest that the relationship between both constructs is negative (Cuéllar, Arnold, and González 1995; c.f., Chapter IV). Therefore, the effect of acculturation agents on individuals' familism is likely to be 
negative. As individuals' contact with non-Hispanic acculturation agents outside their family increases, their ties and feelings towards their nuclear and extended family members is likely to change, decreasing their feelings of obligation and cohesion (c.f., Chapter IV; Sabogal et al. 1987; Cuéllar, Arnold, and González 1995).

Taking into consideration the previous discussion it is hypothesized that:

$\mathrm{H}_{1}$ : The higher the exposure to non-Hispanic acculturation agents:

a) The lower the preference for Spanish language

b) The higher the American identification

c) The lower the Hispanic identification

d) The lower the familism

Evidence from biculturalism suggests that acculturation is a process in which individuals may change by incorporating different dimensions of the new culture, while retaining other dimensions of their culture of origin (Cortés, Rogler, and Malgady 1994; Cuéllar, Arnold, and Maldonado 1995; Marín and Gamba 1996; Mendoza 1989; Szapocznik, Kurtines, and Fernandez 1980; Zea et al. 2003). However, the existing literature does not provide evidence suggesting any of the possible relationships among the acculturation dimensions. Berry (1980) proposed that acculturation affected the areas of psychological functioning (language, identity, attitudes among others), after the initial contact, through a gradual linear change. In time, a "hypothetical conflict" (p. 17) is reached generating an inflection point. Following this point individuals have the choice of three possible adaptation strategies: maintain the assimilation trajectory, return to the initial point, or stay between both alternatives. For example, in the case of language, after the inflection point individuals might choose to shift completely to the dominant culture's language, maintain their mother tongue, or be bilingual. Berry's (1980) conceptualization 
considers the acculturation changes in the domains parallel, and does not explain in detail the relationship between them.

Other conceptualizations of the acculturation process suggest a sequential order among the acculturation domains. Marín (1992) suggested that the acculturation process occurred at three levels: the superficial, the intermediate, and the significant level. The superficial level involves changes of behaviors, such as the adoption of new fashionable clothing, inclusion in the daily diet foods from the dominant culture, etc. The intermediate level includes more central behaviors, such as use and preference of language and media. The significant level involves changes in the individual's beliefs, values, and norms. Since values are enduring beliefs, they are likely to change at a slower rate compared to other behaviors similar to language use (Cuéllar, Nyberg, Maldonado, and Roberts 1997). Gordon (1964) suggested not only that acculturation occurred at different levels, but he also proposed the order in which changes occur. According to Gordon (1964), acculturation changes assimilating to the dominant culture occur first at a language level, followed by behavioral participation, with identification with the new culture occurring only later, perhaps not until the next generation.

The bilinear and multidimensional conceptualization of acculturation suggests a sequential order among the acculturation domains. It would be likely that individuals' acculturation process be gradual, initially changing their superficial behaviors, eventually modifying their language preferences. According to evidence in the literature (Jun, Ball, and Gentry 1993; Perez and Padilla 2000; Phinney 2003; Zea et al. 2003), although language preference change is evident in the first and second generations, ethnic 
identification with the culture of origin remained strong in subsequent generations suggesting that ethnic identification change was posterior to language acculturation.

Similarly, it would be expected that familism would change in subsequent generations. Sabogal et al. (1987) provided evidence that Hispanics support for their family remained constant even across generations $\left(\mathrm{M}_{1 \mathrm{st}}=3.72, \mathrm{M}_{\mathrm{Other}}=3.76, \mathrm{~F}<1\right)$, while familial obligations mostly changed between first and subsequent generations $\left(\mathrm{M}_{1 \mathrm{st}}=4.42, \mathrm{M}_{\text {Other }}\right.$ $=4.07, \mathrm{~F}=28.23, \mathrm{p}<.001)$. Perez and Padilla's (2000) results provide additional support (Table 2); as the Hispanic and American cultural orientation measures based on language preference and ethnic identification shifted across generations, family support did not change significantly. Therefore, this study proposes that contact with the acculturation agents generates a change/retention process of language preferences affecting subsequently their ethnic identification and familism. Hence,

$\mathrm{H}_{2}$ : The effects of the acculturation agents on familism and Hispanic and American identification are mediated by language preference.

\section{$\underline{\text { Acculturation and Consumer Behavior }}$}

As interesting as the study of consumer acculturation is, per se, this research seeks to determine the effects of the consumer acculturation process on Hispanics' consumer behavior patterns. The main purpose is to examine the effects of acculturation on a different domain that has been scarcely researched, consumer behavior. The Psychology, Anthropology, and Sociology literature have used acculturation as a core construct in contemporary social and behavioral research with ethnic groups (Chun, Balls Organista, and Marín 2003); however, the attempts to include acculturation in marketing are rare. 
Under the assumption that Hispanic and non-Hispanic consumers have some significantly different consumption patterns, it would be likely that as consumers increase their exposure to non-Hispanic acculturation agents, like media and shopping institutions, their language preference and American identification increase; this in turn is likely to have an effect on Hispanics' consumption patterns, generating changes towards the dominant culture. However, as previously described, acculturation is a bilinear process that reflects individuals' choice not to assimilate. Therefore, as Hispanic consumers choose to be predominately exposed to Hispanic acculturation agents such as media and retail stores, their identity with their Hispanic heritage is likely to be strong and they are likely to retain their consumption patterns. Finally, Hispanic consumers' familism is likely to decrease by their socialization with non-Hispanic agents such as friends, coworkers, church-members, etc. generating change on their values and consequently affecting their consumer behavior. However, familism is expected to have an effect only on family related consumption patterns, through attitudes or product attribute preferences (Vinson, Scott and Lamont 1997).

Based on previous research in the marketing literature, four variables were selected as dependent given their distinctiveness among Hispanic consumers: brand loyalty, attitudes towards high quality and prestigious brands, purchase frequency, and savings allocation for their children.

Brand loyalty is probably the consumer behavior that has been researched most among Hispanic consumers (Saegert et al. 1985; Petroshius, Newell and Ross 1995; Deshpande, Hoyer, and Donthu 1986; Donthu, and Cherian 1994; Williams and Mulhern 
1994); however, the findings of the different studies are contradictory. One set of researchers state that Hispanics are more brand loyal compared to Anglos, and that these differences are significant also when comparing Hispanic acculturation groups (Deshpande, Hoyer, and Donthu 1986; Donthu, and Cherian 1992; Donthu, and Cherian 1994), and other studies suggest that Hispanics are not significantly more loyal than the rest of the population and that they are more price sensitive compared to Anglos (Saegert et al. 1985; Williams and Mulhern 1994; Brown 2004). In addition to brand loyalty, the literature has suggested that Hispanic consumers are more brand-conscious and seek prestigious and high quality brands (Deshpande, Hoyer, and Donthu 1986; Donthu and Cherian 1994).

Assuming that Hispanic consumers are more loyal and brand conscious than nonHispanic consumers, the acculturation process is likely to affect their loyalty and their attitudes towards prestigious and high quality brands. Hispanics seeking to retain their heritage are apt to repeatedly purchase their preferred brands. According to Berman (2003), Hispanic consumers are loyal to those brands they used back in their country of origin, and to those brands their parents used to purchase. Saegert et al. (1985) proposed that Hispanics are more drawn to familiar stores, suggesting that Hispanics patronage certain brands because of their familiarity, instead of commitment. Therefore, as Hispanic consumers are exposed increasingly to American retail institutions, their familiarity with new brands and promotions is likely to propel consumers' trial of new brands; consequently, Hispanic consumers' are likely to decrease their purchase repetition behavior, reducing their loyalty. 
Purchase frequency is another behavior that has been suggested as distinctive among Hispanic consumers (McArthur, Viramontez, and Nocetti 2001; Valdez 2002). According to previous research, Hispanic consumers have a higher probability of purchasing fresh food compared to Anglo consumers (Paulin 2001). Therefore, Hispanic consumers' purchase frequency of groceries (trips to the grocery store) is likely to be higher when compared to Anglo consumers. Similarly, Hispanics' purchase frequency of non-fresh food (canned food and/or frozen food) is likely to be lower compared to non-Hispanics. For example, according to some results reported by AC Nielsen Homescan Hispanic panel (Valdez 2002), Hispanics reported making on average more trips per year to the retail store in order to purchase cooking oil compared to Anglos (5.4 vs. 2.6); they also reported purchasing significantly less frozen breakfast products (pancakes, waffles and French toast) compared to pancake mix. According to Valdez (2002), freshly prepared foods are part of the culture of most Hispanics. These behaviors corroborate McArthur et al.'s (2001) findings. Interviews with Hispanic immigrants suggested that Hispanic immigrants do not regard canned and frozen foods as favorably as fresh foods, and that Hispanics reported being used to purchasing their food on a daily basis. According to McArthur et al. (2001), Hispanic immigrants value their cultural food traditions, which stress the importance of preparing and consuming home-cooked meals. Additional support can be found in the food expenditure patterns for Hispanics compared to nonHispanics. According to Paulin's (2001) results, the probability of purchasing fruits and vegetables is higher for Hispanics compared to non-Hispanics (0.92 vs. 0.87). On the other hand, Hispanics spend less on ice cream, snack foods, pastries, and related items; for example, the probability of purchasing snack foods is higher for non-Hispanics 
compared to Hispanics ( 0.78 vs. 0.72$)$. Hispanic consumers' choice to retain their identification with their culture of origin is likely to generate retention of food consumption patterns and food preparation protocols. At the same time, the exposure to American acculturation agents such as schools, or the lack of contact with more "traditional retail institutions and foods" are likely to increase consumers' identification with the American culture and change their purchase frequency and food selection behavior (McArthur, Viramontez, and Nocetti 2001; Valdez 2002).

Hispanic consumers' savings allocation was considered a behavior that would be directly affected by consumers' values, in particular their familism. Previous literature and consumer reports (Delener and Katzenstein 2000; Strategy Research 2002; Synovate 2004) suggest that Hispanics have significantly different financial product-possession and behavior when compared to non-Hispanic consumers. For example, according to the 2004 U.S. Hispanic Market Report of Synovate, Hispanic households reported having significantly lower bank accounts (69\%) and funds for retirement (26\%) compared to the general market households ( $97 \%$ and $66 \%$ respectively).

It has been suggested that adult Hispanics are likely to feel obligated towards their parents (Freeberg and Stein 1996), children, and relatives (Sabogal et al. 1987; Cuéllar, Arnold, and González 1995). Increased contact with the American culture characterized by their individualistic orientation (Hofstede 1980) is likely to change Hispanic consumers' feelings of obligation to support and provide their children above everything else, even themselves; consequently, their savings motives are expected to change. It 
would be likely that as Hispanics familism decreases, their savings for their children's future would decrease.

Taking into consideration the previous discussion it is hypothesized that:

$\mathrm{H}_{3}$ : The lower Hispanic consumers' American identification the higher their:

a) Brand loyalty

b) Attitudes towards prestigious brands

c) Purchase frequency

d) Savings for their children's future

$\mathrm{H}_{4}$ : The higher Hispanic consumers' Hispanic identification the higher their:

a) Brand loyalty

b) Attitudes towards prestigious brands

c) Purchase frequency

d) Savings for their children's future

$\mathrm{H}_{5}$ : The higher the Hispanic consumers' familism the higher their savings for their children's future.

In summary, $\mathrm{H}_{3}, \mathrm{H}_{4}$, and $\mathrm{H}_{5}$, propose that ethnic identification (Hispanic and American) and familism are significant predictors of Hispanic consumer patterns. However, when considered within the acculturation model, these dimensions are expected to mediate the effects of language preference on subsequent changes in consumer patterns.

\section{$\underline{\text { Acculturation Moderators }}$}

Evidence suggesting that individual differences are factors likely to differentiate individuals' acculturation process is contradictory (e.g., Szapocznik et al. 1978; Cuéllar, Arnold, and Maldonado 1995). In the following sections these results will be described. 
This research seeks to determine whether the acculturation process is, indeed, moderated by individual differences caused by gender, age, and country of origin.

Gender: Previous results regarding the moderating effects of gender are contradictory. Szapocznik et al.'s (1978) results support the proposition that males' behavioral acculturation rate is faster than females' when acculturation is operationalized as behavioral changes $\left(M_{F}=53.2, n=198\right.$ vs. $\left.M_{M}=63, n=127\right)$. Holding age constant, the mean acculturation difference is significant $\left(\mathrm{F}_{(2,320)}=3.71, \mathrm{p}<.05\right)$ and in the predicted direction. However, Szapocznik et al.’s (1978) study reported finding no differences between genders when acculturation was measured through the individuals' values, this is with their preferred family relational style $\left(\mathrm{F}_{(2,320)}=2.46, \mathrm{p}<.11\right)$. Moreover, Cuéllar, Arnold, and Maldonado's (1995) results based behavioral and ethnic identification acculturation found no significant differences between males' and females' mean acculturation scores. A cross-tabulation of gender by acculturation level yielded a $\chi_{(4, N=321)}^{2}=9.17(p>.05)$, which suggests that both variables are independent. However, the female acculturation scores reported are higher than males' scores $\left(\mathrm{M}_{\mathrm{F}}=.73, \mathrm{n}=181\right.$ vs. $\mathrm{M}_{\mathrm{M}}=.36, \mathrm{n}=162$ ), contrary to Szapocznik et al.'s (1978) findings.

It has been suggested that differences in women's and men's socializing roles are likely to affect consumers' acculturation (Torres-Matrullo 1980; Grǿnhaug, Gilly, and Peñaloza 1993), and that Hispanic traditional husbands are more likely to play external roles compared to women, including education (Vega 1995). Hence, Hispanic males are more likely to have contact with non-Hispanic acculturation agents and exhibit a faster language acculturation compared to Hispanic females, who, according to their sex-role, 
are more likely to spend most of their time at home (Díaz-Guerrero 1972; TorresMatrullo 1980). Taking into consideration the previous discussion the following hypothesis is offered:

$\mathrm{H}_{6}$ : The relationship between the acculturation agents and language preference is moderated by gender.

Age: Again, previous results on the moderating effects of age on acculturation are contradictory. According to Szapocznik et al. (1978), the rate of behavioral (language) acculturation was an inverse linear function of age, suggesting that younger individuals adapt more rapidly to new cultural environments. However, when acculturation was measured through preferred family relational style (values), the results did not reflect the expected linear pattern, even though acculturation differed significantly across age groups (Table 3). Instead of controlling for the number of years living in the U.S., Szapocznik and his colleagues showed that the differences in the average number of years living in the United States across age groups were non-significant (Table 3). On the other hand, Cuéllar, Arnold, and Maldonado's (1995) study correlated the individuals' acculturation score with their age and found it to be not significant, failing to support Szapocznik et al.’s (1978) proposition.

Country of Origin: Almost like an urban legend is the belief that Cuban-Americans are different from Puerto Rican-Americans and Mexican-Americans among other Hispanic groups. According to Synovate (2004), Puerto Ricans exhibit language use differences when compared to consumers reporting other countries of origin; in particular, their 
preferences for the Spanish language at home (34\%), and at social occasions (42\%) are significantly lower compared to Mexican (67\% and 69\%, respectively), and Cuban ( $76 \%$ and $75 \%$, respectively)consumers' Spanish language preferences. Therefore,

$\mathrm{H}_{8}$ : The relationship between acculturation agents and language preference is moderated by individuals' country of origin.

Table 3

MEANS, STANDARD DEVIATIONS AND F-RATIOS FOR THE ACCULTURATION SCALES AND FOR YEARS LIVING IN THE U.S. BY PSYCHOLOGICAL STAGE

\begin{tabular}{|c|c|c|c|c|c|c|c|}
\hline \multirow[b]{2}{*}{ Age Group } & \multirow[b]{2}{*}{$\mathbf{N}$} & \multicolumn{2}{|c|}{ Behavioral Acculturation } & \multicolumn{2}{|c|}{ Value Acculturation } & \multicolumn{2}{|c|}{ Years in the U.S } \\
\hline & & $\mathbf{x}$ & SD & $\bar{x}$ & SD & $\mathbf{x}$ & $\overline{S D}$ \\
\hline $\begin{array}{l}\text { Early Adolescence } \\
(13-17)\end{array}$ & 90 & 68 & 16.9 & 49.1 & 7.5 & 9.2 & 4.7 \\
\hline $\begin{array}{l}\text { Later Adolescence } \\
(18-22)\end{array}$ & 91 & 66.2 & 19.8 & 52.2 & 10.7 & 8.4 & 4.7 \\
\hline $\begin{array}{l}\text { Early Adulthood } \\
(23-30)\end{array}$ & 32 & 63.2 & 13.7 & 56.6 & 12.1 & 8.7 & 4.1 \\
\hline $\begin{array}{l}\text { Middle Adulthood } \\
(31-50)\end{array}$ & 67 & 54.9 & 16.6 & 48.7 & 8.3 & 9.1 & 4.9 \\
\hline $\begin{array}{l}\text { Later Adulthood } \\
(50+)\end{array}$ & 43 & 27.7 & 16.2 & 42.99 & 8.9 & 8.1 & 5.5 \\
\hline$\overline{\text { F Ratio }}$ & & $47.10^{\star \star \star}$ & & $8.32^{\star \star}$ & & 0.55 & \\
\hline
\end{tabular}

${ }^{* *} \mathrm{p}<.01 ;{ }^{* * * *} \mathrm{p}<.0001$

Adapted from the original Szapocznik et al. (1978, p. 127)

\section{Acculturation Outcomes}

According to the literature review covered in Chapter II, most bilinear acculturation models classify individuals in four groups, according to the adaptation strategy that they have chosen: change to the dominant culture orientation, retention of their culture of origin, both, or none. For example, Berry's acculturation model (1980), by recognizing the individuals' choice and the strategy of the larger society, offered four acculturation outcomes: assimilation, integration, separation, and marginalization. 
Peñaloza's (1994) model also includes four acculturation types: assimilation, maintenance, resistance, and segregation. Both models suggest that the process of contact between cultures can also produce a rejection of either culture or the "deculturation" of the individual (Marín 1992, p. 241). Rejection is assumed to occur when individuals are marginalized or segregated by the dominant culture. Hence, individuals are forced to be apart from their cultural origins but prevented from getting in contact with the dominant one. Following Marín's (1992) proposition, this research will only consider as acculturation outcomes a high/low acculturation levels and biculturalism because "they seem to be the most applicable options for Hispanics in the United States" (p. 241). The socio-political environment of the United States neither prevents immigrants from adapting to the American culture, nor limits the individuals' freedom to retain their culture of origin. Additionally, on a methodological note, empirical findings suggest that the segregation or marginalization acculturation type has not been found statistically reliable (Cuéllar, Arnold, and Maldonado 1995). Accordingly, this research will consider three acculturation outcomes: high acculturation, low acculturation and biculturalism.

A high acculturation level is achieved when consumers change from their original cultural orientation and adapt to the host consumer environment. Some individuals are more likely to experience overall assimilation to the American culture than others; individuals for whom family and friends are mainly non-Hispanic and their media language preference is English and the church, school, or shopping institutions they attend are non-Hispanic, are more likely to be further acculturated to the "American" 
culture. However, acculturation should be understood as a never-ending-process (Berry, Trimble, and Olmedo 1986).

On the other hand, consumers exhibit low acculturation levels when their cultural environment (agents) does not provide enough contact with the host culture or when they voluntarily decide they wish to maintain the cultural orientation of their country of origin. Some individuals might not experience overall assimilation given their age of migration, or education, or the Latino population density of the place they live in, that hinder their contact with non-Hispanic agents of acculturation (Cavalcanti and Schleef 2001).

Finally, there may be individuals who share agents between both cultures, for example they might have a Hispanic family, and at the same time most of their friends are non-Hispanic. This type of individual might experience "biculturalism" (Mendoza 1989, p. 379), exhibiting cultural shifts or role playing depending on the situational context (Stayman and Deshpande 1989; Oswald 1999; Padilla 1994).

In summary, Chapter III has developed a consumer acculturation model. The overall elements and relationships developed through the chapter can be visualized in Figure 4. According to the model, consumers are confronted with Hispanic and nonHispanic acculturation agents that facilitate or hinder the consumers' contact with consumers' culture of origin and the American culture. The acculturation process initially affects consumers' language preference. Consumers' exposure to Anglo/Hispanic acculturation agents is likely to generate change/retention of their preference for Spanish language in different communication contexts. In time, the change/retention of 
consumers' language preference is expected to generate an increase/decrease of consumers' feelings towards the American culture, feelings towards their Hispanic heritage, and familism. In other words, language preference is expected to mediate the effects of the acculturation agents on the other acculturation dimensions: familism, Hispanic identification, and American identification. Additionally, the acculturation process is expected to affect Hispanic consumers' consumption patterns through consumers' ethnic identification and familism. Lastly, individual differences like age, gender, and country of origin are factors likely to affect individuals' acculturation process, moderating the effects of the acculturation agents on the acculturation domains.

Figure 4

HISPANIC CONSUMER ACCULTURATION MODEL

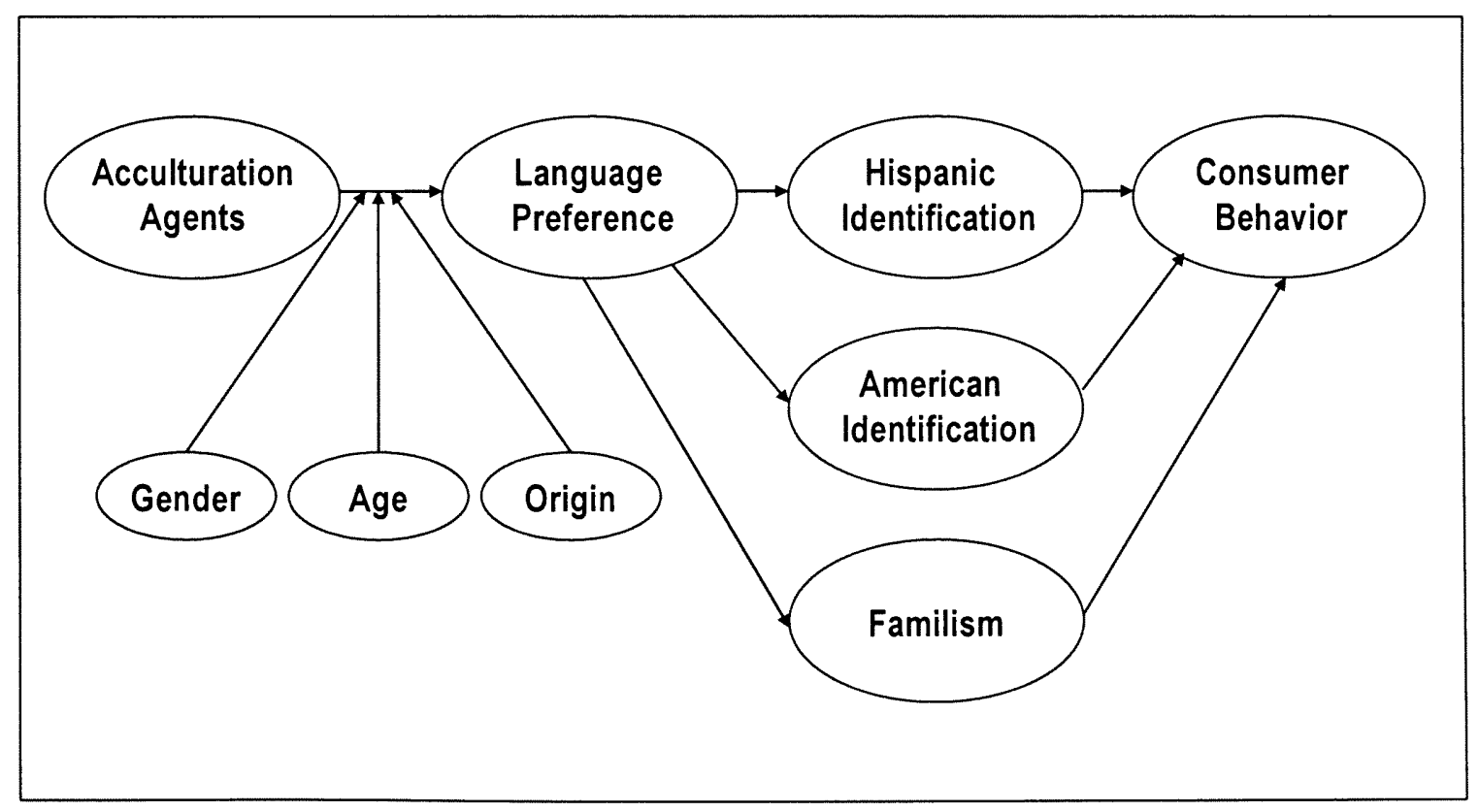




\section{CHAPTER IV}

\section{VALUES AND ACCULTURATION}

As pointed out in the introduction, consumer behavior research has successfully associated ethnic identification and language preferences to certain consumer behaviors like brand loyalty, coupon use, advertising, and information search behavior (e.g., Deshpande et al.1986; Nicholls and Roslow 1996; Petroshius, Newell, and Ross 1995; Webster 1992; Donthu and Cherian 1994). For example, Donthu and Cherian (1994) explored the nature of Hispanic retail shopping behaviors and the importance of ethnicity on the selection of a service provider in low and high involvement services. Strong Identified Hispanic consumers $(\mathrm{SIH})$ preferred Hispanic vendors more than Weak Identified Hispanics (WIH). Regarding the purchase behavior items, it was found that SIH are significantly less driven by economic value than $\mathrm{WIH}(\mathrm{M}=2.13$ vs. $\mathrm{M}=2.74$, respectively); $\mathrm{SIH}$ are more brand loyal (especially to brands purchased by their parents) than WIH $(\mathrm{M}=3.17$ vs. $\mathrm{M}=1.94$, respectively); and $\mathrm{SIH}$ are more affected by ads (especially those targeted towards Hispanics) than WIH (mean 3.27 vs. 2.30).

There is also evidence that language is an effective predictor of consumer behavior (Webster 1991, 1992, 1994 and 1997; Petroshius, Newell, and Ross 1995; Nicholls and Roslow 1996; Korgaonkar, Karson, and Lund 2000). For example, Korgaonkar et al.'s (2000) study investigates the purchase behavior, attitudes and beliefs of Hispanic consumers toward direct marketing advertising (DMA). In order to classify the respondents according to their assimilation to the American culture, respondents were asked to rate themselves on their English proficiency. According to their results 
assimilated Hispanics are significantly: (1) more prone to order items from print media; (2) more positive regarding DMA in general; (3) more likely to find DMA useful, as well as enjoyable, compared to the less assimilated Hispanics. The analysis of the data controlled not only for income but also for education, age, and years living in the USA.

There are other examples of studies that have considered language preference and ethnic identification jointly as measures of consumer acculturation. For example, Kara and Kara (1996) employed the consumers' self identification as an ethnicity measure and a combination of language, behavior and demographic based scales. The purpose of their study was to examine the effects of acculturation on consumer choice behavior. The choice behavior of Anglos and low and high acculturated Hispanics were compared for low and high involvement products (job selection and toothpaste) using a hybrid conjoint model. Results of this study indicated that Hispanics with a high level of acculturation and Anglos were very similar to each other but different from Hispanics with a low acculturation level in terms of the utilities placed on the product attributes of jobs and toothpaste.

However, no attempt has been made in the literature to comprehend and measure the impact of the value acculturation dimension on consumer behavior. Hence, Chapter IV will develop a comprehensive literature review of values and will consider the effects of values on acculturation and consumer behavior. 


\title{
$\underline{\text { Values and Consumer Behavior }}$
}

Social scientists' concept of value is closely related to a principle, a standard, or a belief, that determines individuals' motivation, a course of action that ultimately influences their behavior. According to Rokeach (1973):

\begin{abstract}
"A value is an enduring belief that a specific mode of conduct or end-state of existence is personally or socially preferable to an opposite or converse mode of conduct or end-state of existence. A value system is an enduring organization of beliefs concerning preferable modes of conduct or endstates of existence along a continuum of relative importance." (p. 5)
\end{abstract}

Hence, values are general cognitions that vary in importance and are enduring; they refer to a single belief that transcends any particular situation. Values function as a guide of human action in daily life; they give expression to human needs and strongly determine their motivation. Therefore, they are more stable, once they are learned through life experiences or acquired through a dominant cultural influence they become part of an individual value system in which each value is prioritized relative to other values.

Empirical evidence has supported the general theory that consumers' value orientations are determinants of certain aspects of consumer behavior (Vinson, Scott, and Lamont 1977; Henry 1976; Scott and Lamont 1973; Allen, Hung Ng, and Wilson 2002; Allen 2001; Schopphoven 1991; Daghfous, Petrof, and Pons 1999). For example, according to Vinson, Scott, and Lamont (1977), individuals' values represent a criterion that consumers use in the formulation of attitudes, product attribute preferences, and consumer life styles. Allen (2001) suggests that values influence consumer decisions in 
two ways: directly, and indirectly through the importance of the product's attributes. This relationship is moderated by consumers' preference for utilitarian or symbolic product meaning. Allen's (2001) results showed that among individuals whose direct influence of their values predicted their product choice more accurately, preferred symbolic meaning and affective judgments. On the other hand, individuals whose values more accurately predicted their product choice indirectly via the importance of the product's tangible attributes, preferred utilitarian meaning and piecemeal judgments. In summary, Allen concludes that human values can affect consumer choice directly or indirectly through the preference for certain product attributes.

Research on human values has long been present in the anthropology, sociology, and psychology literatures. Most of the research on human values relies on Rokeach's (1973) work. Rokeach's (1973) value survey produced two lists of 18 instrumental and terminal values that represent American society's value systems (Table 4). Other value structures based on the original 36 values of Rokeach's (1973) value survey have generated structures of a few higher-order values. Of these, three streams of research can be mentioned: Schwartz and his colleague's "Structure of Human Values" (Schwartz and Bilsky 1987; Schwartz and Bilsky 1990; Schwartz 1994a; Schwartz 1994b), Mitchell's (1983) "Values and Life Styles (VALS)," and Khale's (1983) "List of Values (LOV)." Structure of Human Values: Schwartz's (1994a) typology of values reflects a continuum of related motivations. This continuum of motivations captures the notion that the pursuit of different values can be compatible or in conflict with other values. Schwartz's (1994a) seven value types (conservatism, intellectual autonomy, affective autonomy, hierarchy, 
egalitarian commitment, mastery, and harmony) are organized in two bipolar dimensions that generate four higher order dimensions: openness to change (lower-left quadrant) vs. conservation (upper-right quadrant) and self-transcendence (lower-right quadrant) vs. self-enhancement (upper-left quadrant). Schwartz and Bilsky (1990) tested the universality of their value structure in seven countries. Their results revealed the same structure in each sample, except for Hong Kong, where individuals' value priorities included an additional value, social power.

Table 4

ROKEACH'S VALUE SURVEY

\begin{tabular}{ll}
\hline \multicolumn{1}{c}{ Terminal } & \multicolumn{1}{c}{ Instrumental } \\
\hline \hline A comfortable life & Ambitious \\
An exciting life & Broadminded \\
A sense of accomplishment & Capable \\
A world at peace & Cheerful \\
A world of beauty & Clean \\
Equality & Courageous \\
Family security & Forgiving \\
Freedom & Helpful \\
Happiness & Honest \\
Inner harmony & Imaginative \\
Mature love & Independent \\
National security & Intellectual \\
Pleasure & Logical \\
Salvation & Loving \\
Self-respect & Obedient \\
Social recognition & Polite \\
True friendship & Responsible \\
Wisdom & Self-controlled \\
\hline
\end{tabular}

*Adapted from the original (1973, p. 57-58)

Values and Lifestyles (VALS): VALS (values and lifestyles) is a widely used psychographic approach to market segmentation originated by Arnold Mitchell (1983) and SRI International. The concept addresses the question of how people's values on life may influence spending values. VALS uses a hierarchical topology with 9 life style 
groups: (1) survivors; (2) sustainers - low income individuals; (3) belongers - the conservative and conforming members of the middle class; (4) emulators - intensely striving people, likely to be in debt; (5) achievers - leaders in business, professions, and government; (6) I-Am-Me - the transitional individual who is young and individualistic; (7) experientials - those who are deeply involved with issues; (8) societally conscious those concerned with issues, trends, and events; and (9) integrated - those who tend to be self-actualized. Rather than a classification of human values, the VALS typology is one of consumers' lifestyles, reflecting the idea that consumers buy products in part to reflect their values and actualize their value driven lifestyles. The VALS instrument consists of about 30 demographic and attitudinal questions that classify individuals into one of the nine lifestyle groups. VALS was developed as a proprietary segmentation system. Therefore, scant academic research has been based on it. Nonetheless, this segmentation system achieved a strong commercial success. Many companies have used VALS, such as AT\&T, The New York Times, and American Motors, among others (Kahle, Beatty, and Homer 1985).

List of Values (LOV): The List of Values (LOV) (Khale 1983), is an abbreviated measurement instrument that includes only nine of Rokeach's (1973) terminal values, and reflects Maslow's (1954) needs hierarchy. The LOV is fundamentally based on social adaptation theory (Kahle 1983). According to Kahle the primary function of a value system is adaptation. Values are developed actively through social relations. The individual actively filters societal and cultural demands, redefining their values in order to adapt to their world. The list is comprised of nine values: self respect, security, warm 
relationships with others, sense of accomplishment, self-fulfillment, sense of belonging, being well respected, fun and enjoyment in life, and excitement. The LOV has been successfully employed to classify consumers in value segments by employing the most important value profiled by the consumer's attitudes (Kahle and Kennedy 1988). Hence, it does not make reference to the complete value system; it is rather based on the individual's top value.

The three value structures described are similar in their content, even though the measurement instrument varies. Several comparisons between VALS and LOV have been published, supporting the superiority of the LOV instrument as a classification tool and as a predictor of consumer preferences and behavior (Kahle, Beatty, and Homer 1985; Schopphoven 1991). Kahle et al. (1985) used both instruments to predict several criterion variables that represented different trends in consumer behavior. These variables included consumers' marketing beliefs (e.g., belief about the improvement of the quality of products), consumers' media habits (e.g., frequency of watching certain type of TV shows), consumers' hobbies (e.g., frequency of attending the movies, jogging, etc.), and consumers' frequency of use of certain products (e.g., cold remedies, breakfast cereals, carbonated sodas, etc.). Kahle et al.'s (1985) results, after normalizing the ordinal data and including demographic variables (the same demographic variables that are part of the VALS algorithm), suggest that LOV significantly predicts consumer behavior more often than VALS (significance was reached for 32 vs. 12 criterion variables). Additionally, the $\mathrm{R}^{2}$ for LOV was larger than the $\mathrm{R}^{2}$ for VALS a significantly higher proportion of the time $(\mathrm{p}<.001)$ 


\section{$\underline{\text { Values and Culture }}$}

Marín and Triandis (1985) suggested that an important characteristic of the Latin American and Hispanic culture is their allocentrism. The Allocentric/Idiocentric dichotomy is defined by the authors as the correspondence for Individualism /Collectivism dichotomy, at the individual level. Hence, allocentrism reflects individuals' concern and identification with their in-groups; allocentrism has been associated with high levels of interdependence and family integrity. On the other hand, idiocentrism is best described as emotional detachment and represents those individuals who determine their social behavior in terms of their personal goals (Triandis, McCusker and Hui 1990).

According to Marín and Triandis' (1985) research, Hispanics' allocentrism pervades other values that distinguish Hispanics from non-Hispanics:

Avoidance of Interpersonal Competition: According to Marín and Triandis (1985), Hispanics seem to prefer cooperation over competition. Research conducted with nonHispanic and Hispanic-American children suggest that while non-Hispanic children chose rivalry and competition as a winning strategy, Hispanic children chose cooperative alternatives (Kagan 1977). This value has also been called the Active/Passive Syndrome (Díaz-Guerrero 1968). According to this syndrome, Mexican culture can be described as passive, polite, agreeable, complacent, harmonious, cooperative, and pluralistic; while the American culture reflects activity, autonomy, independence, confidence, competitiveness, and practicality. 
"Simpatia": This personal quality has been pointed out as a cultural script of Hispanics (Ramirez 1990; Marín and Triandis 1985). According to Marín and Triandis (1985) simpatia has no equivalent in English but refers to "an individual perceived as likable, attractive, fun to be with, and easy going" (p. 96). An individual described as simpático would show levels of conformity and an ability to share in others' feelings; he would strive for harmony in interpersonal relations seeking for respect and dignity towards others. Personal goodness and getting along with others are considered more important than individual ability and material success (Ramirez 1990).

Role Perceptions within the Family: Various authors have suggested the perceived patriarchal dominance of the husband, the role of subordination in parent-child relationships (Díaz-Guerrero 1993; Díaz-Loving and Draguns 1999). The Hispanic self exhibits a collective identity that is dependent on strict social rules, like parents are supposed to provide their children with a proper upbringing and the children should always obey their parents. The wife-husband relationship also creates an important role perception. The father is the head of the household; as such, he is responsible for providing everything needed at home, while the wife/mother is responsible for the upbringing and education of the children as well as all the housework (Díaz-Guerrero 1972). Hence, on one side Hispanics are brought up to value obedience, discipline, respect and humbleness; while at the same time value authority and power.

Familism: Usually described as including a strong identification and attachment of individuals to their families (nuclear and extended). Literature on Latin Americans and Hispanics is very consistent in presenting the family as the most important institution in 
the culture (e.g., Sabogal, Marín, and Otero-Sabogal 1987; Díaz Guerrero 1972).

Therefore, the following section will describe in detail this important Hispanic cultural value.

$\underline{\text { Familism }}$

There are several definitions of familism in the Psychology and Anthropology literatures. The first distinction that has been made in the literature is between behavioral and attitudinal familism. On the one hand, attitudinal familism refers to the beliefs and attitudes associated with the extended and nuclear family members. On the other hand, behavioral familism refers to behaviors related to the family members (Sabogal et al. 1987). When referring to Hispanics, particularly to first generation immigrants, it is likely that the behavioral component of familism would be lower compared to the nonHispanics, given that most of them immigrate alone. For example, behaviors such as number of times per week that an individual visits or assists a family member are likely to be low. Subsequently, when all family members have migrated or the family has grown from nuclear to extended, Hispanic families have shown a tendency to live close to one another; they create strong networks of support and assistance, exhibiting higher levels of behavioral familism, distinguishing them from non-Hispanic families, who do not live as close to each other (Keefe 1980). Given that this research seeks to understand the impact of familism as a core Hispanic value, this investigation will concentrate only on the individuals' attitudinal familism. 
Attitudinal familism (familism from this point on) has been defined in several ways. Most definitions include a strong identification and attachment of individuals with their families (nuclear and extended), a deep awareness and pride in family membership. Familism is associated to obligation, support, and perceived roles (Díaz-Guerrero 1993; Díaz-Loving and Draguns 1999) generating feelings of loyalty, reciprocity, solidarity, and sacrifice among members of the same family (Bardis 1959; Heller 1976; Freeberg and Stein 1996; Marín and Triandis 1985; Sabogal et al. 1987).

Sabogal et al.'s (1987) research identified three dimensions of familism. The factors are: (1) familial obligations, that is, the perceived obligation to provide material and emotional support to members of the extended family; (2) support from family, which is the perceived support and help from relatives to solve problems; and (3) family as referents, which is the perception of family members as referents.

Sabogal et al.'s (1987) conceptualization of familism captures some of the individual's attitudes towards the other members of the family. However, there are other aspects of familism that the former conceptualization ignores and that could affect the individual's acculturation process. According to Bardis (1959) an important attitudinal element of familism to be considered is the desire to pursue the perpetuation of traditions and family roots. It is this desire that could determine individuals' decision to assimilate to the host culture, or resist and maintain their cultural orientation. Individuals' choice of ethnic identification could be affected by the group's desire to maintain and perpetuate their family traditions or their desire to blend into the American culture. Another characteristic of Hispanics' familism that is absent from Sabogal et al.'s (1987) 
conceptualization is their tendency to live close to one another (Keefe 1980). This research's acculturation model proposes that the higher the exposure to Hispanic agents, the lower the levels of acculturation. Consequently, if Hispanic families have a tendency to create strong networks of support and assistance by living close to one another (Keefe 1980), they are likely to be highly exposed to Hispanic acculturation agents, slowing their acculturation process. Based on the above, this research defines familism as the individual's perceived obligations (material and emotional) to nuclear and extended family members, and one's desire to live together, maintaining one's family traditions.

Interestingly, familism, as previously defined, has not being included in any of the value structures mentioned previously in this chapter. Rokeach's (1973) value list includes family security as a value. However, familism, according to the prior definition, involves several other obligations, feelings and roles that go beyond security. Schwartz's value structure possess some values that fall in the conservatism and egalitarian commitment value categories that relate to familism. Values such as obedience, respect for traditions, honoring elders, helpfulness, and loyalty describe, in part, some of the obligations and support expected from family members. Nevertheless, according to the familism definition, these values should refer only to family members. For example, individuals high in familism are likely to be helpful to their family, not necessarily at work, nor to society. Finally, the LOV includes values such as "a sense of belonging," and "warm relationships with others." Again, these values could describe an individual relationship with anyone, not exclusively with family members. The lack of representation of familism in the set of values that describe the American society 
(Rokeach's 1973) and subsequently from the following streams of research (Schwartz and Bilsky 1987; Mitchell 1983; Khale 1983) suggest that current value segmentation instruments might not classify Hispanics accurately.

\section{$\underline{\text { Familism and Acculturation }}$}

According to Cabasa (2003) future Acculturation measures "need to move toward more basic measures of cultural change" (p. 140). Yet, what values should be included in the acculturation scale? Which values are useful to discriminate between acculturation groups, and between non-Hispanic and Hispanic-Americans that affect consumer behavior? Cabasa (2003) suggests that the integration of the cross-cultural values, such as collectivism and individualism, can serve as a starting point. The values included in the acculturation scale should not only influence certain consumer behaviors among Hispanics, but also explain the differences in consumers' preferences and brand choices between ethnic groups. Therefore, the scope of this acculturation value scale is not to measure every possible value but concentrate on those for which there is some evidence that Hispanics and non-Hispanics significantly differ and these differences might affect consumer behavior.

Familism has been successfully used as discriminant variable between acculturation groups and between Hispanic and non-Hispanic individuals. According to Marín and Triandis (1985), the most significant difference among Hispanics and nonHispanics is that Hispanics are more willing to sacrifice for the welfare of their extended and nuclear family members, while non-Hispanics were only willing to do it for their 
nuclear family members. For Hispanics "la familia es primero" (family is first). Freeberg and Stein (1996) found empirical evidence that, on average, Mexican-American respondents reported higher levels of familism, more collectivist attitudes, and more helping behavior in their relationships with their parents compared to Anglos, while Anglo respondents reported having more contact with social systems outside the family (Table 5).

Table 5

UNIVARIATE ANOVA EFFECTS, MEANS AND SDs FOR THE CULTURAL ATTITUDE AND FAMILY MEASURES AS A FUNCTION OF ETHNICITY

\begin{tabular}{lccc}
\hline Criterion & $\begin{array}{c}\text { Mexican- } \\
\text { American } \\
(\mathrm{n}=50)\end{array}$ & $\begin{array}{c}\text { Anglo } \\
(\mathrm{n}=50)\end{array}$ & F value \\
\hline \hline Familism & 3.59 & 3.27 & $19.9^{\star *}$ \\
& $(-0.33)$ & $(-3.37)$ & \\
Collectivism & 6.22 & 5.68 & $5.17^{\star}$ \\
Individualism & $(-1.36)$ & $(-0.98)$ & \\
& 5.94 & 5.91 & 0.02 \\
Assistance in Activities of Daily Living & $(-1.19)$ & $(-1.09)$ & \\
& 3.34 & 2.73 & $20.2^{\star *}$ \\
Internal Family Environment Scale & $(-0.71)$ & $(-0.7)$ & \\
& 12.18 & 12.58 & 0.36 \\
External Family Environment Scale & $(-3.14)$ & $(-3.42)$ & \\
& 11.14 & 12.3 & $4.28^{\star}$ \\
& $(-2.86)$ & $(-2.82)$ & \\
\hline
\end{tabular}

${ }^{*} \mathrm{p}<.05 ; * * \mathrm{p}<.01$

Adapted from the original Freeberg and Stein (1996, p. 465)

Considering familism as a core value for Hispanics and considering the empirical evidence provided, it would be expected that familism would have a high discrimination power among Hispanic and non-Hispanic groups. Notwithstanding, demographic differences between Anglos and Hispanics should be taken into account. According to the most recent Census figures, both ethnic groups have significant differences on family composition, income, education, and age. Therefore, we would expect the discriminatory 
power of familism to remain even after controlling for demographic differences among ethnic groups. Hence,

$\mathrm{H}_{9}$ : Hispanic consumers' familism is likely to be higher than Anglo consumers' familism, even after controlling for number of children, income, education and age.

The relationship between familism and acculturation among Hispanics has also been examined before; however, the results are inconsistent. On the one hand, there are studies that suggest that familism acculturates (changes) as individuals' contact with the host culture increases (Sabogal et al. 1987; Rodríguez Montoro and Kosloski 1998; Cuéllar, Arnold, and González 1995). On the other hand, there is also evidence that Hispanic consumers retain their values across generations (Perez and Padilla 2000; FélixOrtiz et al. 1994).

Sabogal et al.'s (1987) research examined the relationship between behavioral acculturation (language use and preference) and familism (familial obligations, perceived support, and family as referents). According to their results, the less acculturated individuals reported higher levels of agreement with the dimensions of familial obligations $(M=4.44)$, and family as referents $(M=3.41)$ compared to the highly acculturated individuals $(M=3.97$ and $M=2.79$, respectively), suggesting a negative relationship between familism and acculturation. The perceived support from the family dimension was the only dimension that was not affected by acculturation.

In a different study, Rodríguez Montoro and Kosloski (1998) replicated Sabogal et al.'s (1987) familism factor structure, finding three conceptually distinct factors that 
accounted for $54 \%$ of the variance. However, unlike Sabogal et al.'s findings, Rodríguez Montoro and Kosloski's family obligation and family support dimensions correlated positively with some acculturation dimensions (Table 6).

Table 6

CORRELATIONS BETWEEN FAMILISM AND ACCULTURATION DIMENSIONS

\begin{tabular}{|c|c|c|c|}
\hline \multirow[b]{2}{*}{ Familism Dimensions } & \multicolumn{3}{|c|}{ Acculturation Factors } \\
\hline & Language & Media & Etnic/Social friends \\
\hline Family Obligations & $0.28^{\star \star}$ & $.23^{\star \star}$ & .07 \\
\hline Perceived Support & .14 & .11 & .05 \\
\hline Family as Referents & $-.18^{\star}$ & $-.20^{\star \star}$ & -.09 \\
\hline
\end{tabular}

Adapted from the original Rodríguez Montoro and Kosloski (1998, p. 381)

According to the authors, the difference between their findings and Sabogal et al.'s (1987) lie in a conceptualization and measurement difference of the variables studied; Sabogal et al.'s acculturation measure was primarily based on language use and preference, while Rodríguez Montoro and Kosloski's acculturation measure tapped two additional acculturation dimensions: media use and preference and ethnic/social friends. A second possible explanation for the observed differences lies in the nature of the samples used in both studies. Whereas Sabogal et al. (1987) studied Mexicans, Cubans, and Central Americans, Rodríguez Montoro and Kosloski (1998) studied Puerto Ricans. Other sample differences, similar to the average number of years of exposure to the American culture (12.7 years vs. 33 years, respectively), could also be related to Rodríguez and Kosloski’s (1998) results. 
Cuéllar, Arnold, and González (1995) found significant differences in Familism between acculturation groups measured with $\operatorname{ARSMAII}\left(\mathrm{F}_{(4,350)}=6.33, \mathrm{p}<.001\right)$, supporting the idea that as individuals acculturate behaviorally, their values, in particular, familism, also acculturate. However, even though the effects reported by Cuéllar, Arnold, and González (1995) show the expected negative relationship between familism and acculturation, their results are minor and correlated to individuals' income and age levels (Table 7).

Table 7

MULTIPLE REGRESSION ANALYSIS ON FAMILISM

\begin{tabular}{cccccc}
\hline & \multicolumn{5}{c}{ Predictor Variables } \\
\cline { 2 - 6 } & Acculturation & SES & Grade & Age & Generation \\
\hline \hline Familism & & & & & \\
$\beta$ & $-.23^{* *}$ & $.12^{*}$ & -.09 & $.15^{* *}$ & -.02 \\
$\mathrm{r}$ & $-.23^{* * *}$ & .04 & -.08 & .15 & -.15 \\
\hline $\mathrm{R}^{2}$ & .098 & & & & \\
\hline${ }^{*} \mathrm{p}<.05 ;{ }^{* *} \mathrm{p}<.01 ;{ }^{* * *} \mathrm{p}<.001$ \\
$\mathrm{SES}=$ Socioeconomic status \\
Adapted from the original Cuéllar, Arnold, and González (1995, p. 349)
\end{tabular}

The studies previously mentioned support a model of assimilation to the American values, across subsequent generations. However, individuals' choice on the acculturation process has to be considered. Hispanic consumers might exhibit resistance to change and maintain their values, even if their behaviors and identification change and assimilate faster. Previous research conducted by Perez and Padilla (2000) provides evidence among Hispanic adolescents that as generational level progresses from immigrant status to third generation, American cultural orientation increases and Hispanic cultural orientation decreases (the authors employed the Bicultural Involvement Questionnaire to measure these orientations). Regardless, family support remained stable across the first three 
generations (Table 2). Félix-Ortiz et al.'s (1994) study also provides evidence that some values have weak discriminatory power among Hispanic acculturation groups. In her study Félix-Ortiz and colleagues measured two values: respect for elders and sex roles (feminism), along with language proficiency and preference. Results showed that while language proficiency and preference were significantly different among ethnic groups, the values that were measured (feminism and respect) showed no significant difference among groups (Table 8).

Table 8

COMPARISONS OF FOUR CULTURAL IDENTITY GROUPS ON SEVERAL DEPENDENT VARIABLES

\begin{tabular}{lccccc}
\hline & \multicolumn{5}{c}{ Cultural Identity Group } \\
$\begin{array}{lcccc}\text { Dependent } \\
\text { Variables }\end{array}$ & $\begin{array}{c}\text { Highly } \\
\text { Bicultural }\end{array}$ & Latino/a & American & $\begin{array}{c}\text { Low -Level } \\
\text { Bicultural }\end{array}$ & F value \\
\hline \hline Spanish Language & 13.3 & 14.8 & 11.3 & 12.3 & $7.7^{\star \star \star}$ \\
Proficiency & $(3.5)$ & $(2.1)$ & $(3.2)$ & $(2.4)$ & \\
Spanish Language & 8.7 & 10.5 & 5.8 & 7.7 & $16.1^{\star \star \star}$ \\
Preference & $(3.0)$ & $(2.5)$ & $(2.1)$ & $(2.7)$ & \\
Respect for Elders & 13.1 & 13.1 & 14 & 13.9 & 1.52 \\
& $(2.6)$ & $(2.4)$ & $(1.7)$ & $(1.7)$ & \\
Feminism & 6.0 & 6.9 & & & \\
& $(2.3)$ & $(2.3)$ & $(2.7)$ & $(2.3)$ & .93 \\
& & & & & \\
\hline
\end{tabular}

${ }^{*} \mathrm{p}<.05 ;{ }^{* *} \mathrm{p}<.01 ;{ }^{* * *} \mathrm{p}<0.001$

Adapted from the original Félix-Ortiz et al. (1994, p. 109)

Félix-Ortiz et al. (1994) suggested that the values that were measured were less uniquely representative of the Latino culture or that some values may persist for two or three generations before they are supplanted by new values.

Given that values are enduring, stable beliefs (Rokeach 1973) it is proposed that Hispanic consumers' familism is likely to change from first to subsequent generations. First generation Hispanics are likely to have stronger feelings of kinship, obligation, and 
support for their nuclear and extended family members compared to second and third generation Hispanics. First generation Hispanics born abroad have been educated with strong familism values and they are not likely to change them during their lifetimes. However, second and subsequent generations of Hispanics educated in America and exposed to American values are likely to exhibit higher individualism. Therefore, it is expected that familism would differ significantly between first and subsequent generations, even controlling for demographic differences. Hence,

$\mathrm{H}_{10}$ : First generation Hispanic consumers' familism is likely to be higher than subsequent generations' familism, even after controlling for the number of children, income, education, and age.

One last point needs to be addressed. Hispanic familism should be able to explain the differences between Hispanics and non-Hispanics consumer behavior. By definition, values are enduring beliefs that give expression to human needs and strongly determine their motivation, ultimately affecting the consumer's life style and behavior (Vinson, Scott, and Lamont 1977). Accordingly, it is expected that familism would impact Hispanic consumer behavior. Moreover, familism should impact consumer behavior beyond the obvious effects that are granted by demographic differences. For example, it is a fact that Hispanic families are larger than non-Hispanic families, and that the majority of their members are under 18 years of age (Therrien and Ramirez 2000); thus, they are prone to have higher expenditures on child related product categories compared to non-Hispanics. Familism, as a central value of the Hispanic community should tell the 
marketer not only what the consumers' needs and preferences are, but also why they choose to behave the way they do.

For example, research on Hispanics has suggested that they are more prone to buy prestigious brands compared to non-Hispanics (Deshpande, Hoyer, and Donthu 1986; Donthu and Cherian 1994), and that they are more brand loyal (Deshpande, Hoyer, and Donthu 1986; Petroshius, Newell, and Ross 1995). Why? Are these facts related to the Hispanic parents' belief of their obligation to provide their families with the best, or the fact that a good deal of their budget is spent on child rearing? It has been suggested that Hispanic consumers' brand loyalty is associated to Hispanics cultural beliefs (Peñaloza and Gilly 1986). According to Soriano and Dauten (1985), Hispanic mothers view themselves as providers and feel obligated to give their families what they want. Hence, loyalty differences between Hispanics and non-Hispanics are likely to be related to the Hispanic parents' belief of their obligation to provide their families with the best quality products and the most prestigious brands. Therefore,

$\mathrm{H}_{11}$ : Familism is likely to predict consumers':

a) Brand loyalty

b) Attitudes towards high quality brands.

Expenditure priorities are likely to differ between Hispanic and non-Hispanics. Hispanics' expenditures on education, entertainment, housing, insurance, clothing, and technology are likely to be prioritized according to what they value the most, their family. Hispanics are likely to save less for their retirement compared to non-Hispanics (Strategy Research 2002). Is this connected to Hispanics' belief that adult children are expected to take care of their aging parents? Following the rational of familism, adult Hispanics are 
likely to feel obligated towards their parents (Freeberg and Stein 1996), children, and relatives (Sabogal et al. 1987; Cuéllar, Arnold, and González 1995); so, they are likely not only to have different saving priorities when compared to non-Hispanics, but also Hispanics are likely to save less given their immediate obligation towards their family members. Therefore,

$\mathrm{H}_{12}$ : Familism is likely to predict consumers' savings allocation for their children's future.

In summary, Chapter IV has developed a conceptualization of familism reflecting the individuals' attitudes towards family obligations, perceived support, and their desire to live together and maintain family traditions. Under this conceptualization it is assumed a negative relationship between consumers' familism and acculturation agents. Familism has been selected as a core Hispanic value not only because it has powerful discriminatory characteristics among Hispanic and Anglo consumers, but also because it is likely to determine and explain Hispanics' family related consumption patterns. The following chapters describe the research methodology that was undertaken and the results. 


\section{CHAPTER V}

\section{RESEARCH METHOD}

\section{Subjects and Sampling Procedure}

In order to assure a random sample and an acceptable response rate, a commercial sample was purchased from Synovate, a professional marketing research company. A national consumer panel (Synovate Consumer Opinion Panel, SCOP) was employed for the selection of the Hispanic and Anglo samples; however, this consumer panel only includes Hispanic respondents that have a preference to respond questionnaires in English. Therefore, to overcome the under-representation of Hispanics who use Spanish predominately, an additional consumer panel was considered (Diversity SCOP). This panel was recruited in Spanish and at the time that the survey was conducted included the top five Hispanic markets in the U.S. (Los Angeles, New York, Chicago, Miami, and Houston). Together, these markets represent over $40 \%$ of the total Hispanic population in the U.S. Sampling for this cell was proportional to the size of the market.

Three samples were randomly selected: White non-Hispanics, English-dominant Hispanics, and Spanish-dominant Hispanics. For all three groups, the sampling quotas limited the respondents to those that have household incomes of $\$ 35,000$ or over, and age ranges were between 20 to 60 years, balanced to the most recent Census figures.

A total of 1400 surveys were mailed out, the total number of questionnaires received was 793, of which 306 belonged to the Anglo sample, 272 were English dominant Hispanics (EH) and the rest belonged to the Spanish dominant Hispanic sample 
(SH). The overall response rate was $56.6 \%$; however, the response rate was not uniform across samples. The Anglo sample response rate was $76.5 \%$, the EH response rate was $39.8 \%$ and the SH sample response rate was $35 \%$. Of the received questionnaires, cleaning processes eliminated those that had systematic missing values and those whose income was below $\$ 35,000$. Another seven cases were eliminated from the sample; the Box plot of the dependent measure, savings for children's future, showed that these cases were more than two standard deviations higher than the mean. The final sample size included 276 Anglo consumers, 239 English-dominant Hispanics and 138 Spanishdominant Hispanic consumers. The random missing values of the items of the acculturation scales were replaced with the corresponding item means.

The samples' demographic characteristics are described in Table 9. In accordance with Census figures, there are significant differences between Anglo and Hispanic samples in all demographics, with the exception of gender. Comparing the Hispanic samples among themselves, we find significant differences in the number of years living in the U.S. and in education (English-dominant Hispanics are more educated than Spanish-dominant Hispanics), as expected.

\section{Measurement Instrument}

Mail surveys were considered owing to the length of the questionnaire and nature of the questions. The questionnaire included the following sections:

1. Language acculturation scale

2. Ethnic identification scale

3. Familism scale 
4. Consumer behavior measures: purchase frequency, brand selection behavior, brand loyalty and savings allocation.

5. Acculturation agents

6. Demographic variables

Table 9

SAMPLES' DEMOGRAPHIC VARIABLES MEANS AND SIZE

\begin{tabular}{|c|c|c|c|c|c|c|}
\hline & $\begin{array}{c}\text { Anglo Sample } \\
\text { (I) } \\
\end{array}$ & $\begin{array}{l}\mathrm{EH} \\
(\mathrm{J}) \\
\end{array}$ & $\begin{array}{l}\mathrm{SH} \\
\text { (K) } \\
\end{array}$ & $\begin{array}{c}\text { Mean } \\
\text { Difference } \\
(\mathrm{I}-\mathrm{J}) \\
\end{array}$ & $\begin{array}{c}\text { Mean } \\
\text { Difference } \\
(\mathrm{I}-\mathrm{K}) \\
\end{array}$ & $\begin{array}{c}\text { Mean } \\
\text { Difference } \\
(\mathrm{J}-\mathrm{K}) \\
\end{array}$ \\
\hline Education & 4.15 & 3.95 & 3.93 & $0.20^{*}$ & $0.22^{\star}$ & 0.02 \\
\hline S.D. & 1.19 & 1.17 & 1.46 & & & \\
\hline Household Income & 3.75 & 3.31 & 2.67 & $0.44^{\star}$ & $1.08^{*}$ & $0.64^{*}$ \\
\hline S.D. & 1.35 & 1.34 & 0.96 & & & \\
\hline Age & 43.86 & 39.95 & 38.85 & $3.9^{*}$ & $5.01^{*}$ & 1.11 \\
\hline S.D. & 9.72 & 9.53 & 10.70 & & & \\
\hline Years living in U.S. & 43.06 & 34.79 & 24.02 & $8.26^{\star}$ & $19.04^{*}$ & $10.77^{\star}$ \\
\hline S.D. & 11.22 & 13.17 & 13.80 & & & \\
\hline Gender & 1.44 & 1.47 & 1.36 & -0.03 & 0.08 & 0.11 \\
\hline S.D. & 0.50 & 0.50 & 0.48 & & & \\
\hline Sample Size & 276 & 239 & 138 & & & \\
\hline
\end{tabular}

The questionnaire included a cover letter providing the respondents with the questionnaire instructions and specifying which individual of the household should respond. The questionnaire had three different versions: version one was developed in English for the English dominant Hispanics and included all the sections mentioned previously (Appendix 1), version two was developed for the Anglo sample and excluded the first two sections (Appendix 2), finally, version three of the questionnaire was the translation of version one in Spanish (Appendix 3). The questionnaire was translated and back-translated by two bilingual experts and checked by Synovate. This study was 
conducted along with another study using the same target population. Therefore, the questionnaire includes a series of questions that were not designed for this study (questions $3,9,14,15,16$, and 17). The next section will describe each scale in detail.

\section{$\underline{\text { Acculturation Agents }}$}

According to the Consumer Acculturation Model the acculturation agents are the ones that generate change; these agents either increase exposure to the host culture and/or promote culture retention, depending on their nature (Hispanic or non-Hispanic). Consequently, a set of items was designed to measure the consumers' exposure to the different acculturation agents: family, friends, work, school, shopping, and religious institutions (question 19). The consumers' exposure to these agents was measured with a five-point scale ranging from 1 = "All Hispanic/Latino," 2 = "More Hispanic than nonHispanic," 3 = "About half and half," 4 = "More non-Hispanic than Hispanic" and $5=$ “All non-Hispanic.” A non-applicable option was given to the respondents as well.

\section{Acculturation Scales}

To operationalize acculturation according to the model presented in Chapter III, the acculturation scale should suggest a multidimensional bilinear process. Therefore, the scale should include an individual's change in the behavioral, affective, and value dimensions. Additionally, the scale should reflect the individual's choice to maintain their own heritage and/or preference to assimilate to the American culture. 
Previous multidimensional acculturation scales (e.g., Cuéllar, Arnold, and Maldonado 1995; Szapocznik, Kurtines, and Fernandez 1978; Marín and Gamba 1996; Zea et al. 2003) have opted to include for each dimension (language, ethnicity, etc.) measures of both Hispanic and English orientations. For example, for each item such as "I enjoy Spanish language TV" there would be another item "I enjoy English language TV," with a one-dimensional response scale ranging from "Not at all" to "Extremely often or almost always" (Cuéllar, Arnold, and Maldonado 1995, p. 297). This approach eliminates the possibility of a zero sum scale that would imply assimilation to the American culture at the expense of the Hispanic culture. However, the resulting scales were either extremely long or included a limited number of items that described the acculturation process. Mendoza (1989) instead used bipolar scales rating items on a fivepoint response scale from: 1 "Spanish all the time," 3 "Both Spanish and English," to 5 "English all the time"; as an alternative to adding the scale, he counted the number of items in which the individual selected each orientation, reflecting both orientations without doubling each item.

With the intention of incorporating as many different contexts as possible, the proposed approach measured language preference using a bipolar scale, similar to the one adopted by Mendoza (1989). By doing so, the scale suggests the individuals' choice of language use in different contexts, as they have to do in every real life situation. Similarly, the familism scale used a five-point Likert scale measuring the individuals' choice through their agreement or disagreement with a list of family related statements. 
Individuals' ethnic identity has been variously operationalized as: ethnic selfidentification (Hirschman 1981), the strength of identification with a specific cultural orientation (Deshpande, Hoyer, and Donthu, 1986), ethnic pride and ethnicity of family and friends (Cuéllar, Arnold, and Maldonado 1995; Marín et al. 1987; Mendoza 1989). This research considers ethnic identification as a personal choice that is a subcomponent of an individual's identity; it represents a self-definition (Cuéllar et al. 1997). Subsequently, a different approach was taken for the ethnic identification subscale. The choice process is different; individuals can identify with both cultures at the same time, while they cannot speak both languages at once. Therefore, this acculturation domain was measured with two dimensions; one that incorporates items that evaluate the extent to which the respondents identify with the American culture, and a second one that includes items that reflect identification with the individual's culture of origin, measured with five-point Likert scales.

Most of the items for each scale were selected from previous published scales and others were included in order to tap all the possible contexts and operationalize the constructs as previously defined (Table 10). The final scale included 52 items: 20 representing the language acculturation scale, 9 describing the American and Hispanic ethnic identification, and 23 measuring the familism scale.

The language acculturation scale was measured with 20 items that asked consumers' language preference in different contexts. Most of the twenty items in the scale have been adapted from previous acculturation measures in order to reflect language preference instead of language proficiency or language use (Félix-Ortiz, Newcomb, and Myers 
1994; Szapocznik et al. 1978; Mendoza 1989). Other items were specifically design to include individuals' contact with the consumer environment (Table 10).

The ethnic identification scale was measured with 9 items, mostly adapted from previous ethnic identification measures (Table 10). The items measured two cultural identifications: one embracing individuals' culture of origin, and the other measuring individuals' identification with the American culture. Ethnic identification is expected to reflect the consumer's choice to retain their culture of origin while assimilating to the American culture.

The 23 items of the familism scale were taken or adapted from previous familism scales (Sabogal et al. 1987; Heller 1976; Bardis 1959). However, other items, reflecting a family's tendency to live close to one another and maintenance of traditions, were included in order to operationalize this research's definition of familism (refer to Table 10 and Chapter IV).

\section{Dependent Measures}

The main purpose of the study was to determine if the acculturation process is related to some of the differences in consumer behavior between Hispanic acculturation groups, and between Hispanics and Anglos. Therefore, a set of dependent measures were taken from previous studies where significant differences between these groups were observed. The set of measures employed were related to the following areas: brand loyalty, brand selection behavior, purchase frequency, and savings allocation. 
Table 10

\section{ACCULTURATION SCALE ITEMS SOURCE}

\begin{tabular}{ll}
\hline \multicolumn{1}{c}{ Language Scale Items } & \multicolumn{1}{c}{ Source } \\
\hline \hline When speaking to children in my family, I prefer to speak & Adapted from Mendoza (1989) \\
When speaking to my friends, I prefer speak & Adapted from Szapocznik et al.(1978) \\
When speaking to my grandparents, I prefer to speak & Adapted from Mendoza (1989) \\
When speaking to my parents, I prefer to speak & Adapted from Mendoza (1989) \\
When speaking at work, I prefer to speak & Adapted from Szapocznik et al.(1978) \\
When speaking to my brothers/sisters, I prefer to speak & Adapted from Mendoza (1989) \\
When speaking to my spouse/partner, I prefer to speak & Adapted from Mendoza (1989) \\
When speaking at home, I prefer to speak & Adapted from Szapocznik et al.(1978) \\
When writing my own notes I prefer to write in & Developed \\
When reading newspapers/ magazines I prefer & Adapted from Szapocznik et al.(1978) \\
I prefer to watch TV in & Adapted from Szapocznik et al.(1978) \\
When speaking at school, I prefer to speak & Adapted from Szapocznik et al.(1978) \\
I prefer to think in & Adapted from Felix-Ortiz et al.(1994) \\
I prefer to listen to the radio in & Adapted from Szapocznik et al.(1978) \\
I prefer to shop at stores where I can speak & Developed \\
When speaking to automated answering services over the phone, I select & Developed \\
While ordering over the phone from catalogs, I prefer to speak & Developed \\
When using an ATM I prefer to use & Developed \\
At church/temple I prefer to speak & Developed \\
I prefer to pray in &
\end{tabular}

\begin{tabular}{ll}
\hline \multicolumn{1}{c}{ Ethnic Identification Scale Items } & Source \\
\hline \hline I feel at home in the United States & Developed \\
I feel proud of having a Hispanic heritage & Adapted from Zea et al. (2003) \\
I feel part of America & Adapted from Zea et al. (2003) \\
I feel good about being Hispanic & Adapted from Zea et al. (2003) \\
I am proud of being an American & Adapted from Zea et al. (2003) \\
I feel strongly associated to my country of origin & Adapted from Laroche et al. (1996) \\
I consider myself an American & Adapted from Laroche et al. (1996) \\
I am proud of my country of origin & Adapted from Zea et al. (2003) \\
I feel comfortable with the American way of life & Suggested by Synovate \\
\hline
\end{tabular}

\section{Familism Scale Items}

Source

A person should always support his relatives if they are in need

People should consult close relatives conceming important decisions

Adult children should often seek their parent's advice

No matter what the cost, helping my relatives with their problems comes first

Children should always have respect for their parents

Relatives are more important than friends

Children should always respect their elders

Some equallity in marriage is good, but by and large the father ought to have

the main say in important family matters

Adult children should make sacrifices to care for their parents

Married children should live close to their parents so they can help each other

Aging parents should live at home with their children

One of the most important goals in life is having children for their parents

Daughters should live with their parents until they get married

Parents should sacrifice themselves in order to provide their children with the best

I work hard to give my children the best education they can get

It is good to have a lot of family living close to you

Children should be taught about their family history

Keeping oid family recepies is important

Parents should feel responsible for children's happiness

In an unhappy marriage, parents should stay together for their children's sake

Children should work while in college

I value my children health above everything

I will be fulfilled as my family succeeds

Adapted from Bardis (1959)
Adapted from Bardis (1959)
Adapted from Bardis (1959)
Adapted from Cuellar, Arnold and Gonzalez (1995)
Adapted from Cuellar, Arnold and Gonzalez (1995)
Adapted from Cuellar, Arnold and Gonzalez (1995)
Adapted from Cuellar, Arnold and Gonzalez (1995)
Adapted from Cuellar, Arnold and Gonzalez (1995)

Adapted from Heller (1976)

Adapted from Heller (1976)

Adapted from Sabogal et al. (1987)

Adapted from Sabogal et al. (1987)

Adapted from Sabogal et al. (1987)

Adapted from Sabogal et al. (1987)

Adapted from Sabogal et al. (1987)

Developed to reflect family cohesion

Developed to reflect family traditions

Developed to reflect family traditions

Developed to reflect the familial obligation dimension

Developed to reflect the familial obligation dimension

Developed to reflect the familial obligation dimension

Developed to reflect the familial obligation dimension

Developed to reflect the familial obligation dimension 
Two sets of measures were employed to examine Hispanics' brand loyalty. The first one included two statements that measured self-reported brand loyalty (behavioral and attitudinal): "I always buy the same brand," "I feel committed to my preferred brands." Respondents were asked to rate their agreement on five-point scales. The second set of questions measured brand loyalty directly. The question defined loyalty as follows: "An extremely loyal customer of a brand is a person who prefers that particular brand and always buys only that brand." Consumers were asked to declare their loyalty for a set of products (soft drinks, fabric softener, shampoo, deodorant) and services (hairstylist and dry cleaning) on a five-point scale ranging from $1=$ "Not at all loyal," $2=$ "Slightly loyal," 3 = "Moderately loyal," 4 = "Very loyal," 5 = "Extremely loyal." The products and services employed in this question were selected based on consumer reports that indicated differences in Hispanic and Anglo consumer behavior (Strategy Research Corporation 2002).

A list of statements reflecting the individuals' attitudes towards brand quality, price sensitiveness and purchase of prestigious brands were measured with five-point Likert scales (items a, b, c, and e from question 6).

Purchase frequency has been suggested as distinctive among Hispanic consumers (McArthur, Viramontez, and Nocetti 2001; Valdez 2002). Consumers were asked to estimate how frequently they purchase certain products. These products were selected based on reports indicating that Hispanics and Anglos exhibit differences on their 
purchase frequency. Two items in the questionnaire measured with a five-point scale ranging from: 1 = "More than once a week," 2 = "Every week," 3 = "Every two weeks," 4 = "Every month," 5 = "Less frequent or never" asked consumers their purchase frequency for frozen and canned products. Similarly, based on consumer reports (Strategy Research, 2002), Hispanics had a higher purchase frequency of hygiene and cleaning products. Therefore, the purchase frequency of shampoo, deodorant and fabric softener measured with the same five-point scale was also employed as a dependent measure. Additionally, question number seven asked consumers to estimate how frequently they bought groceries, in general, on a five-point scale ranging from $1=$ "Three or more times a week," 2 = "Twice a week," 3 = "Once a week," 4 = "About once every two weeks" and 5 = "About once a month."

Previous literature and consumer reports (Strategy Research Corporation 2002; Synovate 2004; Delener and Katzenstein 2000) suggested that Hispanic and Anglo consumers had differences with their financial products possessions and behavior; accordingly, the questionnaire incorporated a question that asked consumers to determine what they would save for if they had $\$ 10,000$ to allocate to savings. The options given to the consumers included emergencies, children's future and education, a home, purchases such as a car or a vacation, retirement, help their relatives, or other. The amounts of money spent on children's future and education were added and considered a dependent measure.

Finally, three scenarios asking the consumers' language preference in marketing communications were given to the respondents (questions number 10,11, and 12). These 
scenarios asked consumers in what language they preferred to receive a brochure, preferred language of a website, and preferred language spoken at a car dealership. In these scenarios consumers were informed they would have both languages available.

\section{Demographic Variables}

In order to control for differences among ethnic groups, the following demographic variables were included in the questionnaire:

- Age

- Gender (categorical)

- Country of birth (categorical)

- Education (categorical)

- Income (categorical)

- Occupation (categorical)

- Number of children

- Number of years living in the U.S.

- Number of years of schooling in the U.S.

Last, the individuals' generational status was determined as follows:

- First generation Hispanics are those that were born abroad.

- Second generation Hispanics are those born in the U.S. that at least have one parent born abroad.

- Third generation Hispanics are all individuals not included in both previous categories. 


\section{CHAPTER VI}

\section{ACCULTURATION SCALES AND DEPENDENT MEASURES ANALYSIS}

This chapter analyzes the internal consistency and validity of the language, ethnicity, and familism scales. In addition, the assumptions made about the dependent variables and the acculturation agents measures are analyzed. The results presented in this chapter establish the reliability and validity of the measures, before attempting to test the relationships proposed in Chapters III and IV. The results for each subscale are presented individually.

\section{$\underline{\text { Acculturation Agents }}$}

Ten items included in question number 19 were intended to measure the acculturation agents. Given that the consumer had a non-applicable option in the response scale, the accumulative percentage of missing and non-applicable answers was above $50 \%$ in some of the scale items (Table 11). For that reason the following three items were excluded from the scale: "The people in my church/temple are," "My classmates are," and "My professors are."

The alpha coefficient of the remaining 7 items in the scale is .87 , suggesting acceptable internal consistency and scale reliability. As proposed by the Hispanic Consumer Acculturation Model, the acculturation agents are the antecedents of the acculturation process. Therefore, it would be expected that the agents would increase from 1 = "All Hispanic/Latino" to 5 = "All non-Hispanic" as the consumers" contact with the American culture increases. Partial correlations controlling for household income, 
education, and age show strong positive correlations between the acculturation agents and the number of years lived in the U.S. (.46), the number of years of schooling in the U.S. (.33), and the percentage of life liven in the U.S. (.46). As expected the acculturation agents vary significantly across samples, generations, and income groups (Table 12).

Table 11

PERCENTAGE OF NOT APPLICABLE AND MISSING VALUES OF THE AGENT ACCULTURATION ITEMS

\begin{tabular}{lccc}
\hline \multicolumn{1}{c}{ Agent } & \% Not Applicable & $\%$ Missing Values & $\%$ Accumulative \\
\hline \hline & & & $6.10 \%$ \\
Family members & $5.30 \%$ & $0.80 \%$ & $13.20 \%$ \\
Spouse/partner's family & $12.30 \%$ & $0.90 \%$ & $6.30 \%$ \\
Friends & $5.20 \%$ & $1.10 \%$ & $13.20 \%$ \\
People at work & $12.30 \%$ & $0.90 \%$ & $23.70 \%$ \\
People at church/temple & $22.00 \%$ & $1.70 \%$ & $58.00 \%$ \\
Classmates & $53.00 \%$ & $5.00 \%$ & $61.50 \%$ \\
Professors & $55.90 \%$ & $5.60 \%$ & $8.20 \%$ \\
People that shop at the stores I go & $6.80 \%$ & $1.40 \%$ & $8.40 \%$ \\
Employees at my bank & $7.30 \%$ & $1.10 \%$ & $6.70 \%$ \\
Employees at my grocery store & $5.80 \%$ & $0.90 \%$ & \\
\end{tabular}

Taking in consideration all the evidence provided the following can be concluded:

- The internal consistency and reliability of the 7-item acculturation agents' scale is acceptable.

- Consumers contact with non-Hispanic agents increases as their exposure to the American culture increases.

- Exposure to non-Hispanic agents is strongly related to the consumers' ethnicity, generation, income, and age. 
Table 12

ANALISIS OF VARIANCE OF THE ACCULTURATION AGENT SCALE AMONG TEST VARIABLES

\begin{tabular}{|c|c|c|c|c|c|c|}
\hline Test Variable & Mean & $n$ & S. D. & ANOVA & Significance & $n^{2}$ \\
\hline \multicolumn{7}{|l|}{ Sample } \\
\hline White non-Hispanic & 29.21 & 276 & 4.2 & $F_{2,650}=351.49$ & $<.001$ & 0.52 \\
\hline $\begin{array}{l}\text { English-dominant Hispanics } \\
\text { Spanish-dominant Hispanics }\end{array}$ & $\begin{array}{l}23.08 \\
17.06\end{array}$ & $\begin{array}{l}239 \\
138\end{array}$ & $\begin{array}{l}4.9 \\
4.2\end{array}$ & & & \\
\hline \multicolumn{7}{|l|}{ Generation } \\
\hline First & 18.70 & 161 & 5.1 & $F_{2,334}=22.98$ & $<.001$ & 0.12 \\
\hline $\begin{array}{l}\text { Second } \\
\text { Third }\end{array}$ & $\begin{array}{l}21.50 \\
23.51\end{array}$ & $\begin{array}{c}108 \\
68\end{array}$ & $\begin{array}{l}5.4 \\
4.8\end{array}$ & & & \\
\hline \multicolumn{7}{|l|}{ Income } \\
\hline less than $\$ 50,000$ & 23.20 & 408 & 6.6 & $F_{1,651}=38.11$ & $<.001$ & 0.06 \\
\hline$\$ 50,000$ or more & 26.34 & 245 & 5.7 & & & \\
\hline \multicolumn{7}{|l|}{ Age } \\
\hline $18-40$ years & 23.36 & 310 & 6.5 & $F_{1,651}=14.89$ & $<.001$ & 0.02 \\
\hline$>40$ years & 25.54 & 343 & 6.3 & & & \\
\hline \multicolumn{7}{|l|}{ Education } \\
\hline High school completed or less & 24.13 & 279 & 6.5 & $F_{1,648}=.66$ & $>.01$ & $<.01$ \\
\hline Higher than High school & 24.54 & 371 & 6.5 & & & \\
\hline \multicolumn{7}{|l|}{ Gender } \\
\hline Male & 24.58 & 283 & 6.4 & $F_{1,651}=.51$ & $>.01$ & $<.01$ \\
\hline Female & 24.22 & 370 & 6.6 & & & \\
\hline
\end{tabular}

\section{$\underline{\text { Language Preference Scale }}$}

To examine the concurrent validity, the language preference scale was compared to other variables that conceptually are related to acculturation. According to the acculturation model proposed, it would be expected that as individuals' contact with the host culture increases, their language preference would change from Spanish to English ( 5 = Spanish all the time, $1=$ English all the time) in the 18 language usage situations. Therefore, it would be likely to observe a negative relationship between language preference and other variables that are indicators of the amount of contact with the host culture, even after controlling for demographic variables. Partial correlations controlling for demographic variables (household income, education, and age) showed a significant 
negative correlation between language preference and the number of years lived in U.S. (-.69), the number of years of schooling in the U.S. (-.58), and the percentage of the individuals' life lived in the U.S. (-.69).

Table 13

LANGUAGE PREFERENCE SCALE DESCRIPTIVE STATISTICS AND ALPHA COEFICIENTS

\begin{tabular}{lcccc}
\hline \multicolumn{1}{c}{ Sample } & N & M & SD & $\boldsymbol{\alpha}$ \\
\hline \hline & & & & \\
English-dominant Hispanic & 239 & 33.00 & 17.01 & 0.97 \\
Spanish-dominant Hispanic & 138 & 55.89 & 19.06 & 0.96 \\
All sample & 377 & 41.38 & 20.91 & 0.97 \\
\hline
\end{tabular}

Table 14

ANALISIS OF VARIANCE OF THE LANGUAGE PREFERENCE SCALE AMONG TEST VARIABLES

\begin{tabular}{|c|c|c|c|c|c|c|}
\hline Test Variable & Mean & $n$ & S.D. & ANOVA & Significance & $\eta^{2}$ \\
\hline \multicolumn{7}{|l|}{$\overline{\overline{\text { Sample }}}$} \\
\hline Spanish-dominant Hispanics & 55.89 & 138 & 19.06 & $F_{1,375}=144.91$ & $<.001$ & 0.28 \\
\hline English-dominant Hispanics & 33.00 & 239 & 17.01 & & & \\
\hline \multicolumn{7}{|l|}{ Generation } \\
\hline First & 56.60 & 161 & 18.66 & $F_{2,334}=112.34$ & $<.001$ & 0.4 \\
\hline Second & 36.50 & 108 & 15.07 & & & \\
\hline Third & 24.22 & 68 & 9.88 & & & \\
\hline \multicolumn{7}{|l|}{ Income } \\
\hline less than $\$ 50,000$ & 43.62 & 269 & 20.94 & $F_{1,375}=11.08$ & $<.01$ & 0.03 \\
\hline$\$ 50,000$ or more & 35.79 & 108 & 19.88 & & & \\
\hline \multicolumn{7}{|l|}{ Age } \\
\hline $18-40$ years & 41.64 & 207 & 19.98 & $F_{1,375}=.071$ & $>.10$ & $<.01$ \\
\hline$>40$ years & 41.06 & 170 & 22.06 & & & \\
\hline \multicolumn{7}{|l|}{ Education } \\
\hline High school completed or less & 41.28 & 170 & 22.05 & $F_{1,373}=.02$ & $>.10$ & $<.01$ \\
\hline Higher than High school & 41.58 & 205 & 20.02 & & & \\
\hline \multicolumn{7}{|l|}{ Gender } \\
\hline Female & 39.81 & 163 & 21.04 & $F_{1,375}=1.6$ & $>.10$ & $<.01$ \\
\hline Male & 42.57 & 214 & 20.79 & & & \\
\hline
\end{tabular}

The language preference scale was compared between Hispanic samples and demographic groups (Table 14). As expected, the results showed significant differences 
between samples $\left(\mathrm{F}_{1,375}=144.9, \mathrm{p}<0.001\right)$; English-dominant Hispanics have an overall lower score compared to the Spanish-dominant Hispanics $\left(\mathrm{M}_{\mathrm{EH}}=33, \mathrm{M}_{\mathrm{SH}}=56\right.$, respectively). Language preference was also compared among generations using an analysis of variance. The results suggested that language preference significantly changed among generations $\left(\mathrm{F}_{2,334}=112.34, \mathrm{p}<0.001\right)$. The effect size of generation is in particular high; forty percent of the language preference variance is explained by generational differences among consumers. Simple contrast revealed that Hispanics who reported being first generation immigrants have a higher preference for Spanish compared to second and third Hispanic generations $\left(\mathrm{M}_{1 \mathrm{st}}=57.3, \mathrm{M}_{2 \mathrm{nd}}=35.8, \mathrm{M}_{3 \mathrm{rt}}=23.7\right.$, respectively).

Figure 5

\section{LANGUAGE PREFERENCE BY CONTEXTS AND GENERATIONAL STATUS}

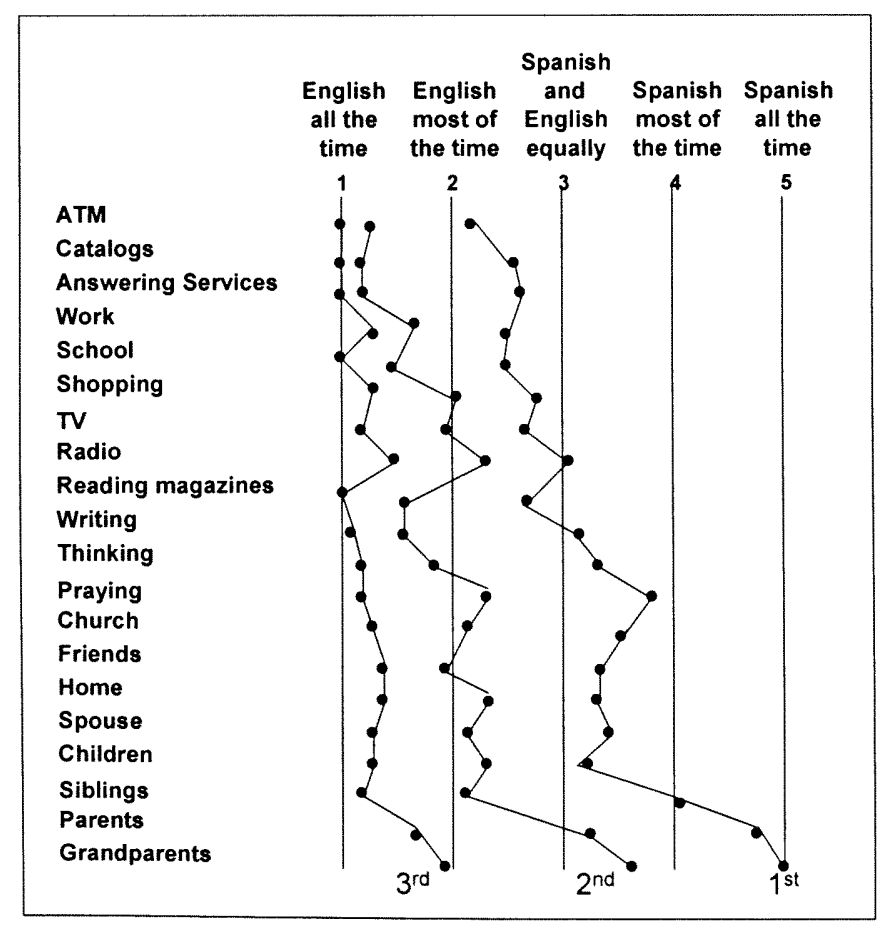


Surprisingly, these means revealed a high preference for English, even among first generation Hispanics. A language preference mean score of 57.3 is just above the scale's middle point, suggesting that first generation Hispanics have a preference in English in some contexts. Figure 5 displays the average language preference by context and by the individuals' generational status. A look into the mean preference among generations per scale item reveals that language preference is not uniform across usage situations, and the preference pattern shifts from the $1^{\text {st }}$ to the $2^{\text {nd }}$ generation. First generation consumers equally preferred English and Spanish for interacting in external context including work school and commercial institutions. However, on their personal relationships consumers preferred Spanish. Second generation consumers showed a strong preference for English except while at home, talking to children, and communicating to their parents. Finally, third generation Hispanic consumers expressed an overall preference for communicating in English. The rest of the results reported in Table 14 suggest that none of the effects of the other demographic variables on language preference are significant, with the exception of income that has an effect size of only three percent.

Three scenarios, where the availability of both languages was made evident to the consumers, were included in the questionnaire in order to exclude the possibility that consumers preferred English because it was the only option available. The scenarios asked for the preferred language of a brochure, a website and a car dealer salesperson. The correlations between these variables and the language preference overall score are $.71, .51$, and .77 respectively, supporting the concurrent validity of the scale. Table 15 
shows the correlation of these three scenarios with the language preference scale items that specifically referred to commercial situations. As expected, in support of the previous findings all the correlations are significantly high and in the expected direction.

Table 15

PEARSON CORRELATIONS BETWEEN LANGUAGE PREFERENCE SCALE ITEMS AND LANGUAGE PREFERNCE SCENARIOS

\begin{tabular}{|c|c|c|c|c|c|c|c|c|}
\hline & Correlations & 1 & 2 & 3 & 4 & 5 & 6 & 7 \\
\hline 1 & $\begin{array}{l}\text { Language preference } \\
\text { of brochure }\end{array}$ & & & & & & & \\
\hline 2 & $\begin{array}{l}\text { Language preference } \\
\text { of car dealer }\end{array}$ & $\begin{array}{l}0.86 \\
<.001\end{array}$ & & & & & & \\
\hline 3 & $\begin{array}{l}\text { Language preference } \\
\text { of website }\end{array}$ & $\begin{array}{l}0.47 \\
<.001\end{array}$ & $\begin{array}{l}0.51 \\
<.001\end{array}$ & & & & & \\
\hline 4 & $\begin{array}{l}\text { Language preference } \\
\text { when shopping }\end{array}$ & $\begin{array}{l}0.52 \\
<.001\end{array}$ & $\begin{array}{l}0.56 \\
<.001\end{array}$ & $\begin{array}{l}0.38 \\
<.001\end{array}$ & & & & \\
\hline 5 & $\begin{array}{l}\text { Language preference } \\
\text { of answering services }\end{array}$ & $\begin{array}{l}0.71 \\
<.001\end{array}$ & $\begin{array}{l}0.72 \\
<.001\end{array}$ & $\begin{array}{l}0.50 \\
<.001\end{array}$ & $\begin{array}{l}0.66 \\
<.001\end{array}$ & & & \\
\hline 6 & $\begin{array}{l}\text { Language preference } \\
\text { when ordering from catalogs }\end{array}$ & $\begin{array}{l}0.71 \\
<.001\end{array}$ & $\begin{array}{l}0.72 \\
<.001\end{array}$ & $\begin{array}{r}0.49 \\
<.001\end{array}$ & $\begin{array}{l}0.66 \\
<.001\end{array}$ & $\begin{array}{r}0.90 \\
<.001\end{array}$ & & \\
\hline 7 & $\begin{array}{l}\text { Language preference } \\
\text { when using ATM }\end{array}$ & $\begin{array}{l}0.60 \\
<.001\end{array}$ & $\begin{array}{l}0.64 \\
<.001\end{array}$ & $\begin{array}{l}0.48 \\
<.001\end{array}$ & $\begin{array}{l}0.63 \\
<.001\end{array}$ & $\begin{array}{l}0.84 \\
<.001\end{array}$ & $\begin{array}{c}0.81 \\
<.001\end{array}$ & \\
\hline 8 & Overall Language Preference & $\begin{array}{l}0.71 \\
<.001\end{array}$ & $\begin{array}{l}0.77 \\
<.001\end{array}$ & $\begin{array}{r}0.51 \\
<.001\end{array}$ & $\begin{array}{l}0.82 \\
<.001\end{array}$ & $\begin{array}{l}0.82 \\
<.001\end{array}$ & $\begin{array}{l}0.83 \\
<.001\end{array}$ & $\begin{array}{r}0.73 \\
<.001\end{array}$ \\
\hline
\end{tabular}

In summary, taking in consideration all the evidence provided the following can be concluded:

- The internal consistency and reliability of the language preference scale is very high.

- There is no difference in the dimensional structure of the language scale of both Hispanic samples.

- Language preference changes with increased contact with the American culture, supporting the assumption that language preference is an indicator of the acculturation process. 
The ethnic identification scale items of both cultural orientations (American and Hispanic) from each sample were factor analyzed using principal component analysis. The initial solution for the SH sample revealed a two-factor structure, according to Kaiser's rule. However, the structure that emerged for the EH sample had three factors with eigenvalues higher than one (Table 16). Therefore, in order to maintain a similar percentage of variation explained in both samples, two factors were retained in both cases (Table 17). In the case of the Spanish-dominant Hispanic sample, the total variance explained by these factors is $59 \%$, while for the $\mathrm{EH}$ sample the percentage of variance explained by the first two factors is $61 \%$. Each dimension explains approximately the same proportion of variability in both samples (Table 17). In this case the interpretation is not straightforward. Given that the factorial composition between samples can not be easily interpreted a Varimax rotation was executed for both samples (Table 18). As expected the percentages of variance explained by each factor changed (although the total variance explained remained constant); however, the changes are small and the order of the components remained the same.

Table 16

PRINCIPAL COMPONENT TOTAL VARIANCE EXPLAINED OF THE ETHNIC IDENTIFICATION SCALE BY SAMPLE

\begin{tabular}{|ccccccc}
\hline & \multicolumn{2}{c}{ English-dominant Hispanics } & \multicolumn{3}{c}{ Spanish-dominant Hispanics } \\
\hline Component & Initial Eigenvalues & \% of Variance & Cumulative \% & Initial Eigenvalues & $\%$ of Variance & Cumulative \% \\
\hline 1 & 3.47 & 38.51 & 38.51 & 3.28 & 36.40 & 36.40 \\
2 & 2.02 & 22.39 & 60.90 & 2.01 & 22.30 & 58.70 \\
3 & 1.36 & 15.06 & & 0.89 & 9.90 & 8.05 \\
4 & 0.63 & 6.97 & & 0.72 & 6.94 \\
5 & 0.42 & 4.72 & & 0.47 & 5.26 \\
6 & 0.37 & 4.12 & & 0.39 & 4.29 \\
7 & 0.29 & 3.17 & & 0.35 & 3.87 \\
8 & 0.24 & 2.67 & & 0.27 & 2.98 \\
9
\end{tabular}


The rotated structure for the Spanish dominant sample generated two factors. The first factor includes items referring to the Hispanic identification dimension while the second factor contains items referring to American identification. This structure is replicated in the English dominant sample factorial structure. In this case the first factor is the equivalent to the second factor of the SH sample; the first factor comprises the same five items reflecting the American ethnic identification. Conversely, the Hispanic identification factor in the SH sample (factor 1) is similar to the EH sample second factor.

Table 17

PRINCIPAL COMPONENT ANALYSIS OF THE ETHNIC IDENTIFICATION SCALE

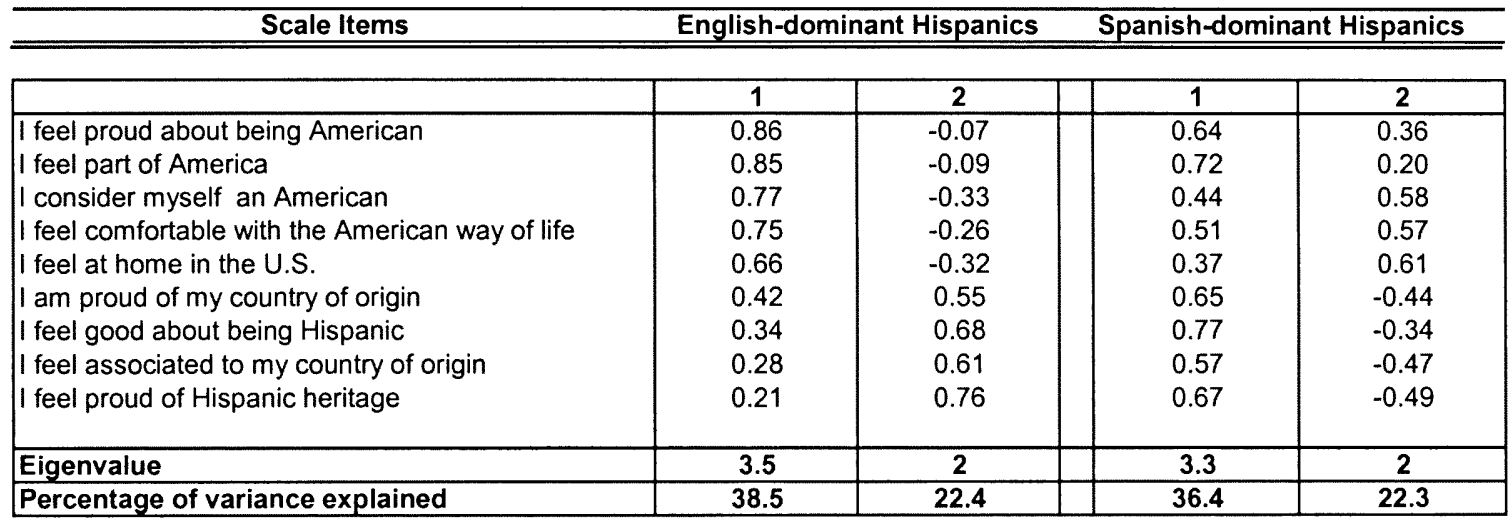

Table 18

ROTATED COMPONENT MATRIX OF THE ETHNIC IDENTIFICATION SCALE

\begin{tabular}{|c|c|c|c|c|}
\hline \multirow[t]{2}{*}{ Scale Items } & \multicolumn{2}{|c|}{ English-dominant Hispanics } & \multicolumn{2}{|c|}{ Spanish-dominant Hispanics } \\
\hline & 1 & 2 & 1 & 2 \\
\hline $\begin{array}{l}\text { I consider myself an American } \\
\text { I feel proud about being American } \\
\text { I feel part of America } \\
\text { I feel comfortable with the american way of life } \\
\text { I feel at home in the U.S. } \\
\text { I feel proud of Hispanic heritage } \\
\text { I feel good about being Hispanic } \\
\text { I feel associated to my country of origin } \\
\text { I am proud of my country of origin }\end{array}$ & $\begin{array}{l}0.28 \\
0.44 \\
\\
0.83 \\
0.82 \\
0.73 \\
0.78\end{array}$ & $\begin{array}{l}0.73 \\
0.68 \\
0.60 \\
0.76 \\
0.71 \\
0.22\end{array}$ & $\begin{array}{l}0.83 \\
0.83 \\
0.82 \\
0.79 \\
0.73\end{array}$ & $\begin{array}{l}0.78 \\
0.76 \\
0.67 \\
0.67\end{array}$ \\
\hline Eigenvalue & 3.32 & 1.96 & 3.4 & 2.01 \\
\hline Percentage of variance explained & 36.9 & 21.8 & 38.5 & 22.4 \\
\hline
\end{tabular}


The scales' descriptive statistics and alpha coefficients by sample are included in Table 19. Unsurprisingly, the average American identification of the SH sample is significantly lower compared to the average American identification of the individuals in the EH sample $\left(\mathrm{F}_{1,375}=42.1 \mathrm{p}<.001\right)$, though there is no significant difference on the Hispanic identification scale between both samples. The alpha coefficients of both scales by sample are among .72 and .87 suggesting that the internal consistency of both scales is good.

Table 19

ETHNIC IDENTIFICATION SCALES DESCRIPTIVE STATISTICS AND ALPHA COEFICIENTS

\begin{tabular}{|c|c|c|c|c|c|c|c|c|}
\hline \multirow[b]{2}{*}{ Sample } & \multicolumn{4}{|c|}{ Hispanic Identification } & \multicolumn{4}{|c|}{ American Identification } \\
\hline & $\mathbf{N}$ & $\mathbf{M}$ & SD & $a$ & $\mathbf{N}$ & $\mathbf{M}$ & SD & $\alpha$ \\
\hline English-dominant Hispanic & 229 & 17.70 & 2.61 & 0.69 & 239 & 23.40 & 3.02 & 0.87 \\
\hline Spanish-dominant Hispanic & 138 & 17.83 & 2.55 & 0.79 & 138 & 21.25 & 3.23 & 0.74 \\
\hline All sample & 367 & 17.75 & 2.59 & 0.72 & 377 & 22.61 & 3.27 & 0.83 \\
\hline
\end{tabular}

The partial correlations between the ethnic identification scales and indicators of acculturation (number of years living in the U.S., number of years of schooling in the U.S., percentage of life, and generation) controlling for household income, gender, age, and education suggested that the ethnic identification factors are good indicators of the bicultural nature of the acculturation process (Table 20).

The correlation between the Hispanic and the American identification scales is 0.18 , suggesting that there is a very small positive correlation between both constructs. These results support the biculturalism proposition: the adoption of feelings towards the American culture does not imply the loss of the individuals' Hispanic identification. These results are contrary to the ones reported by Zea et al. (2003); they reported a higher negative correlation $(-0.21)$ between the U.S. cultural identity and the Latino cultural 
identity. Even more interesting is the correlation with the other indicators of acculturation; the partial correlations suggest that as contact with American culture increases, individuals' American identification increases, and, therefore, acculturates. However, Hispanic identification remained unchanged through generations, though it has a small correlation with the individuals' number of years living in the U.S. and their percentage of life exposed to American culture.

Table 20

PARTIAL CORRELATIONS* BETWEEN THE ETHNIC IDENTIFICATION SCALES AND INDICATORS OF ACCULTURATION

\begin{tabular}{|c|c|c|c|c|c|c|}
\hline & Correlations & 1 & 2 & 3 & 4 & 5 \\
\hline 1 & Hispanic & & & & & \\
\hline 2 & American & $\begin{array}{l}0.18 \\
<.01\end{array}$ & & & & \\
\hline 3 & $\begin{array}{l}\text { Years lived } \\
\text { in U.S. }\end{array}$ & $\begin{array}{l}-0.20 \\
0.03\end{array}$ & $\begin{array}{l}0.28 \\
<.001\end{array}$ & & & \\
\hline 4 & $\begin{array}{l}\text { Years of } \\
\text { schooling in U.S. }\end{array}$ & $\begin{array}{l}-0.10 \\
0.31\end{array}$ & $\begin{array}{l}0.29 \\
<.001\end{array}$ & $\begin{array}{l}0.69 \\
<.001\end{array}$ & & \\
\hline 5 & Generation & $\begin{array}{l}-0.03 \\
0.74\end{array}$ & $\begin{array}{l}0.28 \\
<.001\end{array}$ & $\begin{array}{l}0.53 \\
<.001\end{array}$ & $\begin{array}{l}0.46 \\
<.001\end{array}$ & \\
\hline 6 & $\begin{array}{l}\text { Percentage of life } \\
\text { in the U.S. }\end{array}$ & $\begin{array}{c}-0.19 \\
0.04\end{array}$ & $\begin{array}{l}0.31 \\
<.001\end{array}$ & $\begin{array}{l}0.95 \\
<.001\end{array}$ & $\begin{array}{l}0.72 \\
<.001\end{array}$ & $\begin{array}{l}0.56 \\
<.001\end{array}$ \\
\hline
\end{tabular}

* Controlling for household income, education and age.

Both ethnic identification scales were compared among samples and demographic groups (Table 21). Supporting the partial correlations, the analysis of variance results showed no significant differences in the Hispanic identification means between any of the groups tested, with the exemption of education groups. On the other hand, the American identification scale was significantly different among samples, income groups, and generations. Simple contrasts controlling for income differences showed significant 
dissimilarities among generations $\left(F_{3,333}=18.07, p<.001\right)$, supporting the assumption that American identification acculturates. An analysis of variance examined the differences of both ethnic identification scales by the individuals' place of birth, controlling for income. The Hispanic identification means were not significantly different between individuals born in the U.S. and those born abroad $\left(\mathrm{M}_{U S}=17.75, \mathrm{M}_{\mathrm{LA}}=17.92\right.$, $\left.\mathrm{F}_{2,334}=.59, \mathrm{p}>.10\right)$. On the other hand, there was a significant difference in the American identification scale between individuals born in America and those considered first generation $\left(\mathrm{M}_{U S}=23.4, \mathrm{M}_{1 \mathrm{st}}=21.6, \mathrm{~F}_{2,334}=33.18, \mathrm{p}<.001\right)$. The results are similar to the ones reported by Zea et al.'s (2003) study. The Cultural Identity dimensions of the AMAS-ZABB (Zea et al. 2003) are sources of most of the ethnic identification scale items (Table 10). The reported difference of the Latino Cultural Identity mean scores between U.S.-born and Latin American-born individuals was marginally significant $\left(\mathrm{M}_{\mathrm{US}}=3.36, \mathrm{M}_{\mathrm{LA}}=3.55, \mathrm{t}_{(155)}=1.98, \mathrm{p}=.05\right)$; while the difference in the U.S. Cultural Identity between both groups was statistically significant $\left(\mathrm{M}_{\mathrm{US}}=3.04, \mathrm{M}_{\mathrm{LA}}=2.56, \mathrm{t}_{(155)}\right.$ $=-5.98, \mathrm{p}<.0001)$.

In conclusion, the evidence provided suggests that:

- Both samples hold similar mental structures of the ethnic identification construct. In both samples the ethnic identification is represented by two dimensions one representing a Hispanic identification and a second one reflecting an American identification. 


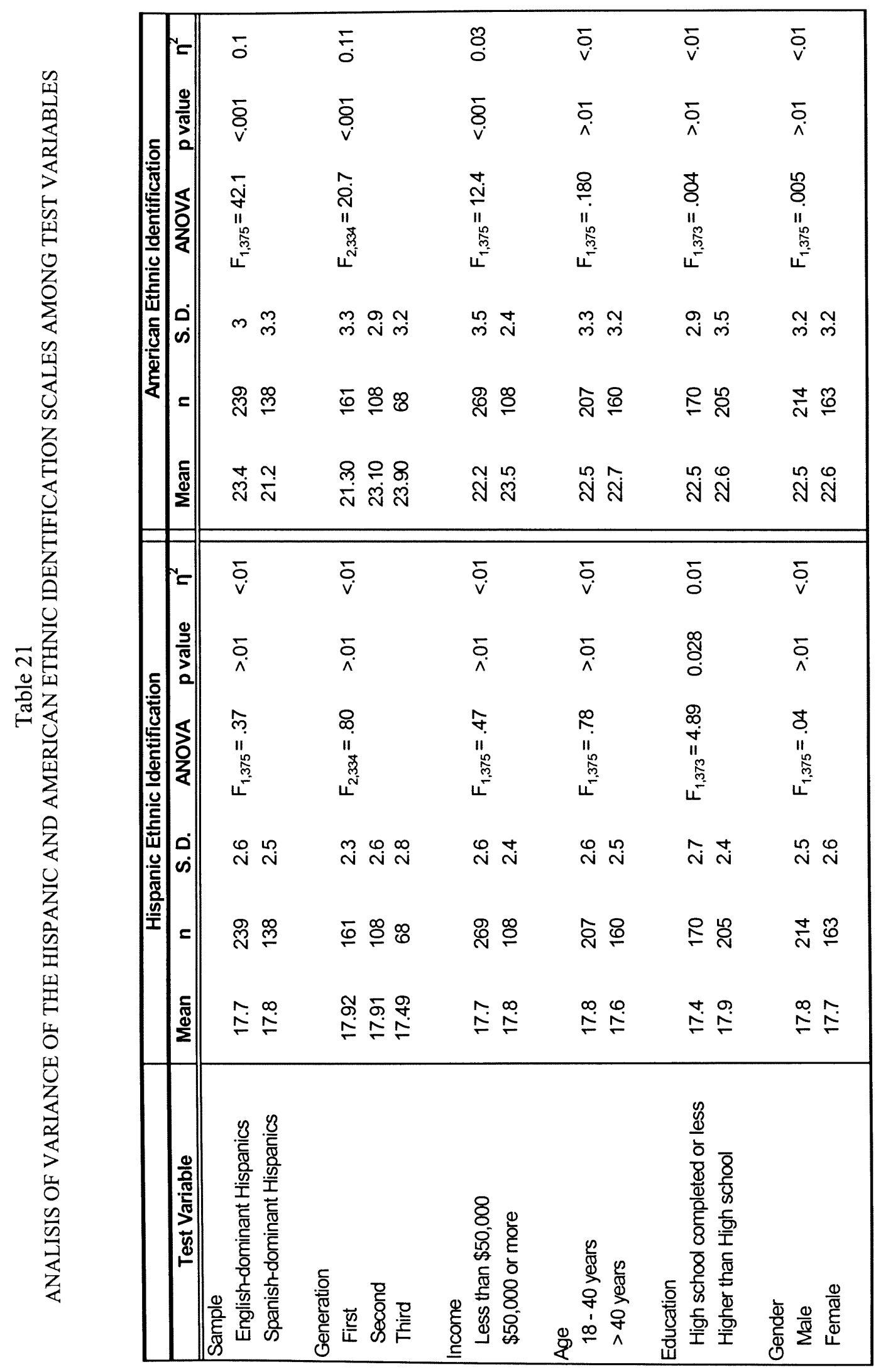

ذ 
- Hispanic identification does not change through generations, suggesting that individuals' feelings towards their Hispanic heritage remain constant while they acculturate in other dimensions.

- American identification changes through generations, supporting the assumption that ethnic identification is an indicator of the acculturation process.

\section{$\underline{\text { Familism Scale }}$}

Given that the familism items were sampled from three populations: White nonHispanics (WNH), English-dominant Hispanics (EH) and Spanish-dominant Hispanics (SH), the scores of each sample were analyzed separately. Descriptive statistics of each sample are included in Table 22. Cronbach alpha coefficients for both English and Spanish dominant Hispanic samples was .88 and .86 respectively, higher than the alpha coefficients reported in Sabogal et al.'s (1987) study (alpha coefficients ranged from .64 to .76 for Sabogal et al.'s three dimensions ${ }^{5}$ ) and the coefficients reported in a later replication by Montoro Rodriguez and Kosloski (1998) (alphas ranged from .70 to .73).

Table 22

FAMILISM SCALE DESCRIPTIVE STATISTICS AND ALPHA COEFICIENT

\begin{tabular}{lcccc}
\hline \multicolumn{1}{c}{ Sample } & N & M & SD & $\boldsymbol{\alpha}$ \\
\hline \hline White non-Hispanic & & & & \\
English-dominant Hispanic & 250 & 75.95 & 9.31 & 0.84 \\
Spanish-dominant Hispanic & 214 & 84.32 & 10.90 & 0.88 \\
All sample & 117 & 86.05 & 10.68 & 0.86 \\
& 581 & 81.07 & 11.13 & 0.87 \\
\hline
\end{tabular}

\footnotetext{
${ }^{5}$ Sabogal et al. (1987) and the later replication by Montoro Rodriguez and Kosloski (1998) consider familism as a three dimensional construct. The dimensions proposed are Family as Referents, Familial Obligations, and Familial Support.
} 
To further understand if the structure of the construct as defined in this study is one-dimensional, the familism items from each sample were factor analyzed using a principal component factor analysis and compared. Both Hispanic samples' principal component structure (Tables 23 and 25) report a similar percentage of total variance explained by the first seven components ( 64.6 for the $\mathrm{EH}$ and 60.5 for the $\mathrm{SH}$ ). The English-dominant Hispanic first principal component explains $29 \%$ of the total variation and 17 of the 23 items included in the analysis load exclusively in this component. The second principal component explains $8.5 \%$ and only 4 items load in this factor. Similarly, the Spanish-dominant Hispanic first principal component explains $25 \%$ of the total variance and 19 of the 23 items load high on this component. The second principal component explains only $10 \%$ and only 2 items load high in this factor.

Table 23

PRINCIPAL COMPONENT TOTAL VARIANCE EXPLAINED OF THE FAMILISM SCALE BY SAMPLE

\begin{tabular}{|c|c|c|c|c|c|c|}
\hline \multirow[b]{2}{*}{ Component } & \multicolumn{3}{|c|}{ English-dominant Hispanics } & \multicolumn{3}{|c|}{ Spanish-dominant Hispanics } \\
\hline & Initial Eigenvalues & $\%$ of Variance & Cumulative \% & Initial Eigenvalues & $\%$ of Variance & Cumulative \% \\
\hline 1 & 6.66 & 28.95 & 28.95 & 5.76 & 25.04 & 25.04 \\
\hline 2 & 1.95 & 8.49 & 37.44 & 2.23 & 9.71 & 34.75 \\
\hline 3 & 1.75 & 7.60 & 45.04 & 1.43 & 6.20 & 40.96 \\
\hline 4 & 1.29 & 5.60 & 50.65 & 1.25 & 5.44 & 46.40 \\
\hline 5 & 1.18 & 5.13 & 55.78 & 1.13 & 4.93 & 51.33 \\
\hline 6 & 1.05 & 4.56 & 60.33 & 1.09 & 4.76 & 56.08 \\
\hline 7 & 0.99 & 4.32 & 64.66 & 1.03 & 4.48 & 60.56 \\
\hline 8 & 0.78 & 3.37 & & 0.96 & 4.16 & \\
\hline 9 & 0.75 & 3.25 & & 0.88 & 3.84 & \\
\hline 10 & 0.72 & 3.13 & & 0.85 & 3.70 & \\
\hline 11 & 0.65 & 2.84 & & 0.78 & 3.40 & \\
\hline 12 & 0.60 & 2.62 & & 0.72 & 3.14 & \\
\hline 13 & 0.58 & 2.54 & & 0.68 & 2.95 & \\
\hline 14 & 0.56 & 2.42 & & 0.60 & 2.60 & \\
\hline 15 & 0.52 & 2.26 & & 0.54 & 2.36 & \\
\hline 16 & 0.48 & 2.07 & & 0.51 & 2.23 & \\
\hline 17 & 0.46 & 1.98 & & 0.48 & 2.07 & \\
\hline 18 & 0.44 & 1.93 & & 0.44 & 1.89 & \\
\hline 19 & 0.39 & 1.68 & & 0.39 & 1.70 & \\
\hline 20 & 0.38 & 1.66 & & 0.37 & 1.60 & \\
\hline 21 & 0.30 & 1.29 & & 0.32 & 1.40 & \\
\hline 22 & 0.28 & 1.22 & & 0.30 & 1.30 & \\
\hline 23 & 0.25 & 1.08 & & 0.25 & 1.09 & \\
\hline
\end{tabular}


Items that conceptually relate to Sabogal et al.'s (1987) Familial Obligations and Family as Referents dimensions load only on the first factor instead of representing two factors. For example, items like "One of the most important goals in life is to have children" and "Daughters should live with their parents until they get married" that are included in Sabogal et al.'s (1987) Family as Referents dimension load high in the first principal component in both Hispanic samples, along with "Adult children should make sacrifices to care for their parents" and "A person should always support his relatives if they are in need" that conceptually relate to Sabogal et al.'s Familial Obligations dimension. Therefore, the principal component analysis confirms the alpha test result that the Hispanic familism acculturation scale is one-dimensional in both samples.

Table 24

ANALISIS OF VARIANCE OF THE FAMILISM SCALE AMONG TEST VARIABLES

\begin{tabular}{|c|c|c|c|c|c|c|}
\hline Test Variable & Mean & $n$ & S.D. & ANOVA & Significance & $n^{2}$ \\
\hline \multicolumn{7}{|l|}{ Sample } \\
\hline Spanish-dominant Hispanics & 86.05 & 214 & 10.6 & $F_{2,578}=56.33$ & $<.001$ & 0.16 \\
\hline English-dominant Hispanics & 84.3 & 117 & 10.9 & & & \\
\hline White non-Hispanics & 75.9 & 250 & 9.3 & & & \\
\hline \multicolumn{7}{|l|}{ Generation } \\
\hline First & 86.3 & 138 & 11.3 & $F_{2,290}=2.4$ & 0.09 & 0.01 \\
\hline $\begin{array}{l}\text { Second } \\
\text { Third }\end{array}$ & 83.5 & 95 & 10.9 & & & \\
\hline Third & & 00 & & & & \\
\hline \multicolumn{7}{|l|}{ Income } \\
\hline less than $\$ 50,000$ & 82.8 & 360 & 10.7 & $F_{1,579}=29.86$ & $<.001$ & 0.05 \\
\hline$\$ 50,000$ or more & 77.9 & 221 & 11.1 & & & \\
\hline \multicolumn{7}{|l|}{ Age } \\
\hline $18-40$ years & 82.4 & 280 & 10.8 & $F_{1,576}=7.83$ & $<0.01$ & 0.01 \\
\hline$>40$ years & 79.8 & 301 & 11.3 & & & \\
\hline \multicolumn{7}{|l|}{ Education } \\
\hline High school completed or less & 82.9 & 248 & 11.3 & $F_{1,576}=11.9$ & 0.001 & 0.02 \\
\hline Higher than High school & 79.7 & 330 & 10.7 & & & \\
\hline \multicolumn{7}{|l|}{ Gender } \\
\hline Male & 81.4 & 329 & 11.0 & $F_{1,579}=.786$ & $>.10$ & 0.001 \\
\hline Female & 80.5 & 252 & 11.3 & & & \\
\hline
\end{tabular}


The scale means were compared among the three samples with an ANOVA analysis. As anticipated, the scale means were significantly different $\left(\mathrm{F}_{2,578}=56.33\right.$, $\mathrm{p}<.001$ ). Simple contrasts comparing the familism scale means between the Anglo sample $\left(\mathrm{M}_{\mathrm{A}}=75.92\right)$ and both Hispanic groups $\left(\mathrm{M}_{\mathrm{EH}}=84.32\right.$ and $\left.\mathrm{M}_{\mathrm{SH}}=85.49\right)$ are significant $(\mathrm{p}<.001)$ and in the expected direction; the Anglo sample has the lowest familism score compared to the other two ethnic groups. However, simple contrasts revealed no significant difference between Hispanic groups ( $p>.10)$. According to the results presented in Table 24 familism scores vary significantly among income, age and education levels, lower income and education levels are associated with higher familism scores; interestingly, consumers between 20 and 40 years of age exhibit higher familism scores compared to consumers reporting ages above 40 .

To examine its concurrent validity, the familism scale was compared to other variables that conceptually are related to acculturation and that previous studies have analyzed. According to the acculturation model proposed, it would be expected that as the individuals' contact with the host culture increases, their familism would decrease. Therefore, it would be likely to observe a negative relationship between familism and other variables that are indicators of the amount of contact with the host culture, even after controlling for demographic variables. Partial correlations controlling for age, household income, and education showed a negative correlation between familism and the number of years lived in U.S. (-.32), the number of years of schooling in the U.S. $(-.18)$ and the percentage of the individuals' life lived in the U.S. $(-.31)$; these results are in accordance with previous findings (Sabogal et al. 1987; Montoro Rodriguez and 
Kosloski 1998). According to the proposed model it would also be expected that as Hispanic consumers increase contact with non-Hispanic individuals, they would exhibit higher acculturation levels and lower familism scores. As expected, the correlation between individuals' friends' ethnicity and familism suggest that as the number of nonHispanic friends increases familism scores decrease (-.34).

Previous acculturation scales have provided evidence of variability of familism (except for family support) among generations (Cuéllar, Arnold, and Maldonado 1995; Perez and Padilla 2000; Cortés 1995; Sabogal et al.1987). The pattern reported in previous research suggests a significant difference between first generation immigrants compared to second and third Hispanic generations. However, the analysis of variance conducted of familism by generational status $\left(\mathrm{M}_{1 \mathrm{st}}=86.3, \mathrm{M}_{2 \mathrm{nd}}=83.5, \mathrm{M}_{3 \mathrm{rd}}=83.56\right.$, respectively) controlling for income, age, and education was not significant $\left(\mathrm{F}_{5,285}=2.06\right.$ $p>.05)$. A second analysis of variance examined differences in familism according to individuals' place of birth, also controlling for income, age, and education. The familism scores of individuals born in the U.S. $\left(\mathrm{M}_{\text {U.S. }}=83.5\right)$ and those born in Latin America $\left(\mathrm{M}_{1 \mathrm{st}}=86.3\right)$ were statistically different after controlling for demographic variables $\left(\mathrm{F}_{4,286}=5.58 \mathrm{p}=.02\right)$.

The evidence provided so far support the following:

- The internal consistency of the 23 item scale is acceptable.

- Familism is a one-dimensional structure in both Hispanic samples.

- Familism changes according to the individual's place of birth.

- Familism is associated to individuals' education, income and age. 


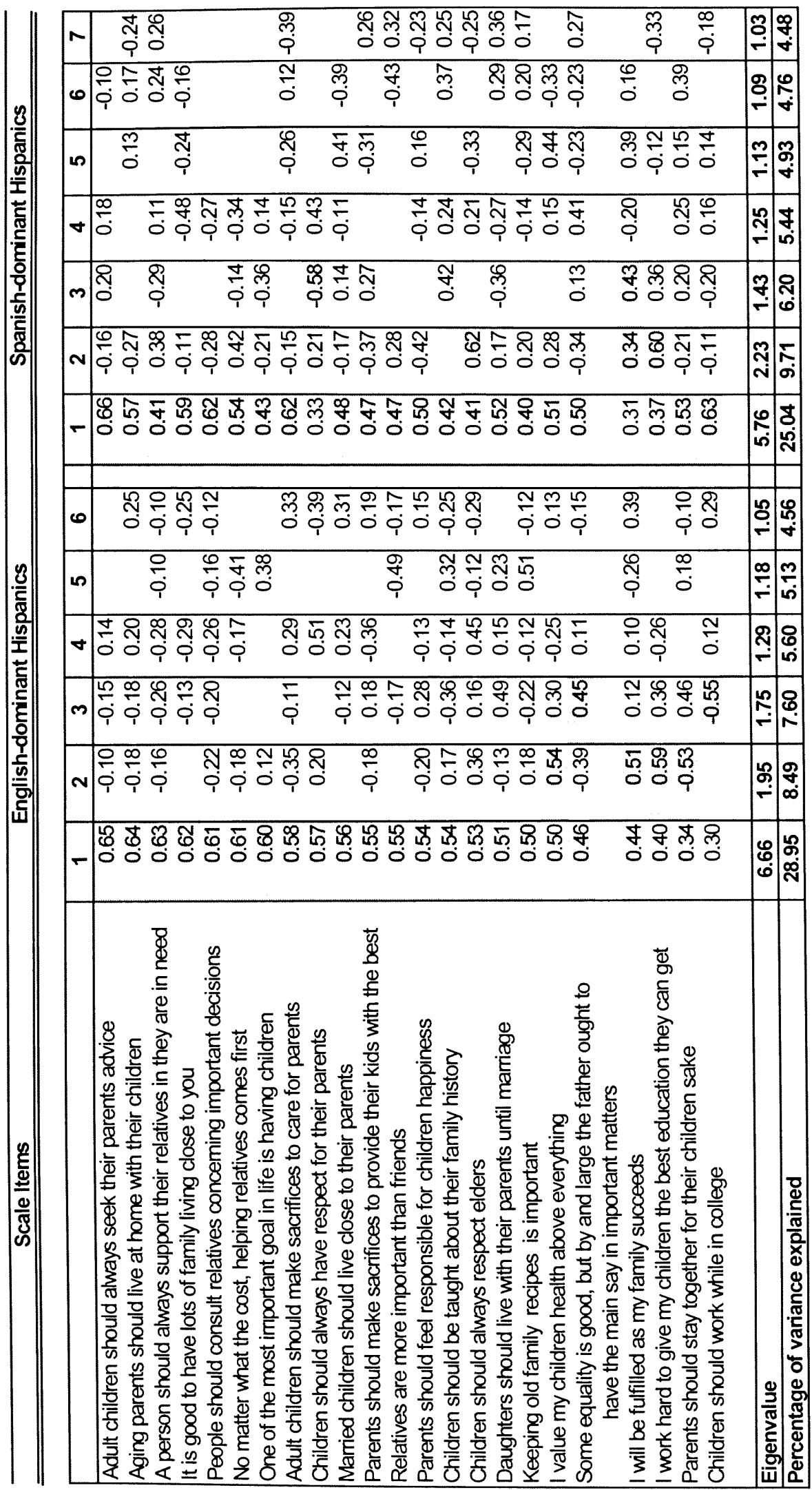




\section{Dependent Measures}

Table 26 describes the items involved in each dependent measure in detail, according to the descriptions provided in Chapter III. The descriptive statistics, correlations, and alpha coefficients of the dependent measures are included in Table 27. The correlations and alpha coefficients of the dependent measures are acceptable, suggesting that the internal consistency and reliability of the dependent measures are good. Therefore, for each dependent measure overall scores were computed adding the scores for each item.

Table 26

DEPENDENT VARIABLES ITEM DESCRIPTION

\begin{tabular}{llc}
\hline \multicolumn{1}{c}{ Dependent Measure } & \multicolumn{1}{c}{ Item } & Question \# \\
\hline \hline & Soft drinks & \\
Self-reported loyalty & Fabric softener & 8 (a) \\
& Shampoo & 8 (b) \\
& Deodorant & 8 (c) \\
& Hairstylist & 8 (d) \\
& Dry cleaning services & 8 (e) \\
& I always buy the same brand & 8 (f) \\
Attitudinal loyalty & I feel committed to my preferred brands & $6(\mathrm{~d})$ \\
& I always look for the highest quality brands & $6(\mathrm{f})$ \\
Brand quality attitudes & I generally do not care what brand I buy & $6(\mathrm{a})$ \\
& I always buy well-known brands & $6(\mathrm{~b})$ \\
& The brand name is an important consideration & $6(\mathrm{c})$ \\
& in my purchase decision & $6(\mathrm{e})$ \\
Purchase frequency & Groceries & \\
Purchase frequency of & & 7 \\
non-fresh food & Ready to eat frozen meals & \\
Purchase frequency of & Canned soups & $5(\mathrm{a})$ \\
hygiene/ cleaning products & Fabric softener & $5(\mathrm{~b})$ \\
& Shampoo & $5(\mathrm{~d})$ \\
Money saved for children & Deodorant & $5(\mathrm{e})$ \\
& & $5(\mathrm{f})$ \\
& Education & $13(\mathrm{~b})$ \\
& Future & $13(\mathrm{c})$ \\
\hline
\end{tabular}


One of the main assumptions made in the development of the Hispanic Acculturation Model was that Anglo and Hispanic consumers differed in some consumer behaviors. In particular, this study measured consumers' brand loyalty, attitudes towards high quality and prestigious brands, frequency of purchase, and their savings allocation. According to the results showed in Table 27, of the two loyalty measures employed, only the self-reported loyalty achieved significant difference among samples. From an overall loyalty score that ranged from 6 to 30 , Hispanic consumers reported an average loyalty score of 20 while Anglo consumers showed an average overall loyalty score of 19 ; in average it could be said that consumers consider themselves very to moderately loyal. Even though the difference is significant, it is not very high. These findings are supported by the results reported by Brown (2004). According to Brown (2004), even though Hispanics report being more loyal than the rest of the consumers, the difference between ethnic groups is not very large.

The brand-quality attitude mean scores are statistically different $\left(\mathrm{F}_{1,651}=14.1\right.$, $\mathrm{p}<.001)$ between Anglo $\left(\mathrm{M}_{\mathrm{A}}=12\right)$ and Hispanic $\left(\mathrm{M}_{\mathrm{H}}=13\right)$ samples, although the means scores reflect neither agreement nor disagreement with the brand quality statements included in the overall scale.

Two of the purchase frequency measures included in the questionnaire showed no significant difference among ethnic groups. However, the purchase frequency of hygiene and cleaning products not only reached statistical difference $\left(\mathrm{F}_{1,651}=33.9, \mathrm{p}<.001\right)$, but also the mean scores suggest that Hispanic consumers purchased hygiene and cleaning 
products every two weeks $\left(M_{H}=9.7\right)$, on average, instead of every month, as the Anglo consumers reported $\left(\mathrm{M}_{\mathrm{A}}=11.3\right)$.

Table 27

ALPHA COEFICIENTS, PEARSON CORRELATIONS AND ANALISIS OF VARIANCE OF THE DEPENDENT MEASURES BY ETHNICITY

\begin{tabular}{|c|c|c|c|c|c|c|}
\hline Ethnic Groups & $\mathbf{N}$ & $M$ & SD & $\alpha / \mathbf{r}$ & $F$ & Sig. \\
\hline \multicolumn{7}{|l|}{ Self-reported loyalty } \\
\hline Hispanic & 361 & 19.89 & 5.0 & $\alpha=0.74$ & $F_{1,651}=8.9$ & $<.01$ \\
\hline Anglo & 270 & 18.76 & 4.8 & $\alpha=0.7$ & & \\
\hline All sample & 631 & 19.41 & 4.9 & $\alpha=0.71$ & & \\
\hline \multicolumn{7}{|l|}{ Attitudinal loyalty } \\
\hline Hispanic & 377 & 6.05 & 1.7 & $r=.42$ & $F_{1,651}=2.19$ & $>.10$ \\
\hline Anglo & 276 & 5.88 & 1.6 & $r=.53$ & & \\
\hline All sample & 653 & 5.98 & 1.7 & $r=.46$ & & \\
\hline \multicolumn{7}{|l|}{ Brand quality attitudes } \\
\hline Hispanic & 377 & 12.99 & 3.1 & $a=0.79$ & $\mathrm{~F}_{1,651}=14.1$ & $<.001$ \\
\hline Anglo & 276 & 12.14 & 2.7 & $a=0.70$ & & \\
\hline All sample & 653 & 12.63 & 3.0 & $a=0.77$ & & \\
\hline \multicolumn{7}{|l|}{$\begin{array}{l}\text { Purchase frequency of } \\
\text { groceries }\end{array}$} \\
\hline Hispanic & 377 & 2.93 & 1.1 & & $F_{1,651}=0.67$ & $>.10$ \\
\hline Anglo & 276 & 2.99 & 1.0 & & & \\
\hline All sample & 653 & 2.95 & 1.0 & & & \\
\hline \multicolumn{7}{|l|}{$\begin{array}{l}\text { Purchase frequency of } \\
\text { non-fresh food }\end{array}$} \\
\hline Hispanic & 377 & 7.27 & 2.3 & $r=.5$ & $F_{1,651}=0.41$ & $>.10$ \\
\hline Anglo & 276 & 7.38 & 2.2 & $r=.55$ & & \\
\hline All sample & 653 & 7.32 & 2.2 & $r=.52$ & & \\
\hline \multicolumn{7}{|c|}{$\begin{array}{l}\text { Purchase frequency of } \\
\text { hygene/ cleaning products }\end{array}$} \\
\hline Hispanic & 377 & 9.71 & 3.4 & $a=0.89$ & $F_{1,651}=33.9$ & $<.001$ \\
\hline Anglo & 276 & 11.26 & 3.2 & $\alpha=0.91$ & & \\
\hline All sample & 653 & 10.36 & 3.4 & $\alpha=0.90$ & & \\
\hline \multicolumn{7}{|l|}{ Money saved for children } \\
\hline Hispanic & 374 & $\$ 2,704$ & $\$ 2,428$ & & $F_{1,646}=32.5$ & $<.001$ \\
\hline Anglo & 274 & $\$ 1,634$ & $\$ 2,272$ & & & \\
\hline All sample & 648 & $\$ 2,252$ & $\$ 2,420$ & & & \\
\hline
\end{tabular}


Finally, the average amount of savings out of $\$ 10,000.00$ that Hispanic consumers would allocate for their children's future and education was on average $\$ 1,000.00$ higher compared to the Anglo consumers $\left(\mathrm{M}_{\mathrm{H}}=\$ 2,704, \mathrm{M}_{\mathrm{A}}=\$ 1,634\right.$, respectively); this difference attained statistical significance $\left(\mathrm{F}_{1,646}=32.5, \mathrm{p}<.001\right)$.

Based on the results previously shown, only self-reported loyalty, brand quality attitudes, purchase frequency of hygiene and cleaning products, and money saved for children are significantly different between Anglo and Hispanic consumers. However, in order to be able to include the dependent variables in the Hispanic acculturation model, the dependent measures have to vary within Hispanic groups as well. The behaviors to be included in the acculturation model should change across generations in order to imply an acculturation process. Therefore, the four dependent measures described above were compared across generations with an ANOVA analysis. According to the results reported in Table 28 only savings for children is significantly different across generations $\left(\mathrm{F}_{2,331}=\right.$ $4.15, \mathrm{p}=.01)$. The other dependent measures did not reach significant differences. The results suggest that even when loyalty, brand attitudes, and purchase frequency vary between Anglos and Hispanics, these behaviors do not acculturate; they do not change as Hispanic consumers increase their contact with the American culture. Accordingly, only savings for children's future will be tested in the acculturation model. The other dependent measures will be employed to test the effects of familism on Hispanic and Anglo consumption patterns. 
In conclusion, the evidence provided suggests that:

- Money saved for children's education and future varies between Hispanic and Anglo consumers, and among generations. The results imply that this behavior is distinctive among Hispanics and acculturates as contact with the American culture increases.

- Self-reported loyalty, brand quality attitudes, and purchase frequency of hygiene and cleaning products, are consumer behaviors and attitudes distinctive of Hispanics; however, they do not change as exposure with the American consumer environment increases.

Table 28

ANALISIS OF VARIANCE OF THE DEPENDENT MEASURES BY GENERATION

\begin{tabular}{lccccc}
\hline \multicolumn{1}{c}{ Ethnic Groups } & N & M & SD & F & Sig. \\
\hline \hline & & & & & \\
Self-reported loyalty & 154 & 19.36 & 5.35 & $F_{2,320}=1.4$ & $>.10$ \\
$\quad$ First & 102 & 20.08 & 4.61 & & \\
$\quad$ Second & 67 & 20.49 & 4.57 & & \\
$\quad$ Third & & & & & \\
Brand quality attitudes & 161 & 13.14 & 3.21 & $F_{2,334}=.75$ & $>.10$ \\
$\quad$ First & 108 & 12.93 & 3.13 & & \\
$\quad$ Second & 68 & 12.60 & 2.64 & & \\
$\quad$ Third & & & & & \\
& & & & & \\
Purchase frequency of & 161 & 9.86 & 3.22 & $F_{2,334}=.21$ & $>.10$ \\
hygiene/ cleaning products & 108 & 9.69 & 3.55 & & \\
$\quad$ First & 68 & 10.01 & 3.28 & & \\
$\quad$ Second & & & & & \\
$\quad$ Third & & & & & \\
$\quad$ Money saved for children & 160 & $\$ 3,129$ & $\$ 2,559$ & $F_{2,331}=4.15$ & 0.01 \\
$\quad$ First & 107 & $\$ 2,689$ & $\$ 2,350$ & & \\
$\quad$ Second & 67 & $\$ 2,128$ & $\$ 2,207$ & & \\
$\quad$ Third & & & & &
\end{tabular}




\section{CHAPTER VI \\ HYPOTHESIZED RESULTS}

\section{$\underline{\text { Acculturation Agents }}$}

$\mathrm{H}_{1}$ predicted that the acculturation process was set in motion by the acculturation agents. In particular, the hypothesis suggested that as the consumers' exposure to Anglo agents such as friends, people at work, people at the shops and people at church increased, their American identification would increase. At the same time, consumers' Hispanic identification, preference for Spanish language, and familism would decrease. To test the hypotheses four regression models were conducted. Language preference, familism, Hispanic identification, and American identification were regressed on acculturation agents (Table 29). In order to support $\mathrm{H}_{1}$, the corresponding regression coefficients need to be significant and in the expected direction. The results support $\mathrm{H}_{1}$. As expected, the acculturation agents are significant predictors of the acculturation dimensions. In particular, the effect of Anglo acculturation agents on Spanish language preference is strong and in the expected direction, the higher the exposure to Anglo agents, the lower the overall preference for Spanish in the different contexts. Thirty seven percent of the variability of language preference among Hispanic consumers is explained by the ethnicity of the acculturation agents. As predicted, the effects of the agents on the consumers' identification is significant; as individuals' exposure to Anglo agents increased, their identification with the American culture increased and their identification with the Hispanic culture decreased. However, the effects are smaller compared to language preference; in both cases the percentage of variability explained of individuals' 
identification is 5 percent. Last, the acculturation agents are significant predictors of Hispanics' familism. Fourteen percent of the variability of Hispanic familism is explained by exposure to either Anglo or Hispanic acculturation agents.

Table 29

REGRESSION OF THE ACCULTURATION AGENTS ON LANGUAGE PREFERENCE, FAMILISM, AMERICAN AND HISPANIC IDENTIFICATION

\begin{tabular}{|c|c|c|c|c|c|c|}
\hline & $\begin{array}{c}\text { Dependent } \\
\text { variable }\end{array}$ & $\begin{array}{c}\text { Independent } \\
\text { variable }\end{array}$ & $\begin{array}{c}\text { Standardized } \\
\text { coefficient } \\
\end{array}$ & $t$ & Adj. $R^{2}$ & $\begin{array}{c}\text { Part } \\
\text { correlation } \\
\end{array}$ \\
\hline 1 & Language Preference & Agents & -0.61 & $-14.9^{\star \star \star}$ & 0.37 & -0.61 \\
\hline 2 & Hispanic Identification & Agents & -0.23 & $-4.7^{\star * \star}$ & 0.05 & -0.23 \\
\hline 3 & American Identification & Agents & 0.22 & $4.4^{\star \star \star}$ & 0.05 & 0.22 \\
\hline & Familism & Agents & -0.37 & $-9.7^{\star \star \star \star}$ & 0.14 & -0.37 \\
\hline
\end{tabular}

\section{$\underline{\text { Acculturation Dimensions }}$}

The second hypothesis examined the relationship among the acculturation dimensions. It was proposed that the effect of the acculturation agents on the consumers' ethnic identification (Hispanic and American) and familism was mediated by the consumers' language preference. According to $\mathrm{H}_{2}$, as consumers increase their exposure to Anglo acculturation agents their Spanish language preference is likely to decrease; this language preference change is expected to influence individuals' feelings towards the American and Hispanic cultures and their familism.

In order to be a mediating variable, language preference has to satisfy three conditions. First, the acculturation agents have to significantly predict all the acculturation dimensions. Second, language preference should significantly predict 
familism, Hispanic identification, and American identification. Last, when both language preference and acculturation agents are included in the analysis, the effects of the acculturation agents on the dependent measures are expected to disappear (not be significant) for a full mediation, or be reduced (reduced part correlation) for a partial mediation effect.

The mediation of language preference was examined via regression analysis. It was already established from the results of $\mathrm{H}_{1}$ that the acculturation agents are significant predictors of language preference, familism, Hispanic identification, and American identification (Table 29). In order to test the second condition familism, Hispanic identification, and American identification were regressed on language preference. According to the results presented in Table 30 (regressions 1, 2, and 3) language preference is a significant predictor of familism, Hispanic identification, and American identification. The relationships have the expected direction; individuals' preference for Spanish language is positively related to their Hispanic identification, negatively related to their American identification, and positively related to their familism.

Last, the acculturation dimensions were regressed on language preference and the acculturation agents. According to the results reported on Table 30 (regression number 4) the effects of language preference and acculturation agents on Hispanic identification are both significant. However, the part correlation of language preference (.23) in regression one decreased when the acculturation agents were included in the model (.11). The evidence so far suggests that even though language preference mediates the effects of the acculturation agents on Hispanic identification, the acculturation agents have a direct 
effect on Hispanic identification as well. Therefore, the effects of language preference partially mediate the relationship between the acculturation agents and Hispanic identification. Regressions five and six (Table 30) examined the mediation effects of language preference on American identification and familism, respectively. The effects of the acculturation agents on American identification and familism when language preference was included in the models were not significant. In both cases, the evidence supports full mediation of language preference.

Table 30

TEST FOR THE MEDIATION EFFECTS OF LANGUAGE PREFERENCE ON FAMILISM, AMERICAN AND HISPANIC IDENTIFICATION

\begin{tabular}{|c|c|c|c|c|c|c|}
\hline & $\begin{array}{c}\text { Dependent } \\
\text { variable } \\
\end{array}$ & $\begin{array}{c}\text { Independent } \\
\text { variable/s } \\
\end{array}$ & $\begin{array}{l}\text { Standardized } \\
\text { coefficient/s }\end{array}$ & $\mathbf{t}$ & Adj. $R^{2}$ & $\begin{array}{c}\text { Part } \\
\text { correlations } \\
\end{array}$ \\
\hline 1 & Hispanic Identification & Language Preference & 0.23 & $4.57^{\star \star \star}$ & 0.05 & 0.23 \\
\hline 2 & American Identification & Language Preference & -0.43 & $-9.27^{\star \star \star}$ & 0.187 & -0.43 \\
\hline 3 & Familism & Language Preference & 0.26 & $4.9^{* * *}$ & 0.065 & 0.26 \\
\hline 4 & Hispanic Identification & $\begin{array}{l}\text { Language Preference } \\
\text { Agents }\end{array}$ & $\begin{array}{r}0.14 \\
-0.15 \\
\end{array}$ & $\begin{array}{r}2.19^{*} \\
-2.38^{*} \\
\end{array}$ & 0.06 & $\begin{array}{r}0.11 \\
-0.12 \\
\end{array}$ \\
\hline 5 & American Identification & $\begin{array}{l}\text { Language Preference } \\
\text { Agents }\end{array}$ & $\begin{array}{l}-0.47 \\
-.07 \\
\end{array}$ & $\begin{array}{l}-8.1 * \star \\
-1.16 \\
\end{array}$ & 0.19 & $\begin{array}{l}-0.38 \\
-0.05 \\
\end{array}$ \\
\hline 6 & Familism & $\begin{array}{l}\text { Language Preference } \\
\text { Agents }\end{array}$ & $\begin{array}{c}0.2 \\
-0.09 \\
\end{array}$ & $\begin{array}{l}3.07^{* *} \\
-1.48 \\
\end{array}$ & 0.074 & $\begin{array}{r}0.16 \\
-0.08 \\
\end{array}$ \\
\hline
\end{tabular}

Of the three acculturation dimensions, the effect of language preference is stronger on American identification (Adj. $\mathrm{R}^{2}=.19$ ) compared with familism (Adj. $\mathrm{R}^{2}=$ .07 ), and Hispanic identification (Adj. $\mathrm{R}^{2}=.05$ ). According to the results, nineteen percent of the variability of American identification is explained by the individuals' language preference. As consumers' exposure to Anglo-agents increases, preference for 
English language in different contexts increases, having a significant effect on consumers' feelings of belonging to the American culture. However, the effects of language preference on the individuals' feelings towards their Hispanic heritage and traditional values (familism) are weaker. These results suggest that Hispanic consumers' exposure to Anglo agents and preference for English language have a small effect on their feelings towards their heritage and their values, supporting the biculturalism proposition. Change on language preference and acquisition of feelings of belonging to American do not imply a loss of Hispanic identification and traditional values.

In summary, individuals' acculturation change/retention of their feelings of identification with the American culture and familism is mediated by their preference for Spanish or English language. Hispanic consumers' feelings towards their Hispanic heritage, though, are retained by their preference for Spanish language and their contact with Hispanic acculturation agents. The evidence provided supports $\mathrm{H}_{2}$; changes in individuals' language (behaviors) antecedes individuals' changes on deeper acculturation dimensions (ethnic identification and familism). These results, not previously tested in the literature, support Marín's (1992) and Gordon's (1964) propositions.

\section{Acculturation and Consumer Behavior}

The Hispanic acculturation model proposes a relationship between Hispanics' acculturation process and their consumption patterns. In particular, $\mathrm{H}_{3}, \mathrm{H}_{4}$ and $\mathrm{H}_{5}$ hypothesized relationships between Hispanics' acculturation process and brand loyalty, attitudes towards high quality brands, purchase frequency, and savings allocation. Owing 
to the lack of significant differences among Hispanic and Anglo consumers and the lack of differences among Hispanic generations, only savings for children's future was tested (c.f., Chapter VI). According to $\mathrm{H}_{3}$, as consumers' preference for English language increases, their identification with the American culture is likely to increase and their savings motives are likely to change reducing the amount of money saved for their children. On the other hand, $\mathrm{H}_{4}$ hypothesized that as Hispanic consumers choose to maintain their preference for Spanish language, their identification with their Hispanic heritage is likely to remain strong and the amount of money saved for their children's future will probably be high. Last, $\mathrm{H}_{5}$ hypothesized that individuals' preference for Spanish language has an influence on the retention of their values, in particular of familism, influencing their savings allocation. Therefore, $\mathrm{H}_{3}, \mathrm{H}_{4}$, and $\mathrm{H}_{5}$ proposed that the acculturation domains (familism, Hispanic identification, and American identification) mediate the effects of language preference on Hispanic consumers' savings for their children's future.

In order to test the mediation of familism and Hispanic and American identification, the three conditions described previously were tested. The effects of language preference on the other three acculturation dimensions were already discussed (Table 30). According to the results presented, language preference is a significant predictor of familism, Hispanic identification, and American identification dimensions. Second, familism, Hispanic identification, and American identification were regressed on savings for children's future (Table 31 ). The results suggest that the three variables are significant predictors of Hispanic consumers' savings for their children. The percentage 
of variability of the money saved for the children explained by the three acculturation domains is approximately $5 \%$. The part correlations suggest that of that $5 \%$, the three dimensions explain independently a similar proportion of the variability $\left(\mathrm{sr}_{\mathrm{F}}=.12, \mathrm{sr}_{\mathrm{H}}=\right.$ .13 and $\mathrm{sr}_{\mathrm{A}}=-.16$ ). In order to test the mediation effects of the familism, Hispanic identification, and American identification domains a regression analysis was conducted including language preference along with the other acculturation domains. The results are reported in Table 31 (regression 2). When language preference is included in the model, the effects of familism, Hispanic identification, and American identification are no longer significant. Language preference not only has a significant effect on the money saved for the children's future, but also the incremental percentage of variability explained is significant. When language preference was introduced to the model, the percentage of variability increased from .047 to .063 . The $\mathrm{F}$ test for incremental proportion of variability explained $^{7}$ is significant at a $5 \%$ confidence level $\left(\mathrm{F}_{(1,322)}=5.49, \mathrm{p}<.05\right)$. Therefore, the effects of language preference on the amount of money saved for children's future is partially mediated by consumers' ethnic identification and familism. Language preference not only affects consumers' savings patterns through their feelings of belonging to the American and Hispanic cultures and their values, but also directly.

In summary, $\mathrm{H}_{3}, \mathrm{H}_{4}$, and $\mathrm{H}_{5}$, are partially supported; consumers' acculturation process affects their savings allocation patterns. As consumers are exposed to Anglo acculturation agents, their Spanish language preference is modified, affecting their feelings of belonging to the American and Hispanic cultures and their familism. This

${ }^{7} \mathrm{~F}=\frac{\left(R_{Y \cdot A B}^{2}-R_{Y \cdot A}^{2}\right) / k_{B}}{\left(1-R_{Y \bullet A B}^{2}\right) /\left(n-k_{A}-k_{B}-1\right)} \approx F_{k_{B}, n-k_{A}-k_{B}-1}$ Cohen and Cohen (1983, p. 145) 
process, in turn, has an effect on Hispanic consumers' savings patterns, increasing or decreasing the amount of money they allocate for their children's future. However, the results show that language preference not only has an effect on the consumers' ethnic identification and familism, but also has a direct effect on the consumers' savings patterns, suggesting that the mediation of ethnic identification and familism is partial.

Table 31

TEST FOR THE MEDIATION EFFECTS OF FAMILISM, AMERICAN AND HISPANIC IDENTIFICATION ON SAVINGS FOR CHILDREN'S FUTURE

\begin{tabular}{|c|c|c|c|c|c|c|}
\hline & $\begin{array}{c}\text { Dependent } \\
\text { variable }\end{array}$ & $\begin{array}{c}\text { Independent } \\
\text { variable/s }\end{array}$ & $\begin{array}{l}\text { Standardized } \\
\text { coefficient/s }\end{array}$ & $t$ & Adj. $R^{2}$ & $\begin{array}{c}\text { Part } \\
\text { correlations }\end{array}$ \\
\hline 1 & Savings for children & $\begin{array}{l}\text { Hispanic identification } \\
\text { American identification } \\
\text { Familism }\end{array}$ & $\begin{array}{c}0.14 \\
-0.16 \\
0.12\end{array}$ & $\begin{array}{l}2.5^{\star} \\
-2.9^{\star \star} \\
2.1^{\star}\end{array}$ & 0.047 & $\begin{array}{c}0.13 \\
-0.16 \\
0.12\end{array}$ \\
\hline 2 & Savings for children & $\begin{array}{l}\text { Hispanic identification } \\
\text { American identification } \\
\text { Familism } \\
\text { Language Preference }\end{array}$ & $\begin{array}{c}0.09 \\
-0.08 \\
0.08 \\
0.16\end{array}$ & $\begin{array}{c}1.60 \\
-1.24 \\
1.42 \\
2.51^{\star}\end{array}$ & 0.063 & $\begin{array}{r}0.09 \\
-0.07 \\
0.08 \\
0.13\end{array}$ \\
\hline
\end{tabular}

${ }^{*} \mathrm{p}<.05 ;{ }^{* *} \mathrm{p}<.01$

$\underline{\text { Acculturation Moderators }}$

$\mathrm{H}_{6}$ proposed that female Hispanic consumers are likely to exhibit higher preference for Spanish language compared to male Hispanics. Given their preconceived sex-role, females are likely to have less opportunities of socialization outside the home compared to male Hispanics. Subsequently female Hispanic consumers have limited contact with Anglo acculturation agents, and their preference for Spanish language is likely to be higher compared to male Hispanic consumers. In order to test $\mathrm{H}_{6}$, the following regression model was adopted:

$$
\mathrm{Lp}=\beta_{0}+\beta_{1} \mathrm{Ag}+\beta_{2} \mathrm{~S}+\beta_{3} \mathrm{Ag} * \mathrm{~S}+\xi
$$


Where Lp stands for language preference, Ag for acculturation agents, $\mathrm{S}$ for gender, and $\xi$ stands for the error. In order to support $\mathrm{H}_{6}, \beta_{3}$ would have to be significant. The regression results are shown in Table 32. Neither the main effect nor the interaction was significant. Gender has no effect on consumers' exposure to acculturation agents, and subsequently on their language preferences. Both genders have similar exposure to Anglo acculturation agents generating similar effects on their language preferences.

It was hypothesized that younger consumers are likely to acculturate faster than older consumers. Specifically, $\mathrm{H}_{7}$ proposed that younger consumers are more prone to socialize with Anglo acculturation agents compared to older consumers and, therefore, have lower preferences for Spanish language. The moderating effects of age were expected to be significant, even after controlling for generation and the number of years living in the United States. The model used to test $\mathrm{H}_{7}$ is the following:

$$
\mathrm{Lp}=\beta_{0}+\beta_{1} \mathrm{Ag}+\beta_{2} \text { Age }+\beta_{3} \mathrm{Ag} * \mathrm{Age}+\beta_{4} \mathrm{G}+\beta_{5} \mathrm{Y}+\xi
$$

Where $\mathrm{G}$ stands for generation and $\mathrm{Y}$ stands for the number of years consumers lived in the United States. In order to support $\mathrm{H}_{7}, \beta_{3}$ would have to be significant. The results reported in Table 32 (regression 2) indicate that age does not moderate the effects of the acculturation agents on language preference. Generation and the number of years living in the U.S. affect significantly individuals' language preference; however, the interaction of age and acculturation agents is not significant, and age lacks a significant main effect on language preference. Therefore, $\mathrm{H}_{7}$ is not supported, and it can be concluded that after controlling for individuals' generation and number of years living in the U.S., the exposure to Anglo acculturation agents have similar effects on consumers' language preference, irrespective of their age. 
Table 32

TEST FOR THE MODERATION EFFECTS OF GENDER, AGE AND COUNTRY OF ORIGIN ON LANGUAGE PREFERENCE

\begin{tabular}{|c|c|c|c|c|}
\hline $\begin{array}{c}\text { Dependent } \\
\text { variable }\end{array}$ & $\begin{array}{c}\text { Independent } \\
\text { variable/s } \\
\end{array}$ & $\begin{array}{l}\text { Standardized } \\
\text { coefficient/s }\end{array}$ & $t$ & Adj. $R^{2}$ \\
\hline 1 Language Preference & $\begin{array}{l}\text { Agents } \\
\text { Gender } \\
\text { Agents*Gender }\end{array}$ & $\begin{array}{c}-0.61 \\
0.03 \\
-0.01\end{array}$ & $\begin{array}{c}-14.72^{\star \star \star} \\
0.20 \\
-0.08\end{array}$ & 0.37 \\
\hline 2 Language Preference & $\begin{array}{l}\text { Agents } \\
\text { Age } \\
\text { Agents*Age } \\
\text { Generation } \\
\text { Years in living in U.S. }\end{array}$ & $\begin{array}{c}-0.42 \\
0.05 \\
-0.06 \\
-0.32 \\
0.17\end{array}$ & $\begin{array}{l}-6.99^{\star \star *} \\
0.88 \\
-0.77 \\
-3.99^{\star \star \star} \\
2.08^{\star}\end{array}$ & 0.58 \\
\hline 3 Language Preference & $\begin{array}{l}\text { Agents } \\
\text { Mexico } \\
\text { Agents }{ }^{\star} \text { Mexico }\end{array}$ & $\begin{array}{l}-0.60 \\
-0.14 \\
0.05\end{array}$ & $\begin{array}{c}-13.39^{\star \star \star} \\
-0.79 \\
0.30\end{array}$ & 0.35 \\
\hline
\end{tabular}

${ }^{*} \bar{p}<.05 ; * * p<.01 ; * * * p<.001$

Finally, it was hypothesized that consumers' country of origin has a moderating effect on language preference. According to the discussion presented in Chapter III, individuals' country of origin affects their exposure to Anglo acculturation agents and, subsequently, their language preference. Given the nature of our final sample the frequency distribution of country of origin did not allow to test the hypothesis as proposed. In order to overcome the insufficient sample size per country of origin, Hispanic consumers were classified in two groups: those that declared Mexico as their country of origin ( $46 \%)$ and those that declared another country $(54 \%)$. Therefore, instead of testing differences among Puerto Ricans, Cubans, and Mexicans, the analysis only tested for differences between Mexican-American Hispanics and other Hispanic consumers. The regression model used to test $\mathrm{H}_{8}$ is the following: 


$$
L p=\beta_{0}+\beta_{1} A g+\beta_{2} M x+\beta_{3} A g * M x+\xi
$$

In the model Mx stands for Mexican origin. Again, in order to support $\mathrm{H}_{8}, \beta_{3}$ would have to be significant. According to the results reported in Table 32 (regression 3), country of origin has no moderating effects on language preference. Individuals reporting Mexico as their country of origin have similar exposure to Anglo acculturation agents and subsequently similar language preference compared to consumers with other country of origin. In summary, none of the hypotheses proposed $\left(\mathrm{H}_{6}, \mathrm{H}_{7}\right.$, and $\left.\mathrm{H}_{8}\right)$ were supported. Neither gender, nor age nor country-of-origin moderates the effects of the acculturation agents on their language preferences.

Figure 6 illustrates the Hispanic acculturation model test results. The figure depicts the results of hypotheses 1 through 8 . In accordance with the findings presented, as Hispanic consumers' choose to expose themselves to Anglo acculturation agents their preference for Spanish language decreases. Language preferences mediate the effects of the acculturation agents on their American identification and familism. However, Hispanic consumers' feelings towards their Hispanic heritage are retained by their preference for Spanish language and their contact with Hispanic acculturation agents. The acculturation process of change/retention of language preference through consumers' familism, and Hispanic and American identification affect Hispanic consumers' savings allocation patterns. The results show that language preference not only has an effect on the consumers' ethnic identification and familism, but also has a direct effect on the consumers' savings patterns, suggesting that the mediation of ethnic identification (Hispanic and American), and familism is partial. Last, according to the model depicted 
in Figure 6 individual characteristics such as gender, age, and country of origin do not mediate the effects of the acculturation agents on individuals' language preferences.

Figure 6

HISPANIC CONSUMER ACCULTURATION MODEL: TETS RESULTS

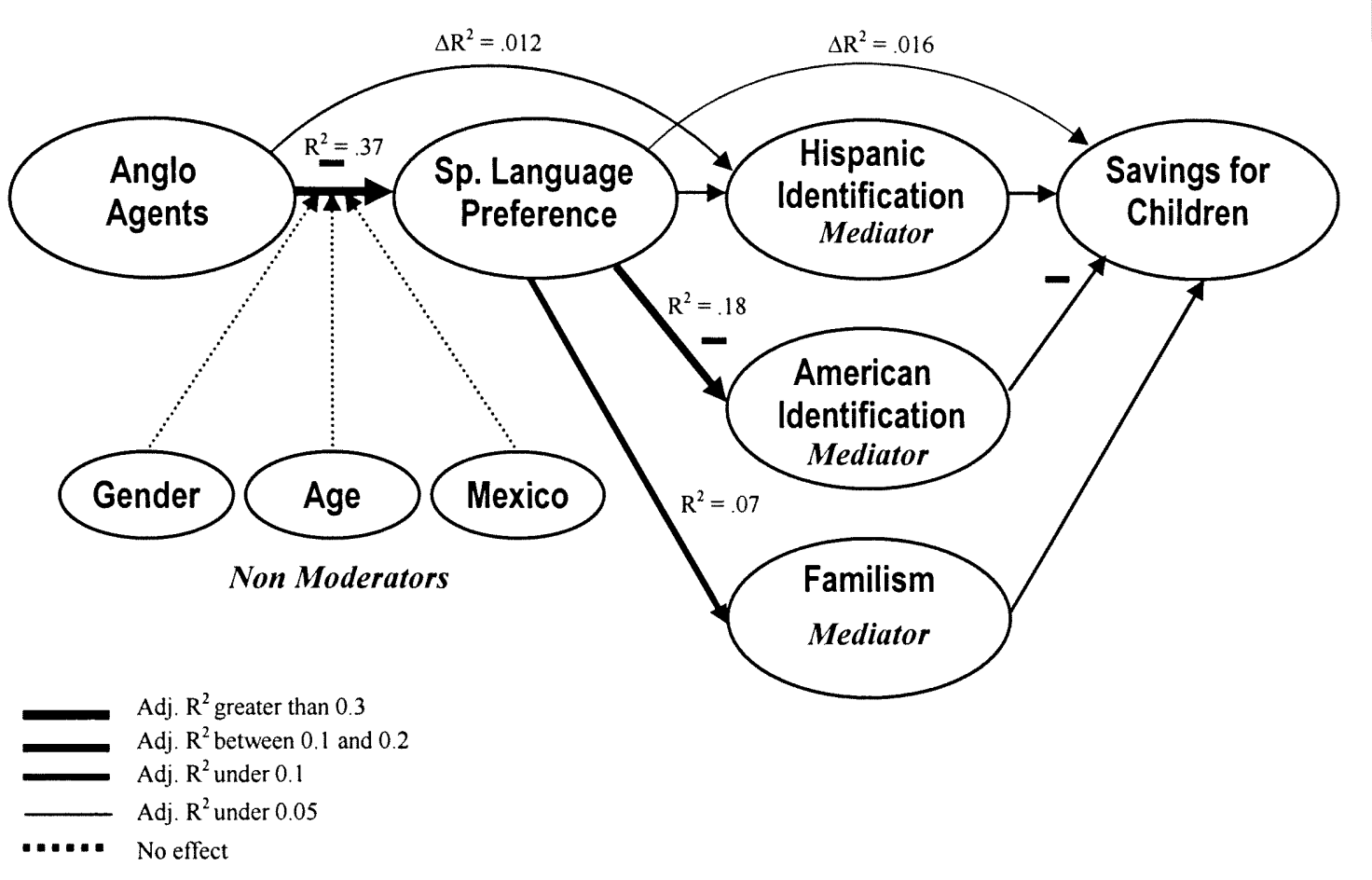

Familism, Acculturation, and Consumer Behavior

Chapter IV proposed that familism discriminates not only Hispanic and Anglo consumers, but also is a significant predictor of differences in consumption patterns among them. The effects of familism on the Hispanic Acculturation Model have been discussed previously. The following analysis attempts to analyze familism among Hispanic and Anglo consumers. As previously stated, further screening processes reduced 
the sample size $\left(\mathrm{n}_{H}=377\right.$ and $\left.\mathrm{n}_{\mathrm{A}}=276\right)$ and replaced the missing values of the familism scale items with the corresponding mean values.

It was proposed that Hispanics are likely to have higher familism scores compared to Anglos, even after controlling for demographic differences $\left(\mathrm{H}_{9}\right)$. In order to test the differences among ethnic groups an ANCOVA analysis was performed. The familism scores were compared among Hispanic and Anglo consumers controlling for age, income, education, and the number of children consumers have. The results of the analysis are presented in Table 33. As expected, the familism scores between Anglo and Hispanic consumers differ significantly, even after controlling for demographic differences $\left(\mathrm{M}_{\mathrm{H}}=85\right.$ and $\left.\mathrm{M}_{\mathrm{A}}=76, \mathrm{~F}_{(1,566)}=62.89, \mathrm{p}<.001\right)$. All the demographic variables tested as covariates, with the exception of education, were significant. According to the results, ten percent of the variability of familism is explained by consumers' ethnicity $\left(\eta^{2}=.10\right)$, having a stronger effect than any of the demographic differences between the groups. Therefore, $\mathrm{H}_{9}$ is supported, and familism significantly discriminates Hispanic and Anglo consumers, beyond the differences granted by age, income, and number of children.

It was also proposed that the differences between Hispanic consumers born abroad and those who were born in the United Stated have significant differences in their familism scores, even after controlling for demographic differences $\left(\mathrm{H}_{10}\right)$. An analysis of covariance of familism controlling for demographic variables was conducted. As predicted, the familism scores between first and subsequent generations of Hispanic consumers differ significantly in the expected direction, after controlling for demographic differences $\left(\mathrm{M}_{1 \mathrm{st}}=86.3\right.$ and $\left.\mathrm{M}_{U S}=83.5, \mathrm{~F}_{1,281}=5.58 \mathrm{p}=.02\right)$. The results reported in 
Table 34 support previous findings in the literature (Sabogal et al. 1987; Montoro

Rodriguez and Kosloski 1998), suggesting that individuals born and raised under

traditional Hispanic values show higher familism scores compared to Hispanic consumers born in the United States. Therefore, it can be concluded that the results support $\mathrm{H}_{10}$, and the place of birth has a significant effect on familism.

Table 33

ANALISIS OF COVARIANCE OF FAMILISM BY ETHNICITY CONTROLLING FOR DEMOGRAPHIC VARIABLES

\begin{tabular}{|c|c|c|c|c|c|c|}
\hline Source & $\begin{array}{r}\text { Type III } \\
\text { Sum of Squ }\end{array}$ & df & $\begin{array}{l}\text { Mean } \\
\text { Square }\end{array}$ & $\mathbf{F}$ & Sig. & $\begin{array}{c}\text { Partial } \\
\eta^{2} \\
\end{array}$ \\
\hline Corrected Model & 16143.08 & 5 & 3228.62 & 33.39 & $<.001$ & 0.23 \\
\hline Intercept & 137090.85 & 1 & 137090.85 & 1417.67 & $<.001$ & 0.71 \\
\hline Number of children & 2640.21 & 1 & 2640.21 & 27.30 & $<.001$ & 0.05 \\
\hline Education & 130.42 & 1 & 130.42 & 1.35 & 0.25 & $<.001$ \\
\hline Income & 1048.07 & 1 & 1048.07 & 10.84 & $<.001$ & 0.02 \\
\hline Age & 518.63 & 1 & 518.63 & 5.36 & 0.02 & 0.01 \\
\hline Ethnicity (Anglo/Hispanic) & 6081.88 & 1 & 6081.88 & 62.89 & $<.001$ & 0.10 \\
\hline Error & 54733.26 & 566 & 96.70 & & & \\
\hline Total & 3830089.00 & 572 & & & & \\
\hline Corrected Total & 70876.34 & 571 & & & & \\
\hline
\end{tabular}

Table 34

ANALISIS OF COVARIANCE OF FAMILISM BY PLACE OF BIRTH CONTROLLING FOR DEMOGRAPHIC VARIABLES

\begin{tabular}{lllllll}
\hline \multicolumn{1}{c}{ Source } & \multicolumn{1}{c}{$\begin{array}{c}\text { Type III } \\
\text { Sum of Squares }\end{array}$} & $\begin{array}{l}\text { df } \\
\text { Square }\end{array}$ & $\begin{array}{c}\text { Mean } \\
\text { Squartial }\end{array}$ & F & $\begin{array}{c}\text { Sig. } \\
\eta^{2}\end{array}$ \\
\hline Corrected Model & 3619.57 & 5 & 723.91 & 6.47 & $<.001$ & 0.10 \\
Intercept & 83075.55 & 1 & 83075.55 & 742.26 & $<.001$ & 0.73 \\
Number of children & 556.31 & 1 & 556.31 & 4.97 & 0.02 & 0.02 \\
Education & 857.14 & 1 & 857.14 & 7.66 & 0.01 & 0.03 \\
Income & 343.83 & 1 & 343.83 & 3.07 & 0.08 & 0.01 \\
Age & 8.87 & 1 & 8.87 & 0.08 & 0.78 & $<.001$ \\
Place of Birth & 624.92 & 1 & 624.92 & 5.58 & 0.02 & 0.02 \\
Error & 31450.40 & 281 & 111.92 & & & \\
Total & 2102869.00 & 287 & & & & \\
Corrected Total & 35069.97 & 286 & & & & \\
\hline
\end{tabular}


Among Hispanic consumers the effects of education are significant (Table 34), while comparing among ethnic groups, education did not have an effect on the familism scores (Table 33). This result seems to suggest that the effects of education on familism are Hispanic specific. To determine if ethnicity moderates the effects of education on familism an ANCOVA analysis was conducted, controlling for income, age, and the number of children in the family. The results of the analysis are included in Table 35. When controlled for the other demographic differences, education does not have a significant main effect on familism, and the interaction is not significant. The results indicate that ethnicity does not moderate the effects of education on familism. These results contradict Cortés' (1995) findings. According to Cortés (1995) results, among Puerto Rican families, education is "the strongest variable affecting familistic beliefs ( $p$. 254).”

Table 35

ANALISIS OF COVARIANCE OF FAMILISM BY ETHNICITY AND EDUCATION CONTROLLING FOR INCOME, AGE AND NUMBER OF CHILDREN

\begin{tabular}{|c|c|c|c|c|c|c|}
\hline Source & $\begin{array}{r}\text { Type III } \\
\text { Sum of Squ } \\
\end{array}$ & df & $\begin{array}{l}\text { Mean } \\
\text { Square } \\
\end{array}$ & $F$ & Sig. & $\begin{array}{c}\text { Partial } \\
\eta^{2} \\
\end{array}$ \\
\hline Corrected Model & 16904.52 & 14 & 1207.47 & 12.46 & $<.001$ & 0.24 \\
\hline Intercept & 146214.69 & 1 & 146214.69 & 1508.96 & $<.001$ & 0.73 \\
\hline Number of children & 2413.66 & 1 & 2413.66 & 24.91 & $<.001$ & 0.04 \\
\hline Income & 1145.06 & 1 & 1145.06 & 11.82 & $<.001$ & 0.02 \\
\hline Age & 422.84 & 1 & 422.84 & 4.36 & 0.04 & 0.01 \\
\hline Education & 312.66 & 5 & 62.53 & 0.65 & $>.10$ & 0.01 \\
\hline Ethnicity & 1542.96 & 1 & 1542.96 & 15.92 & $<.001$ & 0.03 \\
\hline Education ${ }^{\star}$ Ethnicity & 490.32 & 5 & 98.06 & 1.01 & $>.10$ & 0.01 \\
\hline Error & 53971.82 & 557 & 96.90 & & & \\
\hline Total & 3830089.00 & 572 & & & & \\
\hline Corrected Total & 70876.34 & 571 & & & & \\
\hline
\end{tabular}

Hypotheses 11 and 12 proposed that familism is likely to be a significant predictor of brand loyalty, attitudes towards prestigious brands, and savings for their 
children's future. According to $\mathrm{H}_{11 \mathrm{a}}$, familism was likely to significantly predict brand loyalty for Hispanic and Anglo consumers. Referring to Chapter V, the only loyalty measure that showed significant differences between ethnic groups was the self reported loyalty measure (question 8 ). The brand loyalty measure was regressed on familism including Anglo and Hispanic consumers. According to the results included in Table 36, familism is a significant predictor of brand loyalty; however, the percentage of brand loyalty variability explained by familism is small, only $1 \%$. Given that familism among Hispanic consumers depends on the individuals' income, age, and education (Table 25), a second regression model was conducted that included the above demographic variables. According to the results presented in Table 36 (regression 2), familism continues to predict significantly brand loyalty along with income; age and education are not significant predictors. Moreover, the partial correlations suggest that familism contribution to the percentage of brand loyalty variability explained is larger compared to income ( $\mathrm{sr}_{\mathrm{F}}=.12$ and $\mathrm{sr}_{\mathrm{I}}=.08$, respectively). The effects of familism correspond to the expected ones; the higher the familism scores, the higher the loyalty. These results suggest that individuals' brand repetition behavior is related to their feelings of obligation and support to their family members. Given the results presented, it can be concluded that familism is a predictor of brand loyalty and $\mathrm{H}_{11 \mathrm{a}}$ is supported.

In order to test $\mathrm{H}_{11 \mathrm{~b}}$ the brand quality measure (c.f., Chapter V) was regressed on familism. The results are presented in Table 36 (regression 3). According to the results, familism is a significant predictor of individuals' attitudes towards high quality and prestigious brands. As expected, the higher the consumers' familism scores, the higher their preference for high quality and prestigious brands. Given that familism scores 
differed among income groups (Table 25), the brand quality measure was regressed on familism controlling for individuals' income, age, and education (Table 36, regression 4). The results indicate that familism is still significant, while none of the demographic variables have an effect on consumers' attitudes. However, the effect of familism on brand quality attitudes is small, according to the adjusted $R^{2}$ the percentage of variability explained by familism is only $1 \%$.

Table 36

REGRESSION MODELS OF BRAND LOYALTY, BRAND QUALITY ATTITUDES AND SAVINGS FOR CHILDREN'S FUTURE ON FAMILISM AND DEMOGRAPHIC VARIABLES

\begin{tabular}{|c|c|c|c|c|c|c|}
\hline & $\begin{array}{c}\text { Dependent } \\
\text { variable }\end{array}$ & $\begin{array}{c}\text { Independent } \\
\text { variable/s }\end{array}$ & $\begin{array}{l}\text { Standardized } \\
\text { coefficient/s }\end{array}$ & $t$ & Adj. $R^{2}$ & $\begin{array}{c}\text { Part } \\
\text { correlations }\end{array}$ \\
\hline 1 & Brand Loyalty & Familism & 0.1 & $2.45^{\star \star}$ & 0.01 & 0.1 \\
\hline 2 & Brand Loyalty & $\begin{array}{l}\text { Familism } \\
\text { Education } \\
\text { Income } \\
\text { Age }\end{array}$ & $\begin{array}{l}0.13 \\
0.02 \\
0.09 \\
0.00\end{array}$ & $\begin{array}{l}2.95^{\star \star} \\
0.38 \\
1.93^{\star} \\
0.02\end{array}$ & .013 & $\begin{array}{l}0.12 \\
0.02 \\
0.08 \\
<.001\end{array}$ \\
\hline 3 & Brand Quality Attitudes & Familism & 0.11 & $2.67^{\star \star}$ & 0.01 & 0.11 \\
\hline 4 & Brand Quality Attitudes & $\begin{array}{l}\text { Familism } \\
\text { Education } \\
\text { Income } \\
\text { Age }\end{array}$ & $\begin{array}{l}0.13 \\
0.06 \\
0.01 \\
0.05\end{array}$ & $\begin{array}{l}2.95^{\star \star} \\
1.32 \\
0.16 \\
1.12\end{array}$ & 0.01 & $\begin{array}{l}0.12 \\
0.05 \\
0.01 \\
0.05\end{array}$ \\
\hline 3 & Savings for children & Familism & 0.24 & $5.9^{\star \star \star}$ & 0.06 & 0.24 \\
\hline 4 & Savings for children & $\begin{array}{l}\text { Familism } \\
\text { Education } \\
\text { Income } \\
\text { Age } \\
\text { Number of children }\end{array}$ & $\begin{array}{c}0.16 \\
0.02 \\
-0.05 \\
-0.29 \\
0.14\end{array}$ & $\begin{array}{l}3.8^{\star \star *} \\
0.37 \\
-1.1 \\
-6.98^{\star \star \star} \\
3.35^{\star \star \star}\end{array}$ & 0.14 & $\begin{array}{l}0.15 \\
0.01 \\
-0.04 \\
-0.27 \\
0.13\end{array}$ \\
\hline
\end{tabular}

${ }^{*} \mathrm{p}<.05 ; * * \mathrm{p}<.01 ; * * * \mathrm{p}<.001$

The last hypothesis suggested that familism would be a significant predictor of individuals' savings for their children's future $\left(\mathrm{H}_{12}\right)$. Although this hypothesis seems 
similar to $\mathrm{H}_{5}$, in this case we are including not only Hispanic consumers, but also the Anglo consumers. The purpose of $\mathrm{H}_{12}$ is to determine if familism is a predictor of individuals' savings irrespective of their ethnicity. In order to test $\mathrm{H}_{12}$ savings for children's future was regressed on familism (Table 36, regression 5). The results support $\mathrm{H}_{12}$; familism is a significant predictor of individuals' savings for their children's future. The relationship is in the expected direction, as consumers' familism scores increase, their savings for their children increase as well, but the percentage of variability explained by familism is only $6 \%$. Again, we conducted a second regression analysis which included education, income, age, and number of children (Table 36, regression 6). Familism, age, and the number of children in the family affect the amount of money individuals' are willing to save for their children's future. Interesting enough, income and education are not significant predictors of individuals' savings allocation for their children. Familism and the number of children are positively related to the amount of money saved, while age is negatively related. The partial correlations indicate that familism and the number of children explain approximately the same proportion of variability of the amount of money saved for the children's future $\left(\mathrm{sr}_{\mathrm{F}}=.15\right.$ and $\mathrm{sr}_{\mathrm{\# C}}$ $=.13)$.

According to the literature, Hispanic consumers have distinctive brand loyalty, attitudes towards high quality and prestigious brands, and savings patterns (Deshpande, Hoyer, and Donthu 1986; Donthu, and Cherian 1992; Donthu, and Cherian 1994; Strategy Research 2002). This study has shown not only that familism discriminates 
Hispanic and Anglo consumers but also that familism is a significant predictor of consumers' brand loyalty, brand quality attitudes, and savings allocation variability.

\section{$\underline{\text { Acculturation Segments }}$}

In previous acculturation studies, one of the main contributions of studying the acculturation process among Hispanics was a typology of Hispanics according to their acculturation levels. This typology provides a characterization of individuals in line with their assimilation to American culture or retention of their Hispanic heritage. For example, according to Peñaloza's (1994) model (Figure 3) there are four acculturation outcomes: Assimilation, Maintenance, Resistance, and Segregation.

The present research employed SPSS TwoStep cluster analysis to develop this typology. The selection of the cluster used Schwarz's Bayesian criterion. The procedure automatically selected three clusters based on consumers' language preference, Hispanic and American identification, and familism. Table 37 shows the number of cases in the clusters as well as the mean values of the acculturation domains, and Figures 7 to 10 show simultaneous $95 \%$ confidence intervals of the acculturation dimensions by clusters.

Table 37

ACCULTURATION CLUSTER DISTRIBUTION

\begin{tabular}{lcccc}
\hline & & $\begin{array}{c}\text { Cluster } \\
\mathbf{1}\end{array}$ & $\begin{array}{c}\text { Cluster } \\
\mathbf{2}\end{array}$ & $\begin{array}{c}\text { Cluster } \\
\mathbf{3}\end{array}$ \\
\hline \hline & $\mathrm{N}$ & 66 & 82 & 183 \\
& $\%$ & 19.94 & 24.77 & 55.29 \\
Language & Mean & 30.63 & 69.39 & 32.13 \\
Preference & S.D. & 14.65 & 11.91 & 12.42 \\
& & & & \\
Familism & Mean & 80.64 & 90.12 & 84.16 \\
& S.D. & 9.55 & 10.11 & 10.75 \\
Hispanic & Mean & 13.63 & 18.79 & 18.71 \\
Identification & S.D. & 2.29 & 1.52 & 1.37 \\
American & Mean & 21.29 & 19.95 & 24.34 \\
Identificaiton & S.D. & 3.94 & 3.59 & 1.14 \\
& & & & \\
\hline
\end{tabular}


Cluster number one is characterized by consumers with a preference for English language, a familism score slightly bellow the average for Hispanics, approximately average identification with the American culture and a very low identification with their Hispanic heritage. According to Tables 37 and 38, these consumers represent $20 \%$ of the sample and, on average, belong to a second generation. Following the description of the acculturation outcomes provided in Chapter III, cluster one represents the group of consumers who can be considered highly acculturated; mostly are exposed to nonHispanic agents and chose to assimilate to the American culture by changing their language preferences, their Hispanic identification, and familism in order to adapt to their environment.

The second cluster can be best described as the low acculturation group. These consumers exhibit the highest preference for the use of Spanish language in different contexts; have the highest familism scores, show high identification with their Hispanic heritage, and the lowest identification with the American culture (Figures 7-10). On average, consumers in the second cluster have lower incomes and are first generation Hispanics. This group of Hispanics chose to have strong ties with their culture of origin, and is exposed to more Hispanic than non-Hispanic acculturation agents. In turn their desire to maintain contact with their culture of origin allows them to retain their preference for the Spanish language and familism. This cluster constitutes approximately $25 \%$ of the sample.

Finally, cluster number 3 corresponds to the bicultural individuals. This group of consumers exhibits a strong English language preference, an average familism score, and a high identification with American culture, just like the high acculturated cluster. 
However, contrary to cluster one, this group shows a very strong identification with its Hispanic heritage (Table 37). This is truly a confirmation of biculturalism. This group of consumers, who chose to change their language preference, maintains an average familism and identifies highly with both cultures. Cluster three accounts for $55 \%$ of the sample and its members are, on average, second generation Hispanics. This group of Hispanic consumers has, on average, the highest income levels and is exposed, on average, to Hispanic as well as non-Hispanic acculturation agents.

Table 38

ANALISIS OF VARIANCE OF DEMOGRAPHIC VARIABLES AND ACCULTURATION AGENTS BY CLUSTERS

\begin{tabular}{|c|c|c|c|c|c|}
\hline Test Variable & Mean & $\mathrm{n}$ & S. D. & ANOVA & Significance \\
\hline \multicolumn{6}{|l|}{ Generation } \\
\hline First Cluster & 1.87 & 54 & 0.80 & $F_{2,290}=39.8$ & $<.001$ \\
\hline Second Cluster & 1.16 & 82 & 0.40 & & \\
\hline Third Cluster & 1.99 & 157 & 0.77 & & \\
\hline \multicolumn{6}{|l|}{ Education } \\
\hline First Cluster & 3.80 & 65 & 1.15 & $F_{2,328}=1.92$ & $>.10$ \\
\hline Second Cluster & 3.76 & 82 & 1.60 & & \\
\hline Third Cluster & 4.05 & 182 & 1.18 & & \\
\hline \multicolumn{6}{|l|}{ Income } \\
\hline First Cluster & 2.98 & 66 & 0.98 & $F_{2,328}=5.11$ & $<.001$ \\
\hline Second Cluster & 2.79 & 82 & 1.26 & & \\
\hline Third Cluster & 3.31 & 183 & 1.35 & & \\
\hline \multicolumn{6}{|l|}{ Age } \\
\hline First Cluster & 39.85 & 66 & 10.20 & $F_{2,328}=1.46$ & $>.10$ \\
\hline Second Cluster & 40.45 & 82 & 9.91 & & \\
\hline Third Cluster & 38.37 & 183 & 9.65 & & \\
\hline \multicolumn{6}{|l|}{ Gender } \\
\hline First Cluster & 0.18 & 66 & 0.99 & $F_{2,328}=.13$ & $>.10$ \\
\hline Second Cluster & 0.10 & 82 & 1.00 & & \\
\hline Third Cluster & 0.14 & 183 & 0.99 & & \\
\hline \multicolumn{6}{|l|}{ Acculturation Agents } \\
\hline First Cluster & 23.80 & 66 & 5.38 & $F_{2,328}=40.65$ & $<.001$ \\
\hline Second Cluster & 16.96 & 82 & 4.11 & & \\
\hline Third Cluster & 21.71 & 183 & 5.03 & & \\
\hline
\end{tabular}


To summarize, based on individuals' language preference, familism, Hispanic identification, and American identification cluster analysis an acculturation typology was revealed. Hispanic consumers can be classified in one of three acculturation groups: high acculturated, low acculturated, and bicultural. Other acculturation conceptualizations have suggested that individuals exposed to an acculturation process could choose to marginalize and decrease their identification with their culture of origin and the dominant culture (Berry 1980; Padilla 1994; Peñaloza 1994). However, this study has not found any evidence that individuals choose to marginalize from both cultures. In all three clusters, individuals identify highly either with their culture of origin, America, or both cultures.

Figure 7

95\% CONFIDENCE INTERVALS OF LANGUAGE PREFERENCE BY CLUSTER

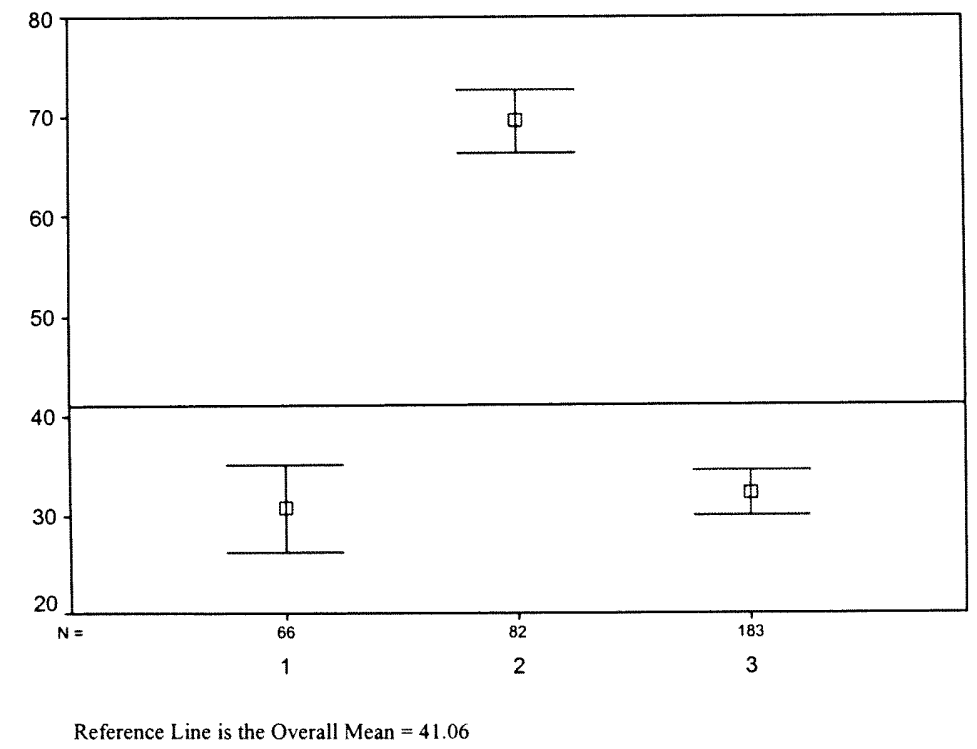


Figure 8

95\% CONFIDENCE INTERVALS OF FAMILISM BY CLUSTER

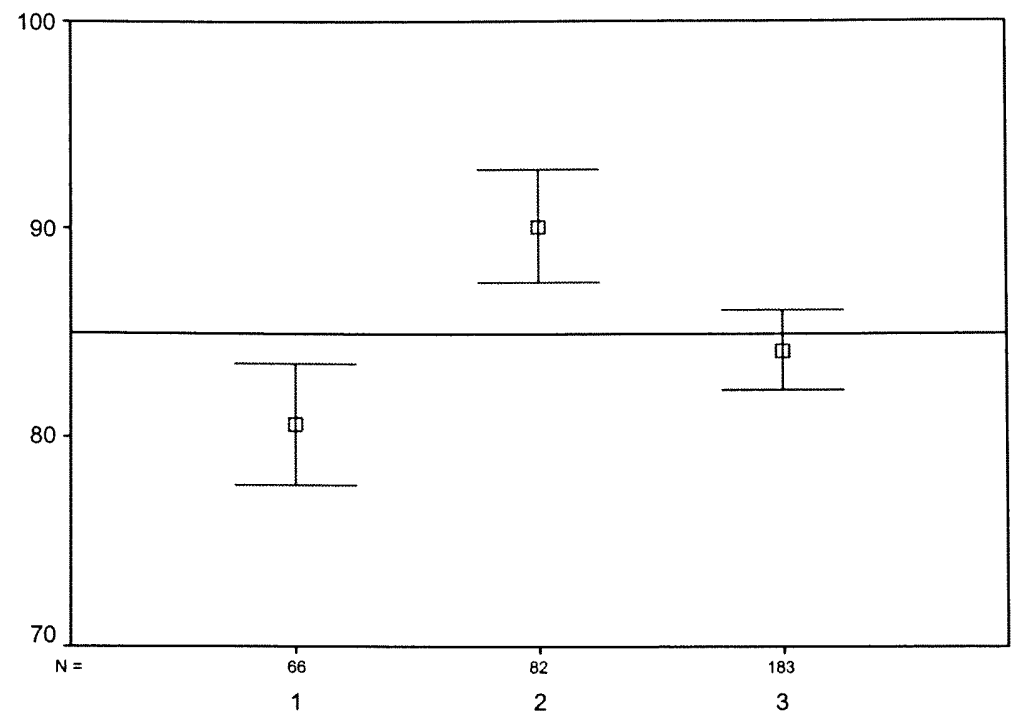

Reference Line is the Overall Mean $=84.93$

Figure 9

95\% CONFIDENCE INTERVALS OF HISPANIC IDENTIFICATION BY CLUSTER

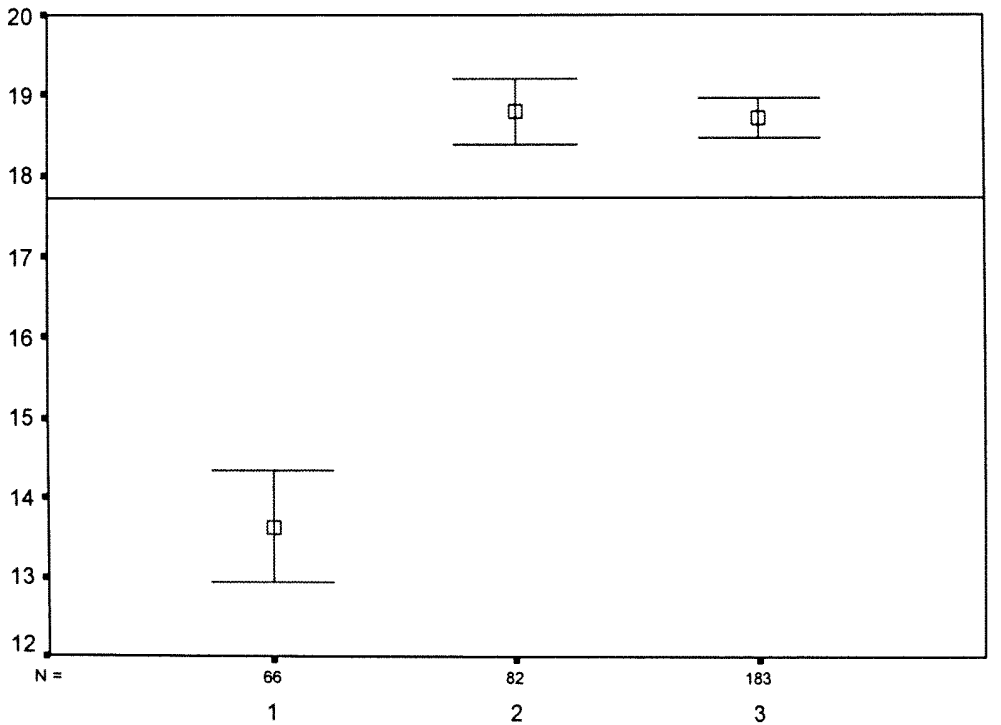

Reference Line is the Overall Mean $=17.72$ 
Figure 10

95\% CONFIDENCE INTERVALS OF AMERICAN IDENTIFICATION BY CLUSTER

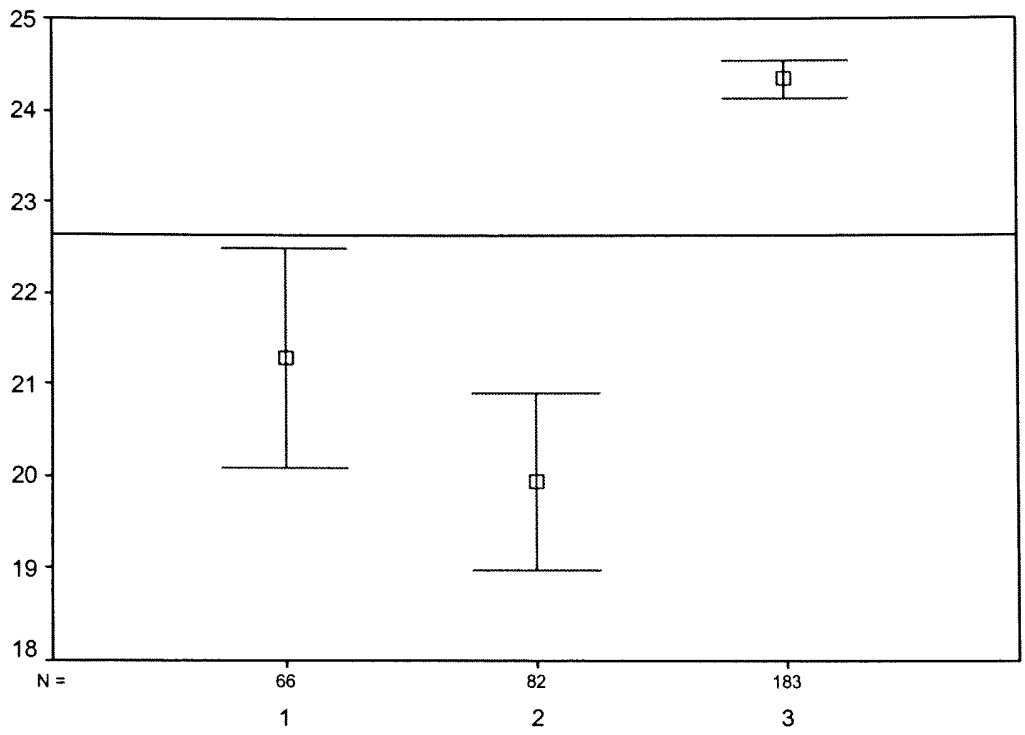

Reference Line is the Overall Mean $=22.65$ 


\section{CHAPTER VII}

\section{DISCUSSION}

Acculturation is a change/retention process, of behaviors, feelings of belonging, and values. Although previous studies in the Anthropology, Sociology, and Psychology fields have proposed acculturation is bilinear and multidimensional, no study appears to have intensively studied the relationship among the acculturation dimensions.

Furthermore, attempts to connect acculturation to consumer behavior are scant, even in the Marketing literature. The objectives of this study were twofold: develop a bilinear multidimensional acculturation scale and build a consumer acculturation model.

With the intention of developing a comprehensive acculturation scale and testing the acculturation model, two random samples were selected. The first sample was taken from a national consumer panel and the second was selected from a Spanish-dominant consumer panel. Only consumers with annual household income levels above $\$ 35,000$, before tax, were included in the sample. It was assumed that consumers with discretionary income above subsistence levels are likely to be able to make choices about brand quality and status. The efforts undertaken to ensure randomness and representativeness of the Hispanic market of the United States overcome the limitations of previous conceptualizations that were developed based on convenience samples of Hispanic consumers drawn primarily from a specific country of origin (e.g., Mexico).

In order to reflect the multidimensional characteristic of acculturation, the scale included four acculturation subscales: language preference, Hispanic identification, 
American identification, and familism. Previous acculturation scales were constructed by measuring each acculturation dimension reflecting two cultural orientations (Hispanic and American). A different approach was taken in this study. Individuals were able to express their language choice in a one-dimensional language preference scale; this was believed to be a measure that realistically reflected consumers' choices in a large number of social contexts. Ethnic identification was considered a bilinear construct, measured by asking individuals' their feelings towards America and their culture of origin. By doing so, consumers were able to express their desire to adapt to a new culture without implying a loss of their Hispanic origin. Finally, the familism scale was evolved from previous familism measures and new items developed to reflect the proposed familism concept. All the scales were initially analyzed by sample; after confirming that dimensional structure of the scales was similar between samples, they were analyzed jointly. The scales showed strong internal consistency and concurrent validity.

It was proposed that the acculturation process is initiated through the consumers' contact and exposure to Anglo acculturation agents. The results reported support the proposition; the exposure to Anglo agents showed a significant negative effect on consumers' Spanish language preference, Hispanic identification, and familism, and a significant positive effect on consumers' American identification. It can be concluded that individuals' exposure to the American/Hispanic culture through family, friends, coworkers, media, church, retail institutions, and marketing communication channels initiate the change/retention process. 
It was hypothesized that the acculturation agents would affect consumers' language preference change/retention first, and subsequently this process would affect consumers' ethnic identification and values. In accordance with the findings presented, as Hispanic consumers' choose to expose themselves to Anglo acculturation agents their preference for Spanish language decreased. The evidence suggests that language preferences mediate the effects of the acculturation agents on their American identification and familism. However, Hispanic consumers' feelings towards their Hispanic heritage are retained by their preference for Spanish language and their contact with Hispanic acculturation agents. These findings suggest that as Hispanic individuals increase their contact with Anglo agents, their first adaptive response generates change with their language preferences, and consequently change with their feelings of belonging to the American culture; however, change with language preference from Spanish to English does not necessarily imply a loss of the individuals' Hispanic identification. According to the results, individuals' Hispanic identification is not fully mediated by their language preference; it is also directly affected by the individuals' exposure to Hispanic acculturation agents. This result supports the biculturalism proposition. As consumers adapt to their new environment, the change/retention process of their language and feelings of belonging to the American culture do not fully determine their identification with their Hispanic heritage. The effects of Anglo agents on Hispanic consumers' familism are also mediated by their language preference. However, according to the study's findings, these effects are most evident in second and third generation immigrants. In summary, the evidence provided suggest that changes in individuals' language (behaviors) antecedes individuals' changes on deeper acculturation dimensions 
(ethnic identification and familism). These results, support Marín's (1992) and Gordon's (1964) propositions, that the adaptation process initially takes place with the individuals' language use and preferences, affecting more enduring acculturation dimensions, like ethnic identification and values, in later generations.

The acculturation process of Hispanic consumers was expected to have an effect on their consumer behavior. It was also hypothesized that the acculturation process could explain the differences between Hispanic and Anglo consumer behaviors reported in previous studies. According to the literature, Hispanic consumers are more loyal, have a preference for high quality and prestigious brands (Deshpande et al. 1986; Donthu and Cherian 1994; Donthu and Cherian 1992), shop more frequently (McArthur et al. 2001; Valdez 2002), and have different financial product possession and behavior (Strategy Research 2002), compared to Anglo consumers. However, the literature has also suggested some discrepancies referring to brand loyalty. For example, after conducting two studies designed to demonstrate that Mexican-American hold greater brand loyalty compared to non-Hispanics, Saegert et al. (1985) only found modest support for the proposition. On the other hand, their results lead us to conclude that Mexican-American consumers are more drawn to familiar stores and are more price-conscious. Other studies reported not finding brand loyalty based on scanner-data. Williams and Mulhern (1994) concluded "that [loyalty] does not manifest itself at the store level. Shoppers in Hispanic markets are as likely as other shoppers to substitute brands in response to retail price changes" (p. 247). In the present research the differences between Hispanic and Anglo consumers were either not found, very small, or did not change across generations. 
According to the results, there were small differences between Hispanic and Anglo consumers in one self-reported brand loyalty measure and consumers' attitudes towards high quality brands. However, among Hispanic groups there were no differences among generations, suggesting that this behavior does not acculturate (change). Other differences were found among Hispanic and Anglo consumers, in particular, their purchase frequency of cleaning and hygiene products. Hispanic consumers reported purchasing cleaning products more frequently compared to Anglo consumers. The scale used to measure purchase frequency reflected differences between both groups, from purchasing the products every two weeks, to purchasing the products once a month. However, this behavior, although distinctive of Hispanics, did not change significantly among generations, suggesting that it does not acculturate. From all the dependent measures only the amount of money saved for children's future was statistically different between Hispanic and Anglo consumers and across generations. This behavior is distinctive of Hispanics and as their contact with American culture increases, their savings for their children's future changes. Consequently, the acculturation model was tested only for savings for children's future.

According to the proposed model, individuals' ethnic identification and familism mediate the effects of language preference on their savings for children's future. The acculturation process of change/retention of language preference, through consumers' familism, and Hispanic and American identification, significantly affected Hispanic consumers' savings allocation patterns. However, the results showed that language preference not only has an effect on the consumers' savings allocation through their 
ethnic identification and familism, but also has a direct effect, suggesting that the mediation of ethnic identification (Hispanic and American) and familism is partial.

The acculturation model proposed that the effects of the acculturation agents on consumers' language preferences were moderated by individual differences. In particular, it was hypothesized that consumers' gender, age, and country of origin moderated individuals' language choice. The results did not support the former propositions; consumers' exposure to Anglo agents and the subsequent effects on their language preference is neither affected by their gender, age, nor country of origin. Previous propositions arguing that gender roles and age differences among Hispanic consumers produced different socialization patterns, and subsequently, reduced/increased contact with Anglo agents, were not supported. Szapocznik et al.'s (1978) results suggested that male Hispanic individuals acculturated faster than females, and that young Hispanics acculturated faster than older Hispanics. However, the conclusions were based on a onedimensional acculturation model that measured individuals' language use and other behaviors, such as music and food consumption. The results reported in this study support Cuéllar, Arnold, and Maldonado's (1995) findings that are based on a bilinear multidimensional acculturation scale. In both studies the nature of their sample could not allow generalization of their results. On the one hand, Cuéllar, Arnold, and Maldonado (1995) studied a student sample of Mexican Americans, varying in socioeconomic status, and proportionally both genders. On the other hand, Szapocznik et al.'s (1978) samples were drawn from the Miami area, consisting mainly of Cuban American HIspanics, with a wide range of ages from 14 to 85 . The nature of the sample studied by Szapocznik et al. (1978) and their reported results suggest that the moderation effects of age and gender 
could be culture specific. In other words, the effects of age and gender could interact with consumers' country of origin.

Given the nature of the sample, the study could not conclude whether individuals' country of origin (Mexico, Cuba, or Puerto Rico) had significant impact on their acculturation process. The test was simplified to compare Mexican consumers and other Hispanics. According to the results, consumers with a Mexican heritage do not differ significantly from Hispanic consumers with a different heritage. Hispanic consumers' exposure to Anglo agents and their language preferences are not significantly different between consumers with a Mexican heritage and consumers with other Hispanic heritages.

The effects of familism were further investigated among ethnic groups. The Familism scores were significantly different between Anglo and Hispanics; additionally, a significant difference between first and subsequent generations of Hispanics was found. It was also tested whether education had an effect on familism and if it was distinctive of Hispanic consumers. According to the results, education has no effect on familism, nor is it a culture specific Hispanic effect. These results contradict Cortés' (1995) findings, which suggest that education is the strongest variable affecting familism across generations. However, Cortés' (1995) findings were obtained from a sample of PuertoRican Americans, and the present study is based on a sample representing the national Hispanic population. 
The consumer behaviors that were significantly different between Hispanics and Anglos were regressed on familism, controlling for demographic differences. Familism predicted significantly consumers' brand loyalty, attitudes towards high quality and prestigious brands, and money saved for children's future, even after controlling for demographic variables. Moreover, the effects of familism on the dependent measures were higher than the effects of income and education.

The acculturation dimensions were employed to develop a typology of Hispanic consumers. Three segments or clusters were found. One segment can be best described as highly acculturated individuals, showing preference for English language, a familism score slightly bellow the average for Hispanics, approximately average identification with the American culture, and a very low identification with their Hispanic heritage. The second cluster represents the low acculturated consumers, they exhibit a preference for the Spanish language, have the highest familism scores, show high identification with their Hispanic heritage, and the lowest identification with the American culture. Finally the third segment can be best described as bicultural consumers. This segment exhibits a strong English language preference, an average familism score and a high identification with the American and their corresponding culture of origin. This findings support previous studies where biculturalism is suggested (Mendoza 1989; Perez and Padilla 2000; Cortés et al. 1994; Cuéllar, Arnold, and Maldonado 1995; Marín and Gamba 1996; Szapocznik, Kurtines and Fernandez 1980). 


\section{Limitations and Future Research}

The present research is not without its limitations. It should be noted again that only upper income Hispanic households were studied. They are of most interest to consumer researchers and marketers as Hispanic incomes rise but they do not represent the great majority of first generation Hispanics whose incomes are below $\$ 35,000$ and who have minimal discretionary income. Throughout the analysis, it was made evident that even among Hispanic consumers with household incomes above $\$ 35,000$, income affected their acculturation process; individuals' exposure to Anglo acculturation agents, language preferences, American identification, and familism showed significant differences between income groups. Future evaluations of the acculturation model should include lower income Hispanic consumers, and test the moderating effects of income.

Contrary to what was expected, individuals' acculturation process was not affected by their country of origin. It was proposed that cultural differences among groups of Hispanics would affect their exposure to Anglo acculturation agents, and therefore, affect their language preferences. This conceptualization assumed that individuals' differences could only impact their acculturation process through their language preferences. However, the moderating variables could affect consumers' ethnic identification as well as their language preferences. Take, for example, individual's motives of immigration; it is likely that individuals' with political motives consider themselves an exile group, and hence, they fail to adopt America as their new home. On the other hand, immigrants with economical motives seek to generate a new and better life for their families. These differences could affect consumers' feelings of belonging 
and identification with the American culture and eventually affect their consumption patterns. Future research could determine the effects of motivation for entry on individuals' ethnic identification and their consumption patterns.

The model presented only included one consumer behavior, savings allocation for children's future. Other consumer behaviors that are claimed to be distinctive among Hispanic consumers were studied in this research but the predicted effects were not observed and need further study. The understanding of Hispanic consumers' behavior needs to move towards including more measures of cultural change by integrating additional cross-cultural values. Future research could attempt to test the model for other consumer behaviors, and include other values distinctive of the Hispanic consumers that could affect their consumption patterns.

Additional research could determine the extent of the effects of familism in other marketing contexts. For example, familism could be used for tailor marketing communications to Hispanic consumers of all generations. By using familism as a core value, Hispanic consumers are likely to feel more identified with the communication, as they would feel towards a communication targeted to the general market.

Research on Hispanic consumers' responses and attitudes towards direct marketing is scant, but suggest two main findings; on the one hand, marketing practitioners claim that "Hispanic households are 3.5 times more likely to respond to a direct marketing solicitation than non-Hispanic households, and $72 \%$ say they always read their mail, including direct marketing" (Sonderup 2004). On the other hand, research 
in the marketing literature suggests that although Hispanics, in general, hold positive overall attitudes towards direct marketing advertising, the assimilated Hispanic group hold more positive attitudes towards direct marketing advertising and is more prone to order items from print media compared to the less assimilated Hispanics (Korgaonkar, Karson, and Lund 2000). Several questions arise. Are Hispanic and Anglo consumers' responses towards direct marketing different? If different, does it change as individuals' increase their exposure to the American consumer environment? What causes these differences? Are they associated to the direct marketing media used? Are they associated to a culture specific characteristic or value?

A replication of the acculturation model including responsiveness towards direct marketing and direct selling as dependent measures could answer the previous research questions. It is proposed that "simpatía" a distinctive Hispanic value representing a personal quality that promotes behaviors that generate smooth and pleasant social relationships (Marin and Triandis 1985), is likely to influence Hispanic consumer responsiveness to direct personal selling but not direct marketing that does not involve personal interaction. This value has been shown to influence the behavior of Hispanic salespeople (Comer and Nicholls 2000) but the influence of this value on the behavior of Hispanic consumers has not been studied.

In closing, it is believed that the present study offers some new insights into an important segment of the American multicultural consumer market. By providing evidence on the relationships and effects of the four acculturation dimensions and the corresponding scales, this research has provided a baseline on which future investigations 
could explore other topics and provide answers to the essential questions: how are Hispanic consumers different? And why? 


\section{LIST OF REFERENCES}

Allen, Michael W. (2001), "A Practical Method for Uncovering the Direct and Indirect Relationships Between Human Values and Consumer Purchases," The Journal of Consumer Marketing, 18 (2), 102-113.

, Sik Hung Ng, and Marc Wilson (2002), "A Functional Approach to Instrumental and Terminal Values and the Value-Attitude-Behavior System of Consumer Choice," European Journal of Marketing, 36, 1/2, 111-135.

Bardis, Panos D. (1959), “A Familism Scale,” Marriage and Family Living, 21 (4), 340341.

Beiser, M. (2000), Strangers at the Gate, Toronto: University of Toronto Press.

Berry, John W. (1980), "Acculturation as Varieties of Adaptation," in Acculturation: Theory, Models, and Findings, Padilla A. ed., Boulder CO: Westview, 9-25. (2003), "Conceptual Approaches to Acculturation," in Acculturation: Advances in Theory, Measurement and Applied Research, Chun Kevin M., Pamela Balls Organista and Gerardo Marín eds., Washington, DC: American Psychological Association, 17-37.

, J. Trimble, and E. Olmedo (1986), "Assessment of Acculturation," in Field Methods in Cross-cultural Research, Loner W. J. and John W. Berry Eds., Beverly Hills: CA, Sage Publications, p 291-324.

Berman, Gary (2003), "Multicultural Marketing," The Miami Herald, April 7 2003, $22-$ 26.

Brown, Sandy (2004), “A New Portrait of Hispanic Consumers,” Adweek, 45(19), 10.

Cabasa, Leopoldo J. (2003), "Measuring Acculturation: Where We Are and Where We Need to Go," Hispanic Journal of Behavioral Sciences, 25 (2), 127-146.

Cavalcanti, H. B. and Debra Schleef (2001), "The Melting Pot Revisited: Hispanic Density and Economic Achievement in American Metropolitan Regions," Hispanic Journal of Behavioral Sciences, 23 (2) 115-135.

Chun, Kevin M., Pamela Balls Organista, and Gerardo Marín (2003), Acculturation: Advances in Theory, Measurement and Applied Research, Washington, DC: American Psychological Association. 
Cohen, Jacob and Patricia Cohen (1983), Applied Multiple Regression/Correlation Analysis for the Behavioral Sciences, Hillsdale, New Jersey: Lawrence Erlbaum Associates.

Comer Lucette B. and J. A. F. Nicholls (2000) "Communication Between Hispanic Salespeople and Their Costumers: A First Look," Journal of Personal Selling and Sales Management, 20 (Summer), 121-127

Cortés, D.E., L. H. Rogler, and R. G. Malgady (1994), "Biculturality Among Puerto Rican Adults in the United States," American Journal of Community Psychology, $22,707-721$.

Cuéllar, Israel, Bill Arnold, and Roberto E. Maldonado (1995), "Acculturation Rating Scale for Mexican Americans-II: A Revision of the Original ARSMA Scale," Hispanic Journal of Behavioral Science, 17 (3), 275-304.

, Bill Arnold, and Genaro González (1995), "Cognitive referents of Acculturation: Assessment of Cultural Constructs in Mexican Americans," Journal of Community Psychology, 23 (October), 339-356.

, Bill Nyberg, Roberto E. Maldonado, and Robert E. Roberts (1997), "Ethnic Identity and Acculturation in a Young-Adult Mexican-Origin Population," Journal of Community Psychology, 25, 535-549.

Daghfous, Naoufel, John V. Petrof, and Frank Pons (1999), "Values and Adoption of Innovations: A Cross-Cultural Study," The Journal of Consumer Marketing, 16 (4), 314-327.

Delener, Nejdet and Herbert Katzenstein (2000), "Credit Card Possession and Other Payment Systems: Use Patterns Among Asian and Hispanic Consumers," The International Journal of Bank Marketing, 12 (4), 13-26.

Deshpande, Rohit, Wayne D. Hoyer, and Naveen Donthu (1986), "The Intensity of Ethnic Affiliation: A Study of the Sociology of Hispanic Consumption," Journal of Consumer Research, 21 (September), 214-20.

Díaz-Guerrero, Rogelio (1968) "The Active and Passive Syndromes," Revista Interamericana de Psychologia, 263-272.

(1972), "Una Escala Factorial de Premisas Histórico-Socioculturales de la Familia Mexicana," Revista Interamericana de Psicología, 6, (3-4), 235-244.

and L. B. Szalay (1993), El Mundo Subjetivo de los Mexicanos y los Norteamericanos, Mexico City: Trillas. 
Díaz-Loving R. and Juris G. Draguns (1999), "Culture, Meaning and Personality in Mexico and in the United States," in Personality and Person Perceptions Across Cultures, Yue-Ting Lee, Clark R. McCauley and Juris G. Draguns, eds., Mahwah, NJ: Lawrence Erlbaum Associates, 103-126.

Donthu, Naveen and Joseph Cherian (1992), "Hispanic Coupon Usage: The Impact of Strong and Weak Ethnic Identification," Psychology and Marketing, 9(6), 501-510.

(1994), "Impact of Strength of Ethnic Identification on Hispanic Shopping Behavior," Journal of Retailing, 70 (4), 383-393.

Eckert, Penelope (1984), "Age and Linguistic Barriers," in Age and Anthropological Theory, David I. Kertzer and Jennie Keith, eds., London: Cornell University Press, 219-233.

Félix-Ortiz, M., M. D. Newcomb, and H. Myers (1994), "A Multidimensional Measure of Cultural Identity for Latino and Latina Adolescents," Hispanic Journal of Behavioral Sciences, 16, 99-114.

Freeberg, Andrew L. and Catherine H. Stein (1996) "Felt Obligation Towards Parents in Mexican-American and Anglo-American Young Adults," Journal of Social and Personal Relationships, 13 (3), 457-471.

Gordon, Milton M. (1964), Assimilation in the American Life: The Role of Race, Religion, and National Origins, New York: Oxford University Press.

Grønhaug, Kjell, Mary Gilly, and Lisa Peñaloza (1993), "Barriers and Incentives in Consumer Acculturation," European Advances in Consumer Acculturation, 1, 278286.

Heller, Peter L. (1976), "Familism Scale: Revalidation and Revision," Journal of Marriage and the Family, 38(3), 423-429.

Henry, Walter A. (1976), "Cultural Values Do Correlate With Consumer Behavior," Journal of Marketing Research, 13 (May), 121-127.

Hirschman, Elizabeth C. (1981), "American Jewish Ethnicity: Its Relationship to Some Selected Aspects of Consumer Behavior," Journal of Marketing, 45 (Summer), 102-110.

Hofstede, Geert (1980), Culture's Consequences, International Differences in Working Related Values, Beverly Hills, CA: Sage.

Jun, Sunkyu, A. Dwayne Ball, and James W. Gentry (1993), "Modes of Consumer Acculturation," Advances in Consumer Research, 20, 76-82. 
Kagan, Spencer (1977), "Social Motives and Behaviors of Mexican-American and Anglo-American Children," in Chicano Psychology, Joel L. Martinez Jr. ed., New York: Academic Press Inc., 45-86.

Kahle, Lynn R. (1983), Social Values and Social Change: Adaptation to Life in America, New York, NY: Praeger Publishers.

, Sharon E. Beatty, and Pamela M. Homer (1985), "Alternative Measurement Approaches to Consumer Values: The List of Values (LOV) and Values And Life Style (VALS)," Journal of Consumer Research, 13 (December), 405-409.

and Patricia Kennedy (1988), "Using the List of Values (LOV) to Understand Consumers," Journal of Services Marketing, 2 (4), 49-56.

Kara, Ali and Natasha R. Kara (1996), "Ethnicity and Consumer Choice: A Study of Hispanic Decision Process Across Different Acculturation Levels," Journal of Applied Business Research, 12 (2), 22-34.

Keefe, Susan E. (1980) "Acculturation and the Extended Family Among Urban Mexican Americans," in Acculturation: Theory, Models and Some New Findings, Padilla Amado ed., Boulder, CO: Westview Press, 85-110.

Kim, B. S. K., and J. M. Abreu (2001), "Acculturation Measurement: Theory, Current Instruments and Future Directions" in Ponterotto J. G., J. M. Casas, L. A. Suzuki and C.M. Alexander eds., Handbook of Multicultural Counseling, Thousand Oaks, CA: Sage, $2^{\text {nd }}$ edition., 394-424.

Korgaonkar, Pradeep, Eric J. Karson, and Daulatram Lund (2000), "Hispanics and Direct Marketing Advertising,” The Journal of Consumer Marketing, 17 (2), 137-157.

Laroche, Michael, Chankon Kim, Michael K. Hui, and Annamma Joy (1996), “An Empirical Study of Multidimensional Ethnic Change," Journal of Cross-Cultural Psychology, 27 (1), 114-131.

Mann, Joseph (2003), "Study Shows Hispanics' Purchasing Power to Outpace Nation's Through 2020," http://www.shccnj.org/hispanic\%20purchasing\%20powe.htm

Marín, Gerardo and Raymond Gamba (1996), "A New Measurement of Acculturation for Hispanics: The Bidimensional Acculturation Scale for Hispanics (BAS)," Hispanic Journal of Behavioral Science, 18 (3), 297-316.

, Fabio Sabogal, Barbara VanOss Marín, Regina Otero-Sabogal, and Eliseo J. Perez-Stable (1987), "Development of a Short Acculturation Scale for Hispanics," Hispanic Journal of Behavioral Sciences, 9 (2), 183-205. 
and Harry C. Triandis (1985), "Allocentrism as an Important Characteristic of the Behavior of Latin Americans and Hispanics," in Cross-Cultural and National Studies in Social Psychology, R. Díaz Guerrero ed., North Holland: Elsevier Science Publishers B.V., 85-103.

(1992), "Issues in the Measurement of Acculturation Among Hispanics," in Psychological Testing of Hispanics, Geisinger Kurt F. ed., Washington DC: American Psychological Association, 235-251.

Markus, H. R. and S. Kitayama (1991), "Culture and the Self: Implications for Cognition, Emotion, and Motivation," Psychological Review, 98, 224-253.

Maslow, Abraham H. (1954), Motivation and Personality, New York: Harper.

McArthur, Laura H., Ruben P. Viramontez Anguiano, and Diego Nocetti (2001), "Maintenance and Change in the Diet of Hispanic Immigrants in Eastern North Carolina," Family and Consumer Sciences Research Journal, 29(4), 309-335.

McCracken, Grant (1986), "Culture and Consumption: A Theoretical Account of the Structure and Movement of the Cultural Meaning of Consumer Goods," Journal of Consumer Research, 13 (June), 71-84.

Mendoza, Richard H. (1989), "An Empirical Scale to Measure Type and Degree of Acculturation in Mexican-American Adolescents and Adults," Journal of CrossCultural Psychology, 20 (4), 372-385.

Mitchell, Arnold (1983) The Nine American Life Styles, New York: Warner.

Montoro Rodriguez, Julian and Karl Kosloski (1998), "The Impact of Acculturation on Attitudinal Familism in a Community of Puerto Rican Americans," Hispanic Journal of Behavioral Sciences, 20 (3), 375-390.

Nicholls, J. A. F. and Peter Roslow (1996), "Main Message Retention: How Important is Language When Advertising to Hispanics," Marketing Research, 8 (1), 39-45.

Norris, Anne E., Kathleen Ford, and Carol A. Bova (1996), "Psychometrics of a Brief Acculturation Scale for Hispanics in a Probability Sample of Urban Hispanic Adolescents and Young Adults," Hispanic Journal of Behavioral Sciences, 18 (1), 29-38.

Oswald, Laura R. (1999), "Culture Swapping: Consumption and the Ethnogenesis of Middle-Class Haitian Immigrants," Journal of Consumer Research, 25 (March), 303-318. 
Padilla, Amado M. (ed.) (1980), Acculturation: Theory Models and Some New Findings, Boulder, Colorado: Western Press.

(1994), "Bicultural Development: A Theoretical and Empirical Evaluation," in Theoretical and Conceptual issues in Hispanic Mental Health, Malgaday Robert and Rodriguez Orlando eds., Malabar, FL: Krieger Publishing Co. Inc., 20-51.

and William Perez (2003), "Acculturation, Social Identity, and Social Cognition: A New Perspective," Hispanic Journal of Behavioral Science, 25 (February), 35-55.

Parker, Betty J. (1999), "The Consumer Behavior of Hispanic Populations in the United States," Journal of Segmentation in Marketing, 3 (2), 61-78.

Paulin, Geoffrey D. (2001), "Variation in Food Purchases: A Study of Inter-Ethnic and Intra-Ethnic Group Patterns Involving the Hispanic Market," Family and Consumer Sciences Research Journal, 29 (4), 336-341.

Peñaloza, Lisa (1994), “Atravesando Fronteras/Border Crossings: A Critical Ethnographic Exploration of the Individual Acculturation of Mexican Immigrants," Journal of Consumer Research, 21 (June), 32-54.

and Mary C. Gilly (1999), "Marketer Acculturation: The Changer and the Changed," Journal Marketing, 63 (July), 84-104.

Perez, William and Amado M. Padilla (2000), "Cultural Orientation Across Three Generations of Hispanic Adolescents," Hispanic Journal of Behavioral Sciences, 22 (3), 390-398.

Petroshius, Susan M., Stephen J. Newell, and Steven J. Ross (1995), "The Role of Hispanic Acculturation on Media Exposure, Coupon Use, and Brand Loyalty" MidAmerican Journal of Business, 10 (2), 35-44.

Phinney, Jean S. (2003), "Ethnic Identity and Acculturation," in Acculturation: Advances in Theory, Measurement, and Applied Research, Chun, Kevin M., Pamela Balls Organista, and Gerardo Marín eds., Washington DC: American Psychology Association, 63-81.

Ramirez, A. G., Jennifer Cousins, Yolanda Santos, and Josie D. Supik (1986), “A MediaBased Acculturation Scale for Mexican-Americans: Application to Public Health Education Programs," Journal of Family Community and Health, 9 (3), 63-71.

Ramirez, Oscar (1990), "Mexican American Children and Adolescents," in Children of Color, J. T. Gibbs and L. N. Huang eds., San Francisco CA: Jossey-Bass, 224-250. 
Ramirez, Roberto R. and G. Patricia de la Cruz (2003), "The Hispanic Population in the United States: March 2003," Current Population Reports, Washington DC: Census Bureau, 20-545.

Redfield, R., R. Linton, and M. Herskovits (1936), "Memorandum on the Study of Acculturation," American Anthropologist, 38, 149-152.

Rodríguez, Julián Montoro and Karl Kosloski (1998) "The Impact of Acculturation on Attitudinal Familism in a Community of Puerto Rican Americans," Hispanic Journal of Behavioral Sciences, 20 (3), 375-390.

Rokeach, Milton (1973), The Nature of Human Values, New York, NY: Free Press.

Sabogal, Fabio, Gerardo Marín, and Regina Otero-Sabogal, (1987) "Hispanic Familism and Acculturation: What Changes and What Doesn't?," Hispanic Journal of Behavioral Sciences, 9 (4), 397-412.

Saegert, Joel, Robert J. Hoover, and Marye Tharp Hilger (1985), "Characteristics of Mexican-American Consumers," Journal of Consumer Research, 12 (June), 104109.

Schwartz, Shalom H. (1994a), "Beyond Individualism/Collectivism: New Cultural Dimensions of Values," in Individualism and Collectivism: Theory, Method and Applications, Kim, Uichol, Harry C. Triandis, Cigdem Kagitcibasi, Sang-Chin Choin, and Gene Yoon, eds., Thousand Oaks, CA: Sage, 85-119.

(1994b), "Are There Universal Aspects in the Structure and Contents of Human Values?” Journal of Social Issues, 50 (4), 19-45.

and Wolfgang Bilsky (1987), "Towards a Universal Psychological Structure of Human Values," Journal of Personality and Social Psychology, 53 (3), 550-562.

and Wolfgang Bilsky (1990), "Towards a Theory of the Universal Content and Structure of Values: Extensions and Cross-Cultural Replications," Journal of Personality and Social Psychology, 58 (5), 878-891.

Schopphoven, Iris (1991), "Values and Consumption Patterns: A Comparison between Rural and Urban Consumers in Western Germany," European Journal of Marketing, 25 (12), 20-35.

Scott, Jerome E. and Lawrence M. Lamont (1973), "Relating Consumer Values to Consumer Behavior: A Model and Method for Investigation," in Increasing Marketing Productivity, Greer, T.W. ed., Chicago, IL: American Marketing Association, 283-288. 
Skinner, John H. (2002), "Acculturation: Measures of Ethnic Accommodation to the Dominant American Culture" in Multicultural Measurement in Older Populations, Skinner, John H., Teresi, Jeanne A., Douglas Holmes, Sidney M. Stahl, and Anita L. Stewart, eds., New York, NY: Springer Publishing Co, 37-51.

Social Science Research Council (1954), "Acculturation: An Exploratory Formulation," American Anthropologist, 56, 973-1002.

Sonderup, Laura (2004) "Hispanic Marketing: A Critical Market Segment," Advertising and Marketing Review, http://www.ad-mkt-review.com, April 2004

Soriano, E. and D. Dauten (1985), "Hispanic Dollar Votes Can Impact Market Shares," Marketing News, September 13, 45-46.

Stayman, Douglas M. and Rohit Deshpande (1989), "Situational Ethnicity and Individual Behavior," Journal of Consumer Research, 16 (December), 361-371.

Strategy Research Corporation (2002), 2002 U.S. Hispanic Market Report.

Suarez-Orozco, M. (2001), "Everything You Wanted to Know About Assimilation But Were Afraid to Ask," in The Free Exercise of Culture, Shweder R., M. Minow and H. Markus eds., New York, NY: Russell Sage Publications, 1-30.

Synovate (2004), 2004 U. S. Hispanic Market Report.

Szapocznik Jose, Mercedes Arca Scopetta, William Kurtines, and Maria de los Angeles Andrade (1978), "Theory and Measurement of Acculturation," International Journal of Psychology, 12, 113-130.

, William Kurtines, and T. Fernandez (1980) "Bicultural Involvement and Adjustment in Hispanic American Youths," International Journal of Intercultural Relations," 4, 3553-365

Therrien, Melissa and Roberto R. Ramirez (2000), "Current Population Reports U.S.," Washington DC: Census Bureau, 20-535

Torres-Matrullo, Christine M. (1980), "Acculturation, Sex-Role, Values and Mental Health Among Mainland Puerto Ricans," in Acculturation: Theory, Models, and Findings, Padilla A. ed., Boulder, CO: Westview, 111-137.

Triandis, Harry C., Christopher McCusker, and C. Harry Hui (1990) "Multimethod Probes of Individualism and Collectivism," Journal of Personality and Social Psychology, 59 (5), 1006-1020. 
Trimble, Joseph E. (2003) "Social Change and Acculturation," in Acculturation: Advances in Theory, Measurement, and Applied Research, Chun, Kevin M., Pamela Balls Organista, and Gerardo Marín eds., Washington DC: American Psychology Association, 3-13.

Valencia, Humberto (1989), "Hispanic Research and Subcultural Research,” Journal of the Academy of Marketing Science, 17 (1), 23-38.

Valdez, Isabel M. (2002), Marketing to American Latinos: A Guide to the In-Culture Approach, New York, NY: Paramount Market Publishing Inc.

Vega, William A. (1995), “The Study of Latino Families," in Understanding Latino Families, Zambrana Ruth E. ed., Thousand Oaks, CA: Sage Publications, 3-17.

Vinson, David E., Jerome E. Scott, and Lawrence Lamont (1977), “The Role of Personal Values in Marketing and Consumer Behavior," Journal of Marketing, 41 (April), 44-50.

Webster, Cynthia (1991), "Attitudes towards Marketing Practices: The Effects of Ethnic Identification," The Journal of Applied Business Research, 7 (2), 107-115.

(1992), "The Effects of Hispanic Subcultural Identification on Information Search Behavior," Journal of Advertising Research, (September/October), 54-61

(1994), "Effects of Hispanic Identification on Marital Roles in the Purchase Decision Process" Journal of Consumer Research, 21 (September), 319-331.

(1997), "Resource Theory in a Cultural Context: Linkages Between Ethnic Identity, Gender Roles, and Purchase Behavior," Journal of Marketing Theory and Practice, 5 (1), 1-6.

Williams, Jerome D. and Francis J. Mulhern (1994), "A Comparative Analysis of Shopping Behavior in Hispanic and Non-Hispanic Market Areas," Journal of Retailing, 70 (3), 231-251.

Zane, Nolan and Winnie Mak (2003), "Major Approaches to the Measurement of Acculturation Among Ethnic Minority Populations: A Content Analysis and an Alternative Empirical Strategy," in Acculturation: Advances in Theory, Measurement, and Applied Research, Chun, Kevin M., Pamela Balls Organista, and Gerardo Marín, eds., Washington, DC: American Psychology Association, 39-60.

Zea, Maria Cecilia, Kimberly K. Asner-Self, Dina Birman, and Lydia P. Buki (2003), "The Abbreviated Multidimensional Acculturation Scale: Empirical Validation with Two Latino/Latina Samples," Cultural Diversity and Ethnic Minority Psychology, 9 (2), 107-126. 
APPENDIX 1

ENGLISH QUESTIONNAIRE VERSION ONE 


\section{0 \\ synovate}

Consumer Opinion Panel

Dear Panel Member,

Please give the questionnaire to the person whose age and gender appear above.

Today we are sending you a questionnaire about you and your household that we would like you to complete for us.

The questionnaire is short and I'm sure you will find it very easy to answer. Once you have completed the questionnaire, please return it in the enclosed postage-paid envelope.

Thank you for your help.

Cordially,

Marie Brighton 
Please indicate your language preference on the following statements. ("X" ONE BOX FOR EACH STATEMENT)

When speaking to children in my family, I prefer to speak.......

$\begin{array}{cc}\text { SPANISH } & \text { SPANISH } \\ \text { ALL THE } & \text { MOST OF } \\ \text { TIME } & \text { THE TIME }\end{array}$

SPANISH

TIME

THE TIME

When speaking to my friends, I prefer speak

$\mathrm{B}_{5}$

$\mathrm{B}_{4}$

ENGLIS

EQUALLY

ENGLISH ENGLISH

UALLY THE TIME TIME

When speaking to my grandparents, I prefer to speak

$\mathrm{B}_{5}$

$\mathrm{B}_{3}$

$\mathrm{B}_{2}$

$\mathrm{B}_{1}$

When speaking to my parents, I prefer to speak

$\mathrm{B}_{5}$

$\mathrm{B}_{4}$

$\mathrm{B}_{3}$

$\mathrm{B}_{2}$

$\mathrm{B}_{1}$

When speaking at work, I prefer to speak

$\mathrm{B}_{5}$

$\mathrm{B}_{4}$

$\mathrm{B}_{3}$

$\mathrm{B}_{2}$

$\mathrm{B}_{1}$

$\mathrm{B}_{5}$

$\mathrm{B}_{3}$

$\mathrm{B}_{2}$

$\mathrm{B}_{1}$

When speaking to my brothers/sisters, I prefer to speak .........

$\mathrm{B}_{5}$

$\mathrm{B}_{4}$

$\mathrm{B}_{3}$

$\mathrm{B}_{2}$

$\mathrm{B}_{1}$

When speaking to my spouse/partner, I prefer to speak..........

$\mathrm{B}_{5}$

$\mathrm{B}_{4}$

$\mathrm{B}_{3}$

$\mathrm{B}_{2}$

B

When speaking at home, I prefer to speak.

$\mathrm{B}_{5}$

$\mathrm{B}_{4}$

$\mathrm{B}_{3}$

$\mathrm{B}_{2}$

$\mathrm{B}_{1}$

When writing my own notes I prefer to write in

$\mathrm{B}_{5}$

$\mathrm{B}_{4}$

$\mathrm{B}_{3}$

$\mathrm{B}_{2}$

$B_{1}$

When reading newspapers/ magazines I prefer.

$\mathrm{B}_{5}$

$\mathrm{B}_{4}$

$\mathrm{B}_{3}$

$\mathrm{B}_{2}$

$\mathrm{B}_{1}$

I prefer to watch TV in

$\mathrm{B}_{5}$

When speaking at school, I prefer to speak

$B_{5}$

$\mathrm{B}_{4}$

$\mathrm{B}_{2}$

$B_{1}$

$B_{1}$

I prefer to think in

$\mathrm{B}_{5}$

$B_{4}$

$\mathrm{B}_{3}$

$\mathrm{B}_{2}$

$\mathrm{B}_{1}$

I prefer to listen to the radio in.

$\mathrm{B}_{5}$

$\mathrm{B}_{3}$

$\mathrm{B}_{2}$

$B_{1}$

I prefer to shop at stores where I can speak

$\mathrm{B}_{5}$

$\mathrm{B}_{4}$

$\mathrm{B}_{3}$

$\mathrm{B}_{2}$

$B_{1}$

When speaking to automated answering services over the phone, I select

$\mathrm{B}_{5} \quad \mathrm{~B}_{4}$

$\mathrm{B}_{3}$

$\mathrm{B}_{2}$

$B_{1}$

While ordering over the phone from catalogs, I prefer to speak

When using an ATM I prefer to use

$\mathrm{B}_{5} \quad \mathrm{~B}_{4}$

$\mathrm{B}_{3}$

$\mathrm{B}_{2}$

$B_{1}$

At church/temple I prefer to speak..

B 5

$\mathrm{B}_{5}$

I prefer to pray in.

$\mathrm{B}_{5}$

$\mathrm{B}_{4}$

$\begin{array}{lll}B_{3} & B_{2} & B_{1}\end{array}$

$\mathrm{B}_{3} \mathrm{~B}_{2} \quad \mathrm{~B}_{1}$

$\begin{array}{lll}\mathrm{B}_{3} & \mathrm{~B}_{2} & \mathrm{~B}_{1}\end{array}$

$\mathrm{B}_{4}$

$\mathrm{B}_{3}$

$\mathrm{B}_{2}$

$\mathrm{B}_{1}$

2. Now we are interested in your agreement with the following statements.

("X" ONE BOX FOR EACH STATEMENT)

\begin{tabular}{|c|c|c|c|c|c|}
\hline & $\begin{array}{c}\text { COMPLETELY } \\
\text { AGREE }\end{array}$ & AGREE & $\begin{array}{c}\text { NEITHER } \\
\text { AGREE NOR } \\
\text { DISAGREE }\end{array}$ & DISAGREE & $\begin{array}{c}\text { COMPLETELY } \\
\text { DISAGREE }\end{array}$ \\
\hline I feel at home in the United States .................................. & $\mathrm{B}_{5}$ & $\mathrm{~B}_{4}$ & $\mathrm{~B}_{3}$ & $\mathrm{~B}_{2}$ & $B_{1}$ \\
\hline I feel proud of having a Hispanic heritage ...................... & $\mathrm{B}_{5}$ & $\mathrm{~B}_{4}$ & $\mathrm{~B}_{3}$ & $\mathrm{~B}_{2}$ & $\mathrm{~B}_{1}$ \\
\hline I feel part of America. & $\mathrm{B}_{5}$ & $\mathrm{~B}_{4}$ & $\mathrm{~B}_{3}$ & $\mathrm{~B}_{2}$ & $B_{1}$ \\
\hline 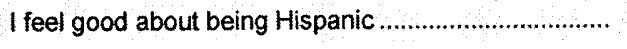 & $\mathrm{B}_{5}$ & $\mathrm{~B}_{4}$ & $\mathrm{~B}_{3}$ & $\mathrm{~B}_{2}$ & $\mathrm{~B}_{1}$ \\
\hline I am proud of being an American & B5 & $\mathrm{B}_{4}$ & $\mathrm{~B}_{3}$ & $\mathrm{~B}_{2}$ & $B_{1}$ \\
\hline I feel strongly associated to my country of origin......... & $\mathrm{B}_{5}$ & $\mathrm{~B}_{4}$ & $\mathrm{~B}_{3}$ & $\mathrm{~B}_{2}$ & $\mathrm{~B}_{1}$ \\
\hline 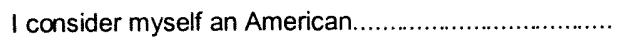 & $\mathrm{B}_{5}$ & $\mathrm{~B}_{4}$ & $\mathrm{~B}_{3}$ & $\mathrm{~B}_{2}$ & $B_{1}$ \\
\hline 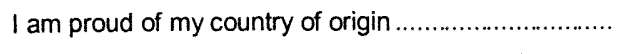 & $\mathrm{B}_{5}$ & $\mathrm{~B}_{4}$ & $\mathrm{~B}_{3}$ & $\mathrm{~B}_{2}$ & $\mathrm{~B}_{1}$ \\
\hline I feel comfortable with the American way of life .......... & $B_{5}$ & $\mathrm{~B}_{4}$ & $\mathrm{~B}_{3}$ & $\mathrm{~B}_{2}$ & $\mathrm{~B}_{1}$ \\
\hline
\end{tabular}

3. When thinking about your possessions please estimate the following. ("X" ONE BOX FOR EACH STATEMENT)

How many paintings, wall hangings, prints and other NONE ABOUT art objects hanging on the walls of your house are Hispanic

How many books in Spanish do you own...

$\mathrm{B}_{1} \quad \mathrm{~B}_{2}$

$\mathrm{B}_{3}$

MOST

How many CDs and tapes in Spanish do you own

$B_{1} \quad B_{2}$

$\mathrm{B}_{3}$

$\mathrm{B}_{4}$

$\mathrm{B}_{5}$

$\mathrm{B}_{1} \mathrm{~B}_{2}$

$\mathrm{B}_{3}$

$\mathrm{B}_{4}$

$\mathrm{B}_{5}$

How many videos or DVDs in Spanish do you own

$\mathrm{B}_{1} \quad \mathrm{~B}_{2}$

$\mathrm{B}_{3}$

$\mathrm{B}_{4}$

$B_{5}$ 
4. Please answer your agreement or disagreement with each of the following family-related statements. ("X" ONE BOX FOR EACH STATEMENT)

I will be fulfilled as my family succeeds

Married children should live close to their

parents so they can help each other...

I value my children's health above my own

I work hard to give my children the best

education they can get.

Children should always respect their elders

Relatives are more important than friends.....

No matter what the cost, helping my

relatives with their problems comes first

Some equality in marriage is good, but by

and large the father ought to have the

main say in important family matters.

Adult children should make sacrifices to care

for their parents

Children should always have respect for their

parents.

Adult children should often seek their parents'

advice

Children should work while in college

One of the most important goals in life is to

have children

Aging parents should live at home with their

children

Parents should feel responsible for their

children's happiness

In an unhappy marriage, parents should stay

together for their children's sake

CoMpletely AGREE

B 5

$\mathrm{B}_{5}$

B 5

B 5

$\mathrm{B}_{5}$

$\mathrm{B}_{5}$

$\mathrm{B}_{5}$

B 5

B 5

$\mathrm{B}_{5}$

B 5

B s

$\mathrm{B}_{5}$

$\mathrm{B}_{5}$

$B_{5}$

Parents should sacrifice themselves in order

to provide their children with the best.

Children should be taught about their family history....

A person should always support his relatives

if they are in need

Daughters should live with their parents until

they get married

It is good to have a lot of family living close to you....

Keeping old family recipes is important

People should consult close relatives concerning

important decisions

5. Please estimate how frequently you buy the following products. ("X" ONE BOX FOR EACH PRODUCT)

\section{MORE THAN}

MORE THAN
ONCE A WEEK

Ready to eat frozen meals

Canned soups

Diet soft drinks

Fabric softener

Shampoo

Deodorant

$$
\mathrm{B}_{1}
$$

$\mathrm{B}_{1}$

B 1

B 1

B 1

B

\section{EVERY WEEK}

\section{$\mathrm{B}_{2}$}

$\mathrm{B}_{2}$

$\mathrm{B}_{2}$

$\mathrm{B}_{2}$

$\mathrm{B}_{2}$

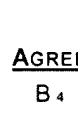

$B_{4}$

$B_{4}$

$B_{4}$

$\mathrm{B}_{4}$

$\mathrm{B}_{4}$

$B_{4}$

B 4

B 4

B 4

$B_{4}$

$\mathrm{B}_{4}$

$B_{4}$

$\mathrm{B}_{4}$

$B_{4}$

$B_{4}$

$\mathrm{B}_{4}$

$\mathrm{B}_{4}$

$B_{4}$

$\mathrm{B}_{4}$

$\mathrm{B}_{4}$

$\mathrm{B}_{4}$

$B_{4}$
NEITHER

AGREE NOR

DISAGREE

$B_{3}$

DISAGREE

$\mathrm{B}_{2}$

CoMpletely DISAGREE

$B$.

$\mathrm{B}_{3}$

$\mathrm{B}_{2}$

B.

$B_{3}$

$\mathrm{B}_{2}$

$\mathrm{B}_{3}$

$\mathrm{B}_{3}$

$\mathrm{B}_{3}$

$\mathrm{B}_{2}$

$\mathrm{B}_{2}$

$B_{2}$

$B_{3}$

$\mathrm{B}_{2}$

$\mathrm{B}_{3}$

$\mathrm{B}_{2}$

$B_{3}$

$\mathrm{B}_{2}$

$B_{3}$

$B_{2}$

$\mathrm{B}_{3}$

$\mathrm{B}_{3}$

$\mathrm{B}_{2}$

$\mathrm{B}_{2}$

$\mathrm{B}_{3}$

$\mathrm{B}_{2}$

$B_{3}$

$\mathrm{B}_{2}$

$\mathrm{B}_{3}$

$\mathrm{B}_{2}$

$\mathrm{B}_{3}$

$\mathrm{B}_{2}$

$\mathrm{B}_{2}$

$\mathrm{B}_{2}$

$\mathrm{B}_{2}$

$\mathrm{B}_{2}$

$B_{2}$

$\mathrm{B}_{2}$

$B_{2}$

EVERY TWO WEEKS

EVERYMONTH

LESS FREQUENT OR NEVER

$\begin{array}{ll}\mathrm{B}_{4} & \mathrm{~B}_{5} \\ \mathrm{~B}_{4} & \mathrm{~B}_{5} \\ \mathrm{~B}_{4} & \mathrm{~B}_{5} \\ \mathrm{~B}_{4} & \mathrm{~B}_{5} \\ \mathrm{~B}_{4} & \mathrm{~B}_{5}\end{array}$

6. We would like to ask your opinion on some statements that describe how you select brands when you shop. Please answer you agreement or disagreement with each statement. (" $X$ " ONE BOX FOR EACH STATEMENT)

I always look for the highest quality brands

I generally do not care what brand I buy.

I only buy well-known brands

I always buy the same brand....................................

The brand name is an important consideration

in my purchase decision

I feel committed to my preferred brands.

\section{COMPLETELY AGREE}

$B_{5}$

B 5

$\mathrm{B}_{5}$

B 5

$B_{5}$

B 5

\begin{tabular}{c} 
AGRE \\
\hline$B_{4}$ \\
$B_{4}$ \\
$B_{4}$ \\
$B_{4}$ \\
$B_{4}$ \\
$B_{4}$
\end{tabular}

AGRE AGREE NOR DISAGREE

$\mathrm{B}_{3}$

$\mathrm{B}_{3}$

$B_{3}$

$\mathrm{B}_{3}$

$\mathrm{B}_{3}$

$\mathrm{B}_{3}$

DISAGREE

Completely DISAGREE

$B_{1}$

$B$.

$B$

B.

B ,

7. Please estimate how frequently you buy groceries.

(“X" ONE BOX)

Three or more times a week ........ $B_{1}$
Twice a week ............................ $B_{2}$
Once a week .......................... $B_{3}$
About once every two weeks ........ $B_{4}$ About once a month..................... B 5 
We are interested in your brand loyalty towards some brands. An extremely loyal customer of a brand is a person who prefers that particular brand and always buys only this brand. Please answer how loyal you are to your preferred brand within the following product categories and services. " $X$ " ONE BOX FOR EACH PRODUCT/SERVICE)

Soft drinks

Fabric softener

$\begin{array}{cc}\begin{array}{c}\text { EXTREMELY } \\ \text { LOYAL }\end{array} & \begin{array}{c}\text { VERY } \\ \text { LOY }\end{array} \\ \text { B }_{5} & B \\ B_{5} & B \\ B_{5} & B \\ B_{5} & B \\ B_{5} & B \\ B_{5} & B\end{array}$

Moderately SlightLy

$\mathrm{B}_{4}$

$\mathrm{B}_{4}$

Shampoo

Deodorant

Hairstylist

Dry cleaning services

\section{LOYAL}

$\mathrm{B}_{3}$

$\mathrm{B}_{3}$

$\mathrm{B}_{3}$

$\mathrm{B}_{3}$

$\mathrm{B}_{3}$
NOT AT

LOYAL ALLLOYAL

$\mathrm{B}_{2}$

$\mathrm{B}_{2}$

$\mathrm{B}_{2}$

$\mathrm{B}_{2}$

$\mathrm{B}_{2}$

$\mathrm{B}_{2}$
$\mathrm{B}_{4}$

$\mathrm{B}_{1}$

B

B

B

9. DO YOU OWn? ("X" ONE BOX FOR EACH FINANCIAL PRODUCT)

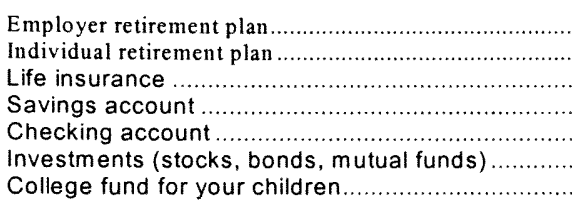

\begin{tabular}{ll} 
YES & NO \\
\hline$B_{1}$ & $B_{2}$ \\
$B_{1}$ & $B_{2}$ \\
$B_{1}$ & $B_{2}$ \\
$B_{1}$ & $B_{2}$ \\
$B_{1}$ & $B_{2}$ \\
$B_{1}$ & $B_{2}$ \\
$B_{1}$ & $B_{2}$
\end{tabular}

10. If Bank of America had a new low home mortgage rate program and sent you a brochure about it, in what language would you prefer to receive it? ("X" ONE BOX)

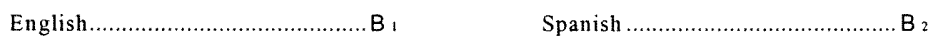

11. If you were planning to buy a new car and visited a dealership, in what language would you prefer to speak? ("X" ONE BOX)

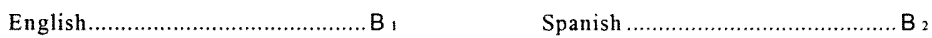

12. Allstate Insurance has English as well as a Spanish language website. Which one would you choose to use? ("X" ONE BOX)

English website $B_{1}$

Spanish website $\mathrm{B}_{2}$

I have no internet access $\mathrm{B}_{3}$

13. If you had $\$ 10,000$ to save, how much of the $\$ 10,000$ would you save for...? (THE AMOUNTS HERE SHOULD ADD UP TO $\$ 10,000)$

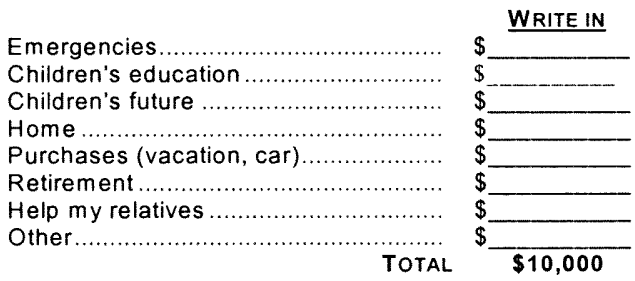

14. If you had $\$ 10,000$ to save or invest, how much would you put in each of the following? (THE AMOUNTS HERE SHOULD ADD UP TO $\$ 10,000)$

\begin{tabular}{|c|c|}
\hline 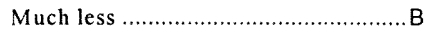 & 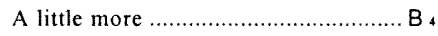 \\
\hline 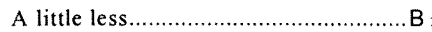 & Much more ...... \\
\hline
\end{tabular}
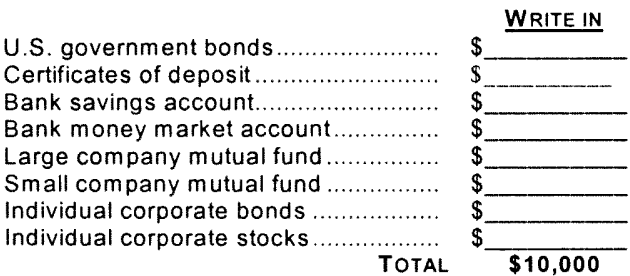

15. Compared to a typical U.S. resident, when it comes to financial services, I know... ("X" ONE BOX)?

16. When saving or investing money with a financial services company, how important is each of the following to you? ("X" ONE BOX FOR EACH STATEMENT)

To know a company representative personally. That the company is based in the United States To have friends or family who use the same firm ...... That the company has a local office that I can visit... That a company representative speaks Spanish. That the firm's brochures are available in Spanish...

$\begin{array}{ccccc}\begin{array}{c}\text { EXTREMELY } \\ \text { IMPORTANT }\end{array} & \begin{array}{c}\text { VERY } \\ \text { IMPORTANT }\end{array} & \begin{array}{c}\text { MODERATELY } \\ \text { IMPORTANT }\end{array} & \begin{array}{c}\text { SLIGHTLY } \\ \text { IMPORTANT }\end{array} & \begin{array}{c}\text { NOT } \\ \text { IMT ALL } \\ \text { IMPORTANT }\end{array} \\ \mathrm{B}_{5} & \mathrm{~B}_{4} & \mathrm{~B}_{3} & \mathrm{~B}_{2} & \mathrm{~B}_{1} \\ \mathrm{~B}_{5} & \mathrm{~B}_{4} & \mathrm{~B}_{3} & \mathrm{~B}_{2} & \mathrm{~B}_{1} \\ \mathrm{~B}_{5} & \mathrm{~B}_{4} & \mathrm{~B}_{3} & \mathrm{~B}_{2} & \mathrm{~B}_{1} \\ \mathrm{~B}_{5} & \mathrm{~B}_{4} & \mathrm{~B}_{3} & \mathrm{~B}_{2} & \mathrm{~B}_{1} \\ \mathrm{~B}_{5} & \mathrm{~B}_{4} & \mathrm{~B}_{3} & \mathrm{~B}_{2} & \mathrm{~B}_{1} \\ & & \mathrm{~B}_{3} & \mathrm{~B}_{2} & \mathrm{~B}_{1}\end{array}$


APPENDIX 2

ENGLISH QUESTIONNAIRE VERSION TWO 
Please answer your agreement or disagreement with each of the following family-related statements. ("X" ONE BOX FOR EACH STATEMENT)

1 will be fulfilled as my family succeeds

Com

Married children should live close to their

parents so they can help each other.

I value my children's health above my own

I work hard to give my children the best

education they can get

Children should always respect their elders

Relatives are more important than friends

No matter what the cost, helping my

relatives with their problems comes first

Some equality in marriage is good, but by

and large the father ought to have the

main say in important family matters.

Adult children should make sacrifices to care

for their parents

Children should always have respect for their parents

Adult children should often seek their parents advice.

Children should work while in college :

One of the most important goals in life is to

have children

Aging parents should live at home with their children

Parents should feel responsible for their children's happiness.

In an unhappy marriage, parents should stay together for their children's sake.

Parents should sacrifice themselves in order to provide their children with the best.

Children should be taught about their family history....

A person should always support his relatives

if they are in need

Daughters should live with their parents until they get married....

It is good to have a lot of family living close to you.......

Keeping old family recipes is important

People should consult close relatives concerning important decisions

2. Please estimate how frequently you buy the following products ("X

\begin{tabular}{|c|c|}
\hline & $\begin{array}{l}\text { MORE THAN } \\
\text { ONCE A WEEK } \\
\end{array}$ \\
\hline 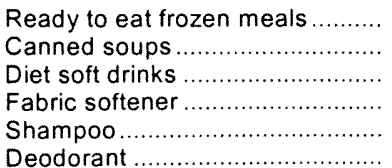 & $\begin{array}{l}\mathrm{B}_{1} \\
\mathrm{~B}_{1} \\
\mathrm{~B}_{1} \\
\mathrm{~B}_{1} \\
\mathrm{~B}_{1} \\
\mathrm{~B}_{1}\end{array}$ \\
\hline
\end{tabular}

\begin{tabular}{c} 
EVERY WEEK \\
\hline $\mathrm{B}_{2}$ \\
$\mathrm{~B}_{2}$ \\
$\mathrm{~B}_{2}$ \\
$\mathrm{~B}_{2}$ \\
$\mathrm{~B}_{2}$ \\
$\mathrm{~B}_{2}$
\end{tabular}

\begin{tabular}{c} 
("X" ONE BOXF FR \\
EVERY \\
TWO WEEKS \\
\hline$B_{3}$ \\
$B_{3}$ \\
$B_{3}$ \\
$B_{3}$ \\
$B_{3}$ \\
$B_{3}$
\end{tabular}

NEITHER AGREE NOR AGREE

B 5

\section{AGREE} DISAGRE

B 5

$\mathrm{B}_{5}$

$\mathrm{B}_{4}$

$\mathrm{B}_{4}$

$B_{5}$

$\mathrm{B}_{4}$

$\mathrm{B}_{4}$

$\mathrm{B}_{5}$

$\mathrm{B}_{4}$

$B_{5}$

$B_{4}$

$\mathrm{B}_{3}$

DisAgreE

Completely DISAGRE

B 5

$B_{4}$

$\mathrm{B}_{3}$

$\mathrm{B}_{3}$

$\mathrm{B}_{2}$

$\mathrm{B}_{2}$

$B_{1}$

B 5

$B_{4}$

$\mathrm{B}_{3}$

$\mathrm{B}_{2}$

$\mathrm{B}_{2}$

$$
\mathrm{B}_{2}
$$

$\mathrm{B}_{3}$

$\mathrm{B}_{2}$

B 1

B 1

B 1

$B_{1}$

B.

B 1

B 5

$B_{4}$

$\mathrm{B}_{3}$

$\mathrm{B}_{2}$

B 1

$\mathrm{B}_{3}$

$\mathrm{B}_{2}$

$B_{1}$

$\mathrm{B}_{5}$

$B_{4}$

$\mathrm{B}_{3}$

$B_{2}$

B 1

$\mathrm{B}_{3}$

$\mathrm{B}_{2}$

B 1

B 5

$\mathrm{B}_{3}$

$\mathrm{B}_{2}$

$B_{1}$

B 5

$B_{4}$

$\mathrm{B}_{3}$

$\mathrm{B}_{2}$

B 1

B 5

$B_{4}$

$\mathrm{B}_{3}$

$B_{2}$

B ,

B 5

B 4

$\mathrm{B}_{3}$

$\mathrm{B}_{2}$

$B_{1}$

$B_{5}$

$B_{4}$

$\mathrm{B}_{3}$

$\mathrm{B}_{2}$

B:

$\mathrm{B}_{5} \quad \mathrm{~B}_{4}$

$\mathrm{B}_{3}$

$\mathrm{B}_{2}$

$B_{1}$

$B_{5} \quad B_{4}$

$B_{3}$

$\mathrm{B}_{2}$

$B_{1}$

$\mathrm{B}_{5} \quad \mathrm{~B}_{4}$

$\mathrm{B}_{4}$

$\mathrm{B}_{3}$

$\mathrm{B}_{2}$

$B_{1}$

$B_{5}$
$B_{5}$

$B_{4}$

B

$\mathrm{B}_{2}$

B 1

$B_{1}$

$\mathrm{B}_{3}$

$\mathrm{B}_{2}$

$\mathrm{B}_{3}$

$\mathrm{B}_{2}$

$B_{1}$

3. We would like to ask your opinion on some statements that describe how you select brands when you shop. Please answer you agreement or disagreement with each statement. ("X" ONE BOX FOR EACH STATEMENT)

\begin{tabular}{|c|c|c|c|c|c|}
\hline & $\begin{array}{l}\text { COMPLETELY } \\
\text { AGREE }\end{array}$ & AGREE & $\begin{array}{c}\text { NEITHER } \\
\text { AGREE NOR } \\
\text { DISAGREE }\end{array}$ & DISAGREE & $\begin{array}{l}\text { COMPLETELY } \\
\text { DISAGREE }\end{array}$ \\
\hline 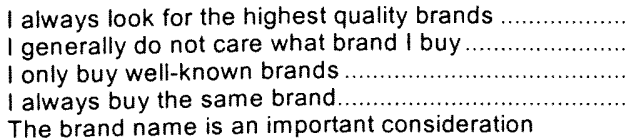 & $\begin{array}{l}\mathrm{B}_{5} \\
\mathrm{~B}_{5} \\
\mathrm{~B}_{5} \\
\mathrm{~B}_{5}\end{array}$ & $\begin{array}{l}\mathrm{B}_{4} \\
\mathrm{~B}_{4} \\
\mathrm{~B}_{4} \\
\mathrm{~B}_{4}\end{array}$ & $\begin{array}{l}\mathrm{B}_{3} \\
\mathrm{~B}_{3} \\
\mathrm{~B}_{3} \\
\mathrm{~B}_{3}\end{array}$ & $\begin{array}{l}\mathrm{B}_{2} \\
\mathrm{~B}_{2} \\
\mathrm{~B}_{2} \\
\mathrm{~B}_{2}\end{array}$ & $\begin{array}{l}B_{1} \\
B_{1} \\
B_{1} \\
B_{1}\end{array}$ \\
\hline 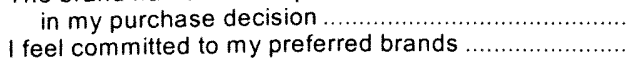 & $\begin{array}{l}\mathrm{B}_{5} \\
\mathrm{~B}_{5}\end{array}$ & $\begin{array}{l}\mathrm{B}_{4} \\
\mathrm{~B}_{4}\end{array}$ & $\begin{array}{l}\mathrm{B}_{3} \\
\mathrm{~B}_{3}\end{array}$ & $\begin{array}{l}\mathrm{B}_{2} \\
\mathrm{~B}_{2}\end{array}$ & $\begin{array}{l}B_{1} \\
B_{1}\end{array}$ \\
\hline
\end{tabular}

4. Please estimate how frequently you buy groceries. ("X" ONE BOX)

Three or more times a week ................. B , Twice a week..................................... $\mathrm{B}_{2}$ Once a week ......................................
About once every two weeks.............. $B_{4}$

About once a month ......................... Bs 
We are interested in your brand loyalty towards some brands. An extremely loyal customer of a brand is a person who prefers that particular brand and always buys only this brand. Please answer how loyal you are to your preferred brand within the following product categories and services. ("X" ONE BOX FOR EACH PRODUCT/SERVICE)

\begin{tabular}{|c|c|c|c|c|c|}
\hline & $\begin{array}{l}\text { EXTREMELY } \\
\text { LOYAL }\end{array}$ & $\begin{array}{l}\text { VERY } \\
\text { LOYAL } \\
\end{array}$ & $\begin{array}{c}\text { MODERATELY } \\
\text { LOYAL }\end{array}$ & $\begin{array}{l}\text { SLIGHTLY } \\
\text { LOYAL }\end{array}$ & $\begin{array}{c}\text { NOT AT } \\
\text { ALL LOYAL }\end{array}$ \\
\hline 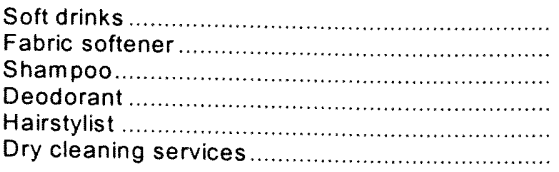 & $\begin{array}{l}B_{5} \\
B_{5} \\
B_{5} \\
B_{5} \\
B_{5} \\
B_{5}\end{array}$ & $\begin{array}{l}\mathrm{B}_{4} \\
\mathrm{~B}_{4} \\
\mathrm{~B}_{4} \\
\mathrm{~B}_{4} \\
\mathrm{~B}_{4} \\
\mathrm{~B}_{4}\end{array}$ & $\begin{array}{l}\mathrm{B}_{3} \\
\mathrm{~B}_{3} \\
\mathrm{~B}_{3} \\
\mathrm{~B}_{3} \\
\mathrm{~B}_{3} \\
\mathrm{~B}_{3}\end{array}$ & $\begin{array}{l}\mathrm{B}_{2} \\
\mathrm{~B}_{2} \\
\mathrm{~B}_{2} \\
\mathrm{~B}_{2} \\
\mathrm{~B}_{2} \\
\mathrm{~B}_{2}\end{array}$ & $\begin{array}{l}B \\
B: \\
B \\
B \\
B \\
B \\
B\end{array}$ \\
\hline
\end{tabular}

6. DO YOU OWn? ("X" ONE BOX FOR EACH FINANCIAL PRODUCT)

\begin{tabular}{|c|c|c|}
\hline & $\underline{\text { YES }}$ & No \\
\hline 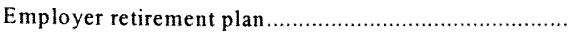 & $\mathrm{B}_{1}$ & $\mathrm{~B}_{2}$ \\
\hline Individual retirement plan ............... & $\mathrm{B}_{1}$ & $\mathrm{~B}_{2}$ \\
\hline Life insurance ................. & $B_{1}$ & $\mathrm{~B}_{2}$ \\
\hline Savings account ... & $\mathrm{B}+$ & $\mathrm{B}_{2}$ \\
\hline Checking account. & $\mathrm{Bi}$ & $\mathrm{B}_{2}$ \\
\hline Investments (stocks, bonds, mutual funds) ............ & $\mathrm{B}_{1}$ & $\mathrm{~B}_{2}$ \\
\hline College fund for your children............................... & $\mathrm{B}_{1}$ & $\mathrm{~B}_{2}$ \\
\hline
\end{tabular}

7. If Bank of America had a new low home mortgage rate program and sent you a brochure about it, in what language would you prefer to receive it? (" $X$ " ONE BOX)

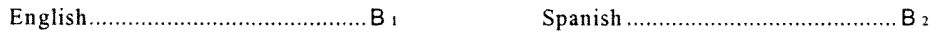

8. If you were planning to buy a new car and visited a dealership, in what language would you prefer to speak? ("X" ONE BOX)

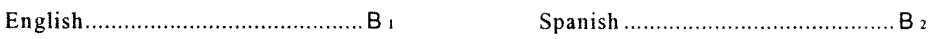

9. Allstate Insurance has English as well as a Spanish language website. Which one would you choose to use? ("X" ONE BOX)

English website ......................... B $\quad$ Spanish website .................... $B_{2} \quad$ I have no internet access ....... B 3

10. If you had $\$ 10,000$ to save, how much of the $\$ 10,000$ would you save for...? (THE AMOUNTS HERE SHOULD ADD UP To $\$ 10,000)$

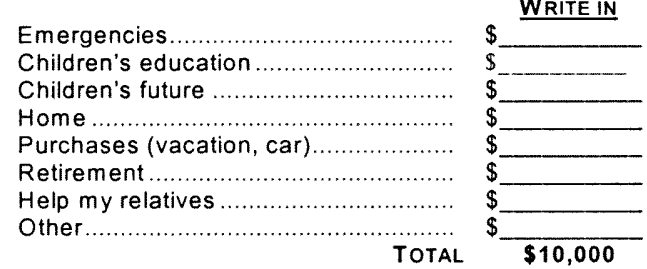

11. If you had $\$ 10,000$ to save or invest, how much would you put in each of the following? (THE AMOUNTS HERE SHOULD ADD UP TO $\$ 10,000)$

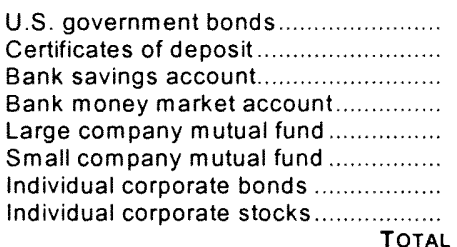

\section{WRITE IN}
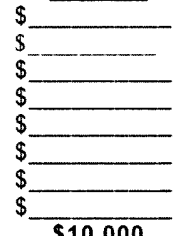

12.

Compared to a typical U.S. resident, when it comes to financial services, I know... ("X" ONE BOX)?

\begin{tabular}{|c|c|}
\hline Much less ............................................ & 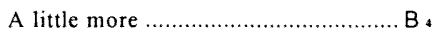 \\
\hline 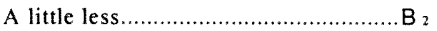 & 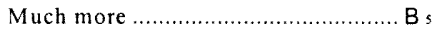 \\
\hline
\end{tabular}

13. When saving or investing money with a financial services company, how important is each of the following to you? (" $X$ " ONE BOX FOR EACH STATEMENT)

To know a company representative personally......... That the company is based in the United States To have friends or family who use the same firm ..... That the company has a local office that I can visit... That a company representative speaks Spanish....... That the firm's brochures are available in Spanish....

\begin{tabular}{|c|c|c|c|c|}
\hline $\begin{array}{l}\text { EXTREMELY } \\
\text { IMPORTANT }\end{array}$ & $\begin{array}{c}\text { VERY } \\
\text { IMPORTANT } \\
\end{array}$ & $\begin{array}{l}\text { MODERATELY } \\
\text { IMPORTANT }\end{array}$ & $\begin{array}{l}\text { SLIGHTLY } \\
\text { IMPORTANT } \\
\end{array}$ & $\begin{array}{c}\text { NOT } \\
\text { AT ALL } \\
\text { IMPORTANT }\end{array}$ \\
\hline $\mathrm{Bs}_{5}$ & $\mathrm{~B}_{4}$ & $\mathrm{~B}_{3}$ & $\mathrm{~B}_{2}$ & $B_{1}$ \\
\hline$B_{5}$ & $\mathrm{~B}_{4}$ & $\mathrm{~B}_{3}$ & $\mathrm{~B}_{2}$ & $\mathrm{~B}$ \\
\hline$B_{5}$ & $\mathrm{~B}_{4}$ & $\mathrm{~B}_{3}$ & $\mathrm{~B}_{2}$ & $B_{1}$ \\
\hline$B_{5}$ & $\mathrm{~B}_{4}$ & $\mathrm{~B}_{3}$ & $\mathrm{~B}_{2}$ & $\mathrm{~B}$ \\
\hline $\mathrm{B}_{5}$ & $\mathrm{~B}_{4}$ & $\mathrm{~B}_{3}$ & $\mathrm{~B}_{2}$ & $B$, \\
\hline $\mathrm{B}_{5}$ & $\mathrm{~B}_{4}$ & $\mathrm{~B}_{3}$ & $\mathrm{~B}_{2}$ & $\mathrm{~B}_{1}$ \\
\hline
\end{tabular}




\section{synovate}

Consumer Opinion Panel

Voices of the Hispanic Family

Voces de la Familia de los Hispanos

\section{Estimada Panelista,}

Por favor, de este cuestionario a la persona que tiene la edad y el sexo mencionó arriba.

En el dia de hoy, mandaremos un cuestionario a usted para contestar por nosotros sobre usted y su hogar.

El cuestionario es breve, y estoy seguro de que lo encontrará muy fácil de entender y contestar. Cuando usted haya completado con el cuestionario, por favor, devuélvalo en el sobre con estampilla pre-pagada y ya dirigida.

Gracias por su ayuda.

Cordialmente,

Maria Sánchez 
Por favor indique el lenguaje que prefiere usar en cada uno de las siguientes afirmaciones. (MARQUE CON UNA "X" UNA OPCIÓN PARA CADA AFIRMACIÓN)

\begin{tabular}{|c|c|c|c|c|c|}
\hline & $\begin{array}{l}\text { INGLES, } \\
\text { TODOEL } \\
\text { TIEMPO }\end{array}$ & $\begin{array}{l}\text { INGLESS LA } \\
\text { MAYORIA DE } \\
\text { LAS VECES }\end{array}$ & $\begin{array}{c}\text { ESPANOL } \\
\text { EINGLES } \\
\text { POR } \\
\text { IGUAL }\end{array}$ & $\begin{array}{c}\text { ESPAÑOL } \\
\text { LA } \\
\text { MAYORIA } \\
\text { DE LAS } \\
\text { VECES }\end{array}$ & $\begin{array}{l}\text { ESPANOLL, } \\
\text { TODOEL } \\
\text { TIEMPO } \\
\end{array}$ \\
\hline Cuando hablo con niños de mi familia prefiero hablar .............. & $\mathrm{B}_{5}$ & $\mathrm{~B}_{4}$ & $\mathrm{~B}_{3}$ & $\mathrm{~B}_{2}$ & $B_{1}$ \\
\hline Cuando hablo con mis amigos prefiero hablar........................... & $\mathrm{B}_{5}$ & $\mathrm{~B}_{4}$ & $\mathrm{~B}_{3}$ & $\mathrm{~B}_{2}$ & $\mathrm{~B}_{1}$ \\
\hline Cuando hablo con mis abuelos prefiero hablar ........................... & $\mathrm{B}_{5}$ & $\mathrm{~B}_{4}$ & $\mathrm{~B}_{3}$ & $\mathrm{~B}_{2}$ & $\mathrm{~B}_{1}$ \\
\hline 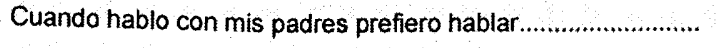 & B5 & $\mathrm{B}_{4}$ & $\mathrm{~B}_{3}$ & $\mathrm{~B}_{2}$ & $B_{1}$ \\
\hline 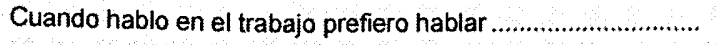 & $\mathrm{B}_{5}$ & $\mathrm{~B}_{4}$ & $\mathrm{~B}_{3}$ & $\mathrm{~B}_{2}$ & $B_{1}$ \\
\hline Cuando hablo con mis hermanos(as) prefiero hablar ................ & $\mathrm{B}_{5}$ & $\mathrm{~B}_{4}$ & $\mathrm{~B}_{3}$ & $\mathrm{~B}_{2}$ & $B_{1}$ \\
\hline Cuando hablo con mi esposo(a)/ pareja prefiero hablar ............ & $\mathrm{B}_{5}$ & $\mathrm{~B}_{4}$ & $\mathrm{~B}_{3}$ & $\mathrm{~B}_{2}$ & $\mathrm{~B}_{1}$ \\
\hline 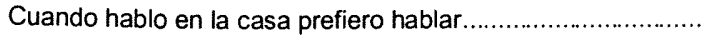 & $\mathrm{B}_{5}$ & $\mathrm{~B}_{4}$ & $\mathrm{~B}_{3}$ & $\mathrm{~B}_{2}$ & $B_{1}$ \\
\hline 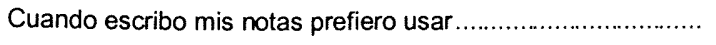 & $\mathrm{B}_{5}$ & $\mathrm{~B}_{4}$ & $\mathrm{~B}_{3}$ & $\mathrm{~B}_{2}$ & $\mathrm{~B}_{1}$ \\
\hline 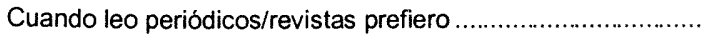 & $\mathrm{B}_{5}$ & $\mathrm{~B}_{4}$ & $\mathrm{~B}_{3}$ & $\mathrm{~B}_{2}$ & $B_{1}$ \\
\hline 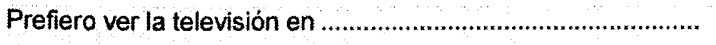 & $\mathrm{B}_{5}$ & $\mathrm{~B}_{4}$ & $\mathrm{~B}_{3}$ & $\mathrm{~B}_{2}$ & $B_{1}$ \\
\hline 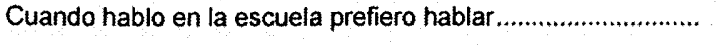 & $\mathrm{B}_{5}$ & $\mathrm{~B}_{4}$ & $\mathrm{~B}_{3}$ & $\mathrm{~B}_{2}$ & $\mathrm{~B}_{1}$ \\
\hline Prefiero pensar en & $\mathrm{B}_{5}$ & $\mathrm{~B}_{4}$ & $\mathrm{~B}_{3}$ & $\mathrm{~B}_{2}$ & $\mathrm{~B}_{1}$ \\
\hline Prefiero escuchar la radio en & $\mathrm{B}_{5}$ & $\mathrm{~B}_{4}$ & $\mathrm{~B}_{3}$ & $\mathrm{~B}_{2}$ & $B_{1}$ \\
\hline Prefiero comprar en tiendas en donde puedo hablar .................... & $\mathrm{B}_{5}$ & $\mathrm{~B}_{4}$ & $\mathrm{~B}_{3}$ & $\mathrm{~B}_{2}$ & $\mathrm{~B}_{1}$ \\
\hline Cuando hablo a un servicio telefónico automático uso .............. & $B_{5}$ & $\mathrm{~B}_{4}$ & $\mathrm{~B}_{3}$ & $\mathrm{~B}_{2}$ & $\mathrm{~B}_{1}$ \\
\hline Cuando ordeno de un catálogo por teléfono prefiero hablar.... & $\mathrm{B}_{5}$ & $\mathrm{~B}_{4}$ & $\mathrm{~B}_{3}$ & $\mathrm{~B}_{2}$ & $\mathrm{~B}_{1}$ \\
\hline 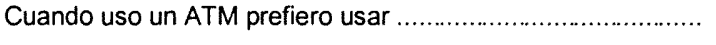 & $\mathrm{B}_{5}$ & $\mathrm{~B}_{4}$ & $\mathrm{~B}_{3}$ & $\mathrm{~B}_{2}$ & $B_{1}$ \\
\hline 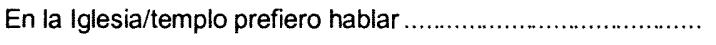 & $B_{5}$ & $\mathrm{~B}_{4}$ & $\mathrm{~B}_{3}$ & $\mathrm{~B}_{2}$ & $\mathrm{~B}_{1}$ \\
\hline Prefiero orar en ................... & $B_{5}$ & $\mathrm{~B}_{4}$ & $\mathrm{~B}_{3}$ & $\mathrm{~B}_{2}$ & $B_{1}$ \\
\hline
\end{tabular}

2. Ahora quisiéramos saber que tan de acuerdo esta usted con cada una de las siguientes afirmaciones. (MARQUE CON UNA " $X$ " UNA OPCIÓN PARA CADA AFIRMACIÓN)

\begin{tabular}{|c|c|c|c|c|c|}
\hline & $\begin{array}{l}\text { COMPLETA- } \\
\text { MENTEDE } \\
\text { ACUERDO } \\
\end{array}$ & $\begin{array}{l}\text { DE } \\
\text { ACUERDO } \\
\end{array}$ & $\begin{array}{c}\text { NI DE ACUERDO } \\
\text { NIEN EN } \\
\text { DESACUERDO }\end{array}$ & $\begin{array}{c}\text { EN } \\
\text { DESACUERDO }\end{array}$ & $\begin{array}{c}\text { COMPLETA- } \\
\text { MENTEEN } \\
\text { DESACUERDO } \\
\end{array}$ \\
\hline 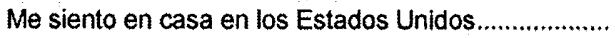 & $B_{5}$ & $\mathrm{~B}_{4}$ & $\mathrm{~B}_{3}$ & $\mathrm{~B}_{2}$ & $B_{1}$ \\
\hline Me siento orgulloso de tener un origen Hispano ........... & $\mathrm{B}_{5}$ & $\mathrm{~B}_{4}$ & $\mathrm{~B}_{3}$ & $\mathrm{~B}_{2}$ & $B_{1}$ \\
\hline 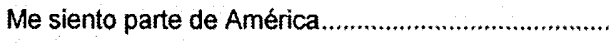 & $\mathrm{B}_{5}$ & $\mathrm{~B}_{4}$ & $\mathrm{~B}_{3}$ & $\mathrm{~B}_{2}$ & $B_{1}$ \\
\hline Me siento bien de ser Hispano & $\mathrm{B}_{5}$ & $\mathrm{~B}_{4}$ & $\mathrm{~B}_{3}$ & $\mathrm{~B}_{2}$ & $\mathrm{~B}_{1}$ \\
\hline 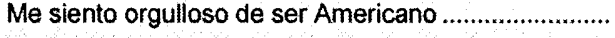 & $\mathrm{B}_{5}$ & $\mathrm{~B}_{4}$ & $\mathrm{~B}_{3}$ & $\mathrm{~B}_{2}$ & $B_{1}$ \\
\hline Me siento fuertemente asociado a mi pais de origen.. & $\mathrm{B}_{5}$ & $\mathrm{~B}_{4}$ & $\mathrm{~B}_{3}$ & $\mathrm{~B}_{2}$ & $B_{1}$ \\
\hline Me considero Americano & $\mathrm{B}_{5}$ & $\mathrm{~B}_{4}$ & $\mathrm{~B}_{3}$ & $\mathrm{~B}_{2}$ & $B_{1}$ \\
\hline 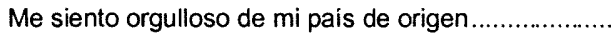 & $B_{5}$ & $\mathrm{~B}_{4}$ & $\mathrm{~B}_{3}$ & $\mathrm{~B}_{2}$ & $B_{1}$ \\
\hline Me siento cómodo con el estilo de vida Americano ... & $\mathrm{B}_{5}$ & $\mathrm{~B}_{4}$ & $\mathrm{~B}_{3}$ & $\mathrm{~B}_{2}$ & $B_{1}$ \\
\hline
\end{tabular}

3. Pensando en las cosas que tiene, por favor estime lo siguiente. (MARQUE CON UNA "X" UNA OPCIÓN PARA CADA AFIRMACIÓN)

Cuántas pinturas, cuadros, y adornos colgados en la pared de su casa son de origen Hispano

Cuántos libros en español tiene.

Cuántos CDs y cintas en Español tiene

$\begin{array}{cccccc}\text { Ninguno } & \text { POCOS } & \begin{array}{c}\text { COMOLA } \\ \text { MitAD }\end{array} & \begin{array}{c}\text { LA } \\ \text { MAYORIA }\end{array} & \text { TODOS } \\ \mathrm{B}_{1} & \mathrm{~B}_{2} & \mathrm{~B}_{3} & \mathrm{~B}_{4} & \mathrm{~B}_{5} \\ \mathrm{~B}_{1} & \mathrm{~B}_{2} & \mathrm{~B}_{3} & \mathrm{~B}_{4} & \mathrm{~B}_{5} \\ \mathrm{~B}_{1} & \mathrm{~B}_{2} & \mathrm{~B}_{3} & \mathrm{~B}_{4} & \mathrm{~B}_{5} \\ \mathrm{~B}_{1} & \mathrm{~B}_{2} & \mathrm{~B}_{3} & \mathrm{~B}_{4} & \mathrm{~B}_{5}\end{array}$


Por favor indique que tan de acuerdo o desacuerdo está con cada una de las siguientes afirmaciones sobre la familia. (MARQUE CON UNA "X" UNA OPCIÓN PARA CADA AFIRMACIÓN)

\begin{tabular}{|c|c|c|c|c|c|}
\hline & $\begin{array}{l}\text { COMPLETA- } \\
\text { MENTE DE } \\
\text { ACUERDO }\end{array}$ & $\begin{array}{c}\text { DE } \\
\text { ACUERDO } \\
\end{array}$ & $\begin{array}{l}\text { NIDE ACUERDO } \\
\text { NIEN } \\
\text { DESACUERDO }\end{array}$ & $\begin{array}{c}\text { EN } \\
\text { DESACUERDO } \\
\end{array}$ & $\begin{array}{l}\text { COMPLETA- } \\
\text { MENTE EN } \\
\text { DESACUERDO }\end{array}$ \\
\hline Yo me sentiré realizado si mi familia tiene exito ............ & $\mathrm{B}_{5}$ & $\mathrm{~B}_{4}$ & $\mathrm{~B}_{3}$ & $\mathrm{~B}_{2}$ & $\mathrm{~B}_{1}$ \\
\hline $\begin{array}{l}\text { Los hijos casados deben vivir cerca de sus padres } \\
\text { para ayudarse mutuamente }\end{array}$ & $\mathrm{B}_{5}$ & $\mathrm{~B}_{4}$ & $\mathrm{~B}_{3}$ & $\mathrm{~B}_{2}$ & $\mathrm{~B}_{1}$ \\
\hline Yo valoro la salud de mis hijos por encima de la mia... & $\mathrm{B}_{5}$ & $\mathrm{~B}_{4}$ & $\mathrm{~B}_{3}$ & $\mathrm{~B}_{2}$ & $\mathrm{~B}_{1}$ \\
\hline $\begin{array}{l}\text { Trabajo duro para darle a mis hijos la mejor } \\
\text { educación que puedan obtener................................ }\end{array}$ & $\mathrm{B}_{5}$ & $\mathrm{~B}_{4}$ & $\mathrm{~B}_{3}$ & $\mathrm{~B}_{2}$ & $B_{1}$ \\
\hline $\begin{array}{l}\text { Los niños siempre deben respetar a las personas } \\
\text { mayores de edad }\end{array}$ & $\mathrm{B}_{5}$ & $\mathrm{~B}_{4}$ & $\mathrm{~B}_{3}$ & $\mathrm{~B}_{2}$ & $B_{1}$ \\
\hline Los familiares son mas importantes que los amigos .... & $\mathrm{B}_{5}$ & $\mathrm{~B}_{4}$ & $\mathrm{~B}_{3}$ & $\mathrm{~B}_{2}$ & $\mathrm{~B}_{1}$ \\
\hline $\begin{array}{l}\text { No im porta el costo, ayudar a mis familiares con } \\
\text { sus problemas es primero ................................ }\end{array}$ & $\mathrm{B}_{5}$ & $\mathrm{~B}_{4}$ & $\mathrm{~B}_{3}$ & $\mathrm{~B}_{2}$ & $B_{1}$ \\
\hline $\begin{array}{l}\text { Tener alguna igualdad en el matrimonio es bueno, } \\
\text { pero por mucho el padre debe tener la última } \\
\text { palabra en asuntos importantes de la familia............ }\end{array}$ & B s & $\mathrm{B}_{4}$ & $\mathrm{~B}_{3}$ & $\mathrm{~B}_{2}$ & $B_{1}$ \\
\hline $\begin{array}{l}\text { Los hijos adultos deben hacer sacrificios para } \\
\quad \text { cuidar a sus padres } \ldots \ldots \ldots \ldots \ldots \ldots \ldots \ldots \ldots \ldots \ldots \ldots \ldots \ldots \ldots \ldots \ldots \ldots \ldots \ldots \ldots \ldots \ldots\end{array}$ & $\mathrm{B}_{5}$ & $\mathrm{~B}_{4}$ & $\mathrm{~B}_{3}$ & $\mathrm{~B}_{2}$ & $B_{1}$ \\
\hline Los hijos deben siempre respetar a sus padres ........... & $\mathrm{B}_{5}$ & $\mathrm{~B}_{4}$ & $\mathrm{~B}_{3}$ & $\mathrm{~B}_{2}$ & $B$ \\
\hline $\begin{array}{l}\text { Los hijos adultos deben frecuentemente buscar } \\
\text { el consejo de sus padres....................................... }\end{array}$ & B s & $\mathrm{B}_{4}$ & $\mathrm{~B}_{3}$ & $\mathrm{~B}_{2}$ & $\mathrm{~B}_{\mathbf{i}}$ \\
\hline $\begin{array}{l}\text { Los hijos deben trabajar mientras estudian en } \\
\text { universidad .......................................................... }\end{array}$ & $\mathrm{B}_{5}$ & $\mathrm{~B}_{4}$ & $\mathrm{~B}_{3}$ & $\mathrm{~B}_{2}$ & $B_{1}$ \\
\hline $\begin{array}{l}\text { Una de las metas más importantes en la vida } \\
\text { es tener hijos }\end{array}$ & $\mathrm{B}_{5}$ & $\mathrm{~B}_{4}$ & $\mathrm{~B}_{3}$ & $\mathrm{~B}_{2}$ & $B_{1}$ \\
\hline $\begin{array}{l}\text { Los padres mayores de edad deben de vivir } \\
\text { en casa de sus nijos } \ldots . . . \ldots \ldots \ldots \ldots \ldots \ldots \ldots \ldots \ldots \ldots \ldots \ldots \ldots \ldots\end{array}$ & $\mathrm{B}_{5}$ & $\mathrm{~B}_{4}$ & $\mathrm{~B}_{3}$ & $\mathrm{~B}_{2}$ & $B_{1}$ \\
\hline $\begin{array}{l}\text { Los padres deben sentirse responsables por la } \\
\text { felicidad de sus hijos }\end{array}$ & $\mathrm{B}_{5}$ & $\mathrm{~B}_{4}$ & $\mathrm{~B}_{3}$ & $\mathrm{~B}_{2}$ & $B_{1}$ \\
\hline $\begin{array}{l}\text { En un matrimonio infeliz, los padres deben } \\
\text { permanecer juntos por el bien de sus hijos............... }\end{array}$ & $\mathrm{B}_{5}$ & $\mathrm{~B}_{4}$ & $\mathrm{~B}_{3}$ & $\mathrm{~B}_{2}$ & $B_{1}$ \\
\hline 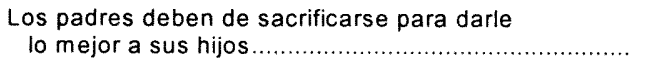 & $\mathrm{B}_{5}$ & $\mathrm{~B}_{4}$ & $\mathrm{~B}_{3}$ & $\mathrm{~B}_{2}$ & $\mathrm{~B}_{1}$ \\
\hline $\begin{array}{l}\text { Se debe enseñar a los niños la historia de su familia... } \\
\text { Una persona siempre debe ayudar a sus familiares }\end{array}$ & $\mathrm{B}_{5}$ & $\mathrm{~B}_{4}$ & $\mathrm{~B}_{3}$ & $\mathrm{~B}_{2}$ & $B_{1}$ \\
\hline 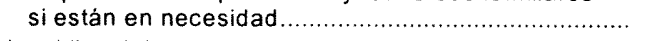 & $\mathrm{Bs}$ & $\mathrm{B}_{4}$ & $\mathrm{~B}_{3}$ & $\mathrm{~B}_{2}$ & $B_{1}$ \\
\hline $\begin{array}{l}\text { Las hijas deben vivir con sus padres hasta que } \\
\text { se casen }\end{array}$ & $B_{5}$ & $\mathrm{~B}_{4}$ & $\mathrm{~B}_{3}$ & $\mathrm{~B}_{2}$ & $B_{1}$ \\
\hline Es bueno tener mucha familia viviendo cerca................. & $\mathrm{B}_{5}$ & $\mathrm{~B}_{4}$ & $\mathrm{~B}_{3}$ & $\mathrm{~B}_{2}$ & $\mathrm{~B}_{1}$ \\
\hline $\begin{array}{l}\text { Es importante conservar viejas recetas de familia........ } \\
\text { Las personas deben de consultar con familiares }\end{array}$ & $\mathrm{B}_{5}$ & $\mathrm{~B}_{4}$ & $\mathrm{~B}_{3}$ & $\mathrm{~B}_{2}$ & $\mathrm{~B}$ \\
\hline cercanos sus decisiones importantes ........................ & $\mathrm{B}_{5}$ & $\mathrm{~B}_{4}$ & $\mathrm{~B}_{3}$ & $\mathrm{~B}_{2}$ & $\mathrm{~B}_{1}$ \\
\hline
\end{tabular}

5. Por favor estime la frecuencia con la que compra los siguientes productos. (MARQUE CON UNA "X" UNA OPCIÓN PARA CADA PRODUCTO)

\begin{tabular}{|c|c|c|c|c|c|}
\hline & $\begin{array}{c}\text { MÁS DE UNA } \\
\text { VEZA LA } \\
\text { SEMANA }\end{array}$ & $\begin{array}{c}\text { UNA VEZ POR } \\
\text { SEMANA }\end{array}$ & $\begin{array}{l}\text { UNA VEZ CADA } \\
\text { DOS SEMANAS }\end{array}$ & $\begin{array}{c}\text { UNA VEZ AL } \\
\text { MES }\end{array}$ & $\begin{array}{c}\text { MENOS } \\
\text { FRECUENTE O } \\
\text { NUNCA }\end{array}$ \\
\hline 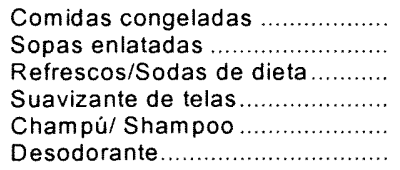 & $\begin{array}{l}\mathrm{B}_{1} \\
\mathrm{~B}_{1} \\
\mathrm{~B}_{1} \\
\mathrm{~B}_{1} \\
\mathrm{~B}_{1} \\
\mathrm{~B}_{1}\end{array}$ & $\begin{array}{l}\mathrm{B}_{2} \\
\mathrm{~B}_{2} \\
\mathrm{~B}_{2} \\
\mathrm{~B}_{2} \\
\mathrm{~B}_{2} \\
\mathrm{~B}_{2}\end{array}$ & $\begin{array}{l}\mathrm{B}_{3} \\
\mathrm{~B}_{3} \\
\mathrm{~B}_{3} \\
\mathrm{~B}_{3} \\
\mathrm{~B}_{3} \\
\mathrm{~B}_{3}\end{array}$ & $\begin{array}{l}\mathrm{B}_{4} \\
\mathrm{~B}_{4} \\
\mathrm{~B}_{4} \\
\mathrm{~B}_{4} \\
\mathrm{~B}_{4} \\
\mathrm{~B}_{4}\end{array}$ & $\begin{array}{l}\mathrm{B}_{5} \\
\mathrm{~B}_{5} \\
\mathrm{~B}_{5} \\
\mathrm{~B}_{5} \\
\mathrm{~B}_{5} \\
\mathrm{~B}_{5}\end{array}$ \\
\hline
\end{tabular}

6. Quisiéramos preguntarle su opinión acerca de las siguientes frases que describen la forma en la que selecciona las marcas que compra. Por favor indique que tan acuerdo o desacuerdo está usted con cada una de las siguientes frases. (MARQUE CON UNA " $X$ " UNA OPCIÓN PARA CADA FRASE)

\begin{tabular}{|c|c|c|c|c|c|}
\hline & $\begin{array}{l}\text { COMPLETA: } \\
\text { MENTE DE } \\
\text { ACUERDO }\end{array}$ & $\begin{array}{c}\mathrm{DE} \\
\text { ACUEROO } \\
\end{array}$ & $\begin{array}{l}\text { NIDE ACUERDO } \\
\text { NIEN } \\
\text { DESACUERDO }\end{array}$ & $\begin{array}{c}\text { EN } \\
\text { DESACUERDO }\end{array}$ & $\begin{array}{l}\text { COMPLETA- } \\
\text { MENTE EN } \\
\text { DESACUERDO } \\
\end{array}$ \\
\hline $\begin{array}{l}\text { Siempre busco las marcas de mayor calidad .............. } \\
\text { En general no me importa que marca compro ............ } \\
\text { Solo compro marcas bien conocidas ........................ } \\
\text { Siempre compro la misma marca .......................... } \\
\text { La marca es un factor importante en mi decisión }\end{array}$ & $\begin{array}{l}\mathrm{B}_{5} \\
\mathrm{~B}_{5} \\
\mathrm{~B}_{5} \\
\mathrm{~B}_{5}\end{array}$ & $\begin{array}{l}\mathrm{B}_{4} \\
\mathrm{~B}_{4} \\
\mathrm{~B}_{4} \\
\mathrm{~B}_{4}\end{array}$ & $\begin{array}{l}\mathrm{B}_{3} \\
\mathrm{~B}_{3} \\
\mathrm{~B}_{3} \\
\mathrm{~B}_{3}\end{array}$ & $\begin{array}{l}\mathrm{B}_{2} \\
\mathrm{~B}_{2} \\
\mathrm{~B}_{2} \\
\mathrm{~B}_{2}\end{array}$ & $\begin{array}{l}\mathrm{B}_{1} \\
\mathrm{~B}_{1} \\
\mathrm{~B}_{1} \\
\mathrm{~B}_{1}\end{array}$ \\
\hline 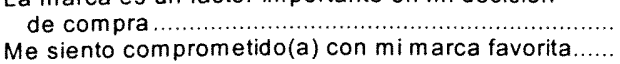 & $\begin{array}{l}\mathrm{B}_{5} \\
\mathrm{~B}_{5}\end{array}$ & $\begin{array}{l}\mathrm{B}_{4} \\
\mathrm{~B}_{4}\end{array}$ & $\begin{array}{l}\mathrm{B}_{3} \\
\mathrm{~B}_{3}\end{array}$ & $\begin{array}{l}\mathrm{B}_{2} \\
\mathrm{~B}_{2}\end{array}$ & $\begin{array}{l}\mathrm{B}_{1} \\
\mathrm{~B}_{1}\end{array}$ \\
\hline
\end{tabular}

7. Por favor estime que tan frecuentemente compra viveres. (MARQUE CON UNA " $X$ " UNA OPCION)

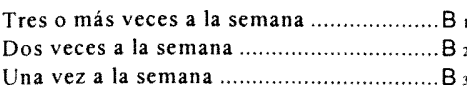

Alrededor de una vez cada dos semanas.............. Alrededor de una vez al mes............................ 
Por favor indique que tan de acuerdo o desacuerdo está con cada una de las siguientes frases. (MARQUE CON UNA "X" UNA OPCIÓN PARA CADA UNA DE LAS SIGUIENTES FRASES)

\begin{tabular}{|c|c|c|c|c|c|}
\hline & $\begin{array}{l}\text { COMPLETA- } \\
\text { MENTEDE } \\
\text { ACUERDO }\end{array}$ & $\begin{array}{c}\text { DE } \\
\text { ACUERDO } \\
\end{array}$ & $\begin{array}{l}\text { NI DE ACUERDO } \\
\text { NIEN } \\
\text { DESACUERDO }\end{array}$ & $\begin{array}{c}\text { EN } \\
\text { DESACUERDO }\end{array}$ & $\begin{array}{l}\text { COMPLETA- } \\
\text { MENTEEN } \\
\text { DESACUERDO } \\
\end{array}$ \\
\hline $\begin{array}{l}\text { Las Instituciones Financieras de los Estados } \\
\text { Unidos son confiables. }\end{array}$ & & & & & \\
\hline Las Instituciones Financieras Latinas son confiables & $\begin{array}{l}\text { B } 5 \\
B_{5}\end{array}$ & $\begin{array}{l}\mathrm{B}_{4} \\
\mathrm{~B}_{4}\end{array}$ & $\begin{array}{l}\mathrm{B}_{3} \\
\mathrm{~B}_{3}\end{array}$ & $\begin{array}{ll}\mathrm{B}_{2} \\
\mathrm{~B}_{2}\end{array}$ & $\begin{array}{l}B_{1} \\
B_{1}\end{array}$ \\
\hline $\begin{array}{l}\text { Las instituciones financieras Europeas son confiables ........ } \\
\text { Las Instituciones Financieras de los Estados Unidos }\end{array}$ & $\mathrm{B}_{5}$ & $\mathrm{~B}_{4}$ & $\mathrm{~B}_{3}$ & $\mathrm{~B}_{2}$ & B. \\
\hline son seguras & $\mathrm{B}_{5}$ & $\mathrm{~B}_{4}$ & $\mathrm{~B}_{3}$ & $\mathrm{~B}_{2}$ & $B_{1}$ \\
\hline $\begin{array}{l}\text { Las Instituciones Financieras Latinas son seguras ............. } \\
\text { Las instituciones financieras Europeas son seguras }\end{array}$ & $\begin{array}{l}\text { B } 5 \\
B_{5}\end{array}$ & $\begin{array}{l}\mathrm{B}_{4} \\
\mathrm{~B}_{4}\end{array}$ & $\begin{array}{l}\mathrm{B}_{3} \\
\mathrm{~B}_{3}\end{array}$ & $\begin{array}{l}\mathrm{B}_{2} \\
\mathrm{~B}_{2}\end{array}$ & $\begin{array}{l}B_{1} \\
B_{1}\end{array}$ \\
\hline $\begin{array}{l}\text { Preferiria invertir en una institución financiera de los } \\
\text { Estados Unidos }\end{array}$ & & & & & \\
\hline 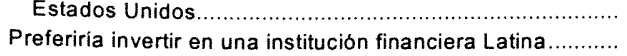 & $B_{5}$ & $\mathrm{~B}_{4}$ & $\mathrm{~B}_{3}$ & $\mathrm{~B}_{2}$ & $B_{i}$ \\
\hline & $B_{5}$ & $\mathrm{~B}_{4}$ & $\mathrm{~B}_{3}$ & $\mathrm{~B}_{2}$ & $B_{1}$ \\
\hline Preferiria invertir en una institución financiera Europea & $B_{5}$ & $\mathrm{~B}_{4}$ & $\mathrm{~B}_{3}$ & $\mathrm{~B}_{2}$ & $B_{1}$ \\
\hline
\end{tabular}

18. Por favor responda a las siguientes preguntas. (MARQUE CON UNA " $X$ " UNA OPCIÓN EN CADA CASO)

\begin{tabular}{|c|c|c|c|}
\hline & $\begin{array}{l}\text { HISPANOI } \\
\text { LATINO }\end{array}$ & NO HISPANO & $\begin{array}{c}\text { No } \\
\text { APLICA }\end{array}$ \\
\hline $\begin{array}{l}\text { Mi esposo(a)/ pareja es } \ldots . . . . . . . . . . . . \\
\text { Mi mejor amigo(a) es }\end{array}$ & $\begin{array}{l}B_{1} \\
B_{1}\end{array}$ & $\begin{array}{l}\mathrm{B}_{2} \\
\mathrm{~B}_{2}\end{array}$ & $\begin{array}{l}\mathrm{B}_{3} \\
\mathrm{~B}_{3}\end{array}$ \\
\hline Mi jefe(a) es. & $B_{1}$ & $\mathrm{~B}_{2}$ & $\mathrm{~B}_{3}$ \\
\hline
\end{tabular}

19. Por favor responda las siguientes preguntas (MARQUE CON UNA " $X$ " UNA OPCION EN CADA FRASE)

\begin{tabular}{|c|c|c|c|c|c|c|}
\hline & $\begin{array}{l}\text { TODOS } \\
\text { HISPANOS/ } \\
\text { LATINOS }\end{array}$ & $\begin{array}{c}\text { MAS } \\
\text { HISPANOS } \\
\text { QUENO- } \\
\text { HISPANOS } \\
\end{array}$ & $\begin{array}{l}\text { MITADY } \\
\text { MITAD }\end{array}$ & $\begin{array}{l}\text { MAS NO- } \\
\text { HISPANOS } \\
\text { QUE } \\
\text { HISPANOS }\end{array}$ & $\begin{array}{l}\text { TODOS NO- } \\
\text { HISPANOS }\end{array}$ & $\begin{array}{c}\text { No } \\
\text { APLICA }\end{array}$ \\
\hline 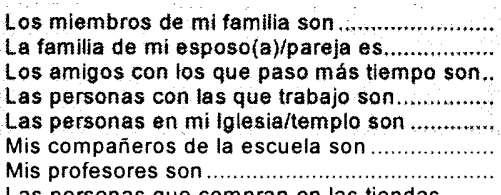 & $\begin{array}{l}\mathrm{B}_{1} \\
\mathrm{~B}_{1} \\
\mathrm{~B}_{1} \\
\mathrm{~B}_{1} \\
\mathrm{~B}_{1} \\
\mathrm{~B}_{1} \\
\mathrm{~B}_{1}\end{array}$ & $\begin{array}{l}\mathrm{B}_{2} \\
\mathrm{~B}_{2} \\
\mathrm{~B}_{2} \\
\mathrm{~B}_{2} \\
\mathrm{~B}_{2} \\
\mathrm{~B}_{2} \\
\mathrm{~B}_{2}\end{array}$ & $\begin{array}{l}\mathrm{B}_{3} \\
\mathrm{~B}_{3} \\
\mathrm{~B}_{3} \\
\mathrm{~B}_{3} \\
\mathrm{~B}_{3} \\
\mathrm{~B}_{3} \\
\mathrm{~B}_{3}\end{array}$ & $\begin{array}{l}\mathrm{B}_{4} \\
\mathrm{~B}_{4} \\
\mathrm{~B}_{4} \\
\mathrm{~B}_{4} \\
\mathrm{~B}_{4} \\
\mathrm{~B}_{4} \\
\mathrm{~B}_{4}\end{array}$ & $\begin{array}{l}B_{5} \\
B_{5} \\
B_{5} \\
B_{5} \\
B_{5} \\
B_{5} \\
B_{5}\end{array}$ & $\begin{array}{l}B_{6} \\
B_{6} \\
B_{6} \\
B_{6} \\
B_{6} \\
B_{6} \\
B_{6}\end{array}$ \\
\hline $\begin{array}{l}\text { Las personas que compran en las tiendas } \\
\text { en las que yo compro son.............................. } \\
\text { Los empleados de mi banco son } \\
\text { Los empleados del supermercado al que }\end{array}$ & $\begin{array}{l}\mathrm{B}: \\
\mathrm{B} ;\end{array}$ & $\begin{array}{l}\mathrm{B}_{2} \\
\mathrm{~B}_{2}\end{array}$ & $\begin{array}{l}\mathrm{B}_{3} \\
\mathrm{~B}_{3}\end{array}$ & $\begin{array}{l}\mathrm{B}_{4} \\
\mathrm{~B}_{4}\end{array}$ & $\begin{array}{l}B_{5} \\
B_{5}\end{array}$ & $\begin{array}{l}B_{6} \\
B_{6}\end{array}$ \\
\hline voy son ........................................... & $\mathrm{B}_{1}$ & $\mathrm{~B}_{2}$ & $\mathrm{~B}_{3}$ & $\mathrm{~B}_{4}$ & $\mathrm{~B}_{5}$ & $B_{6}$ \\
\hline
\end{tabular}

Estas últimas preguntas serán usadas sólo para agrupar sus respuestas con las respuestas de otras personas. Sus respuestas son estrictamente confidenciales y no se identificarán con usted.

20. Por favor responda cada una de las siguientes preguntas. (MARQUE CON UNA "X" UNA OPCIÓN EN CADA CASO)

\begin{tabular}{|c|c|}
\hline & S! \\
\hline Nació usted en los Estados Unidos? & $B_{1}$ \\
\hline $\begin{array}{l}\text { ¿Nació al menos uno de sus padres fuera de los Estados Unidos? } \\
\text { ¿Nació al menos uno de sus abuelos fuera de los Estados Unidos?...................... }\end{array}$ & $\begin{array}{l}B_{1} \\
B_{1}\end{array}$ \\
\hline
\end{tabular}

21. Por favor responda a cada una de las siguientes preguntas. (ESCRIBA SU RESPPUESTA EN EL ESPACIO)

¿Cuántos años ha vivido usted en los Estados Unidos?

ESCRIBA

¿Cuántos años ha estudiado en los Estados Unidos?

¿Cuántos hijos(as) tiene usted?.

¿Cuál es su código postal?

22. Si es usted hispano, ¿cuál es su pais/paises de origen? (MARQUE CON UNA " $X$ " MÁs DE UNA OPCIÓN SI APLICA)

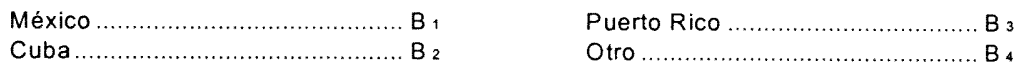

23. ¿Cuál es el mayor grado de educación que usted ha completado? (MARQUE CON UNA "X" UNA OPCIÓN)

\begin{tabular}{|c|c|}
\hline Prim aria & Carrera técnica \\
\hline 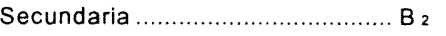 & Universidad \\
\hline Preparatoria & posgrado \\
\hline
\end{tabular}

24. ¿Cuál es el ingreso anual de su hogar antes de impuestos? (MARQUE CON UNA " $X$ " UNA OPCIÓN)

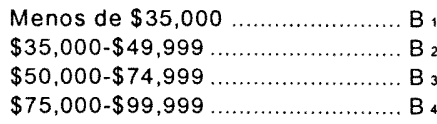

$\$ 100,000-\$ 124,999 \ldots \ldots \ldots \ldots \ldots \ldots$

$\$ 125,000-\$ 149,999 \ldots \ldots \ldots \ldots \ldots \ldots \ldots \ldots$ B

$\$ 150,000$ ó más .......................... B ?

25. ¿ES USted? (MARQUE CON "X" UNA OPCIÓN)

Empleado de tiempo completo...... B Empleado de tiempo parcial.......... $B_{2}$

Trabaja por su cuenta ................... $B_{3}$

Ama de casa ............................. B

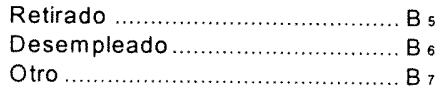




\section{VITA}

\section{CECILIA ALVAREZ}

EDUCATION

2004

Doctoral Candidate in Marketing,

Florida International University,

Miami, Florida

1997

Master in Business Administration, Instituto Tecnológico Autónomo de México (ITAM), Mexico City, Mexico

1987

Bachelor in Actuarial Sciences, Instituto Tecnológico Autónomo de México (ITAM), Mexico City, Mexico.

TEACHING EXPERIENCE

2002-2004

Graduate Assistant

Florida International University, Miami, Florida

$1992-1997$

Assistant Professor of Business Administration Instituto Tecnológico Autónomo de México (ITAM), Mexico City, Mexico.

\section{PUBLICATIONS IN CONFERENCE PROCEEDINGS}

Alvarez-Ortiz, Cecilia (2003) "The Moderating Effects of Knowledge and Attribute Typicality on Attitude Change," Academy of Marketing Science Annual Conference: Current Research in Doctoral Programs: Washington D.C., pp.2

Alvarez-Ortiz, Cecilia and Judy Harris (2002) "Assessing the Structure of Brand Personality among Global and Local Mexican Brands," in the AMA Educator's Proceedings: Enhancing Knowledge Development in Marketing, vol. 13, eds. William J. Kehoe and John H. Lindgren Jr., pp. 263-264.

Alvarez-Ortiz Cecilia, Qian Li, Shazad Mohammed, and Steve Zanakis (2001), "A MultiCountry Comparison of Tobacco Consumption", in International Society for Intercommunication of New Ideas (ISINI) Conference Proceedings, August 15-18 2001, Florida International University. 